Portland State University

PDXScholar

4-27-1998

\title{
The Bolinger Principle and Teaching the Gerunds and Infinitives
}

Anna Maria Baratta-Zborowski

Portland State University

Follow this and additional works at: https://pdxscholar.library.pdx.edu/open_access_etds

Part of the Applied Linguistics Commons Let us know how access to this document benefits you.

\section{Recommended Citation}

Baratta-Zborowski, Anna Maria, "The Bolinger Principle and Teaching the Gerunds and Infinitives" (1998). Dissertations and Theses. Paper 5794.

https://doi.org/10.15760/etd.7665

This Thesis is brought to you for free and open access. It has been accepted for inclusion in Dissertations and Theses by an authorized administrator of PDXScholar. Please contact us if we can make this document more accessible: pdxscholar@pdx.edu. 


\section{THESIS APPROVAL}

The abstract and thesis of Anna Maria Baratta-Zborowski for the Master of Arts in

Teaching English to Speakers of Other Languages were presented

April 27, 1998, and accepted by the thesis committee and the department.

COMMITTEE APPROVALS:
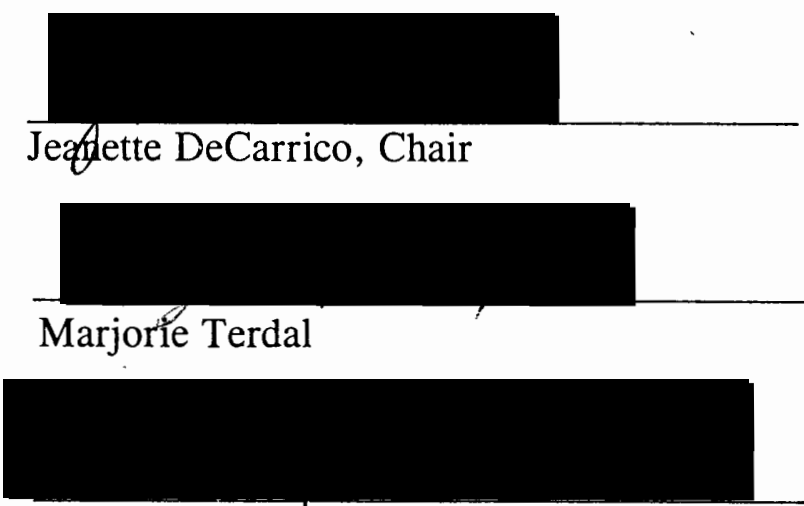

Kimberley A. Brown

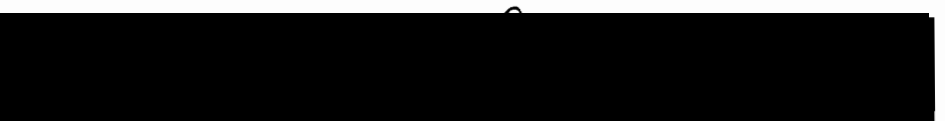

Elaine Limbaugh, Representative of the Office of Graduate Studies

DEPARTMENT APPROVALS:

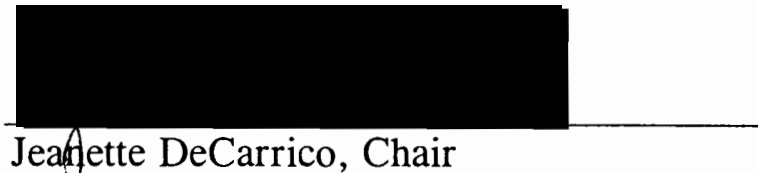

Department of Applied Linguistics 


\begin{abstract}
An abstract of the thesis of Anna Maria Baratta-Zborowski for the Master of Arts in Teaching English to Speakers of Other Languages presented April 27, 1998.
\end{abstract}

Title: The Bolinger Principle and Teaching the Gerunds and Infinitives.

As teachers of English to Speakers of Other Languages, few would dispute the importance of teaching a subject such as English complementation by using a semantic rule. The difference in semantic meaning between the -ing and to-infinitive forms has been the object of many studies which have focused on specific groups of verbs (verbs of effort/ perception, emotive verbs, factive verbs, and implicative verbs). However, not many studies were found that covered, systematically, those verbs that are more often part of a native speakers's vocabulary and that might be found in form of lists in ESL/ENNL (English as a Second Language/ English as a Non-Native Language) textbooks.

The purpose of this experiment was to determine ENNL students' acquisition of gerunds and infinitives by teaching the use of the two complement forms with the Bolinger Principle. This method was previously used in an experiment by Vawser (1988). Using Vawser's quasi-experiment, data were collected via three pre and 
posttests from 78 ENNL students enrolled in ESL academic programs. The seventyeight students, assigned to Control and Experimental Groups, were administered two Discrete Point and Sentence Combining pre and posttests and Writing pre and posttests in order to check for any significant difference between them in the acquisition of the correct usage of gerunds and infinitives.

Although the Control Group showed a significant improvement in the Sentence Combining Posttest, the data generated reveal that there was a significant improvement in the Experimental Group in both the Discrete Point and Sentence Combining posttests. Also, the writing samples reveal an increase in the overall use of gerunds and infinitives in the Experimental Group. However, while the Control Group reveals an increase in the use of gerunds and infinitives, the Experimental Group shows a significant increase in their correct use of gerunds and a decrease in their use of infinitives. Overall, the Experimental Group did better, even though the Control Group did improve on one test. These results led to the conclusion that teaching the use of gerunds and infinitives with the Bolinger principle may represent a useful instructional strategy. 
' THE BOLINGER PRINCIPLE AND

TEACHING THE GERUNDS AND INFINITIVES

by

ANNA MARIA BARATTA-ZBOROWSKI

A thesis submitted in partial fulfillment of the requirements for the degree of

MASTER OF ARTS

in

TEACHING ENGLISH TO

SPEAKERS OF OTHER LANGUAGES

Portland State University

1998 


\section{ACKNOWLEDGEMENTS}

Many individuals supported and encouraged me during my graduate studies, and in particular, during the writing of this thesis. All the problems encountered could not have been overcome without their assistance. I wish to thank my family in particular, for their constant support and encouragement, and my husband Frederick, who was my best mentor. He offered his unconditional support in critical moments and, for this reason, deserves my warmest gratitude.

As a graduate student, I have been fortunate to have many teachers and professors, whose effect on my academic life has been to a great extent a determinant one. I feel grateful to Professor Marjorie Terdal, my academic advisor, for her help and constant advice. She was especially supportive of me at the beginning of my studies and aided me, together with my thesis advisor, in the actual realization of the experiment. I wish to thank my thesis advisor Professor Jeanette DeCarrico, who, with steady hand, led me through the process of conceiving and writing a thesis, helping with her suggestions and cordial encouragement. I also wish to express my gratitude to Professor Kimberley Brown, my professor of culture learning studies and member of the committee, who graciously accepted to be part of the thesis' committee.

The research project would not have been possible without the support of the ENNL teachers. These language educators were instrumental in securing the students' participation in the project and, more importantly, the actual realization of the experiment itself. They facilitated my endeavor by allowing me to carry out the research during their 
teaching hours and to test and teach their students in the stretch of time required for the accomplishment of this study. In doing so, they greatly contributed to the realization of this project.

I also feel grateful to Rosemarie Julie Vawser, the researcher who previously carried out this same experiment in 1988. Along with my advisors, she gave me support and provided me with relevant information on the research design of this experiment; therefore, she contributed to materialize the replication of her own study. For this achievement, she also deserves my sincere gratitude.

Finally, I wish to thank my colleagues, whose advice and moral support helped bring about the completion of my thesis along with those who patiently listened and participated in my effort, my friends. 


\section{TABLE OF CONTENTS}

\section{PAGE}

ACKNOWLEDGEMENTS .................... i

LIST OF TABLES. .....................

LIST OF FIGURES. . . . . . . . . . . . . . . . . vi

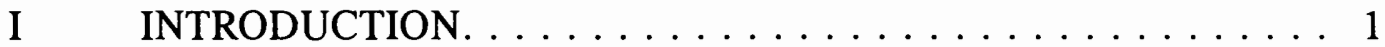

The Problem. ..................... 3

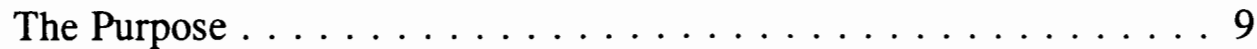

Statement of Research Questions and Hypotheses. . . . . . . . . . . . . 10

Research Methodology. . . . . . . . . . . . . . . . . 11

Summary. . . . . . . . . . . . . . . . . . . 12

II $\quad$ REVIEW OF THE LITERATURE. . . . . . . . . . . 15

Introduction. . . . . . . . . . . . . . . . 15

Theoretical Studies. . . . . . . . . . . . . . . . . . . 16

Grammar Textbooks. . . . . . . . . . . . . . . . . . 67

Empirical Studies. . . . . . . . . . . . . . . . . . . . . . . . . . . . . . . . . .

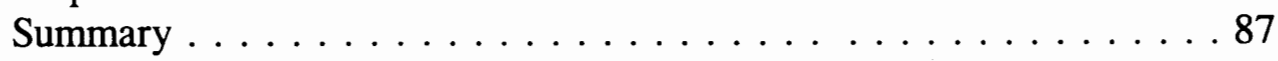

III $\quad$ RESEARCH METHODS. . . . . . . . . . . . . . . . 89

Subjects. . . . . . . . . . . . . . . . . . . . 89

Materials and Procedures. . . . . . . . . . . . . . 95

Description of the Experimental Lesson. . . . . . . . . . . . . . . . . . . . . 98

Description of the Control Lesson. . . . . . . . . . . . . . . . . . . . . . . . . . . . . . . . . . . 100

Description of the Tests . . . . . . . . . . . . . . . . . . . 101

Instruments. . . . . . . . . . . . . . . . . . . 105

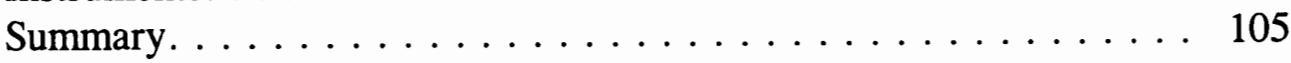

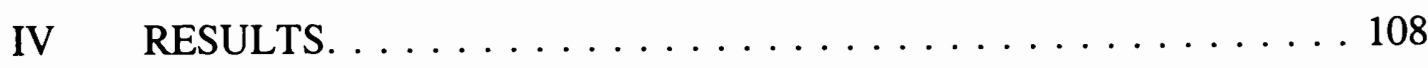

Results of the Discrete Point Tests . . . . . . . . . . . . . 108 
Results of the Sentence Combining Tests. . . . . . . . . . 111

Results of the Writing Sample Tests. . . . . . . . . . . . 113

Summary . . . . . . . . . . . . . . . . . . 120

$\mathrm{V}$ CONCLUSIONS AND RECOMMENDATIONS . . . . . . . 122

Discussion of Hypotheses. . . . . . . . . . . . . . . . . 122

Limitations . . . . . . . . . . . . . . . . . . . . . . . 127

Further Research . . . . . . . . . . . . . . . . . . . . . 134

Summary. . . . . . . . . . . . . . . . . . . . 135

REFERENCES . . . . . . . . . . . . . . . . . . 137

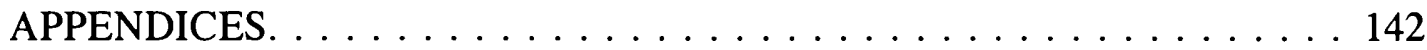

A Consent Form. . . . . . . . . . . . . . . . . 143

B I) Discrete Point Pre-Test. . . . . . . . . . . . . . . . . . . . 144

II) Sentence Combining Pre-Test . . . . . . . . . . . . . 146

III) Writing Sample Pre-Test. . . . . . . . . . . . . . . . . . . . 148

C Demographic Distribution of the Students according to Age (Figure 1a), Residency (Figure 1b), and Length of Time Studying English (Figure 1c) . . . . . . . . . . . . . . . . . . . . . . . 149

D Contextualized Activities . . . . . . . . . . . . . 151

E I) Discrete Point Post-Test . . . . . . . . . . . . . 156

II) Sentence Combining Post-Test. . . . . . . . . . . . . . . . 158

III) Writing Sample Post-Test. . . . . . . . . . . . . . . . . . 160

F Activities for the Control Groups' Review of Gerunds and Infinitives . . . . . . . . . . . . . . . . . . . . . . 161

G Verbs which do not fit the Bolinger Principle . . . . . . . 168

H I) Chart of Preceding Verbs in Discrete Point Pretest . . . . . 169

II)Chart of Preceding Verbs in Discrete Point Posttest . . . . . 169

I I) Chart of Preceding Verbs in Sentence Combining Pretest . . . . . . . . . . . . . . . . . . . . . . . . . 170

II) Chart of Preceding Verbs in Sentence Combining Posttest . . . . . . . . . . . . . . . . . . . . . . . . 170

J Lists of Verbs taking the Infinitive, the Gerund, or Both . . . . . . . . . . . . . . . . . 171 


\section{LIST OF TABLES}

TABLE

PAGE

I Profile of Experimental and Control Groups. . . . . . . 90

II Texts Used by MHCC' and L\&CC' Subjects. . . . . . . . 92

III Two Sample T-Test for the Discrete Point Tests. . . . . . . . 94

IV Two Sample T-Test for the Sentence Combining Tests. . . . . 94

V Scores for the Discrete Point Tests. . . . . . . . . . . 109

VI Scores of the Sentence Combining Tests. . . . . . . . 113

VII T-Test for the Mean Differences of the Total Scores Combined 113

VIII Total Ratio of Correct and Incorrect Gerunds and Infinitives in the Writing Sample Tests . . . . . . . . . . . 115

IX Frequency of Preceding Verbs in the Writing Sample

Tests . . . . . . . . . . . . . . . . . . . . . . . . . 129 


\section{LIST OF FIGURES}

$\begin{array}{lll}\text { FIGURE } & \text { PAGE }\end{array}$

1. Nationality Spread of Experimental and Control Groups. . . . 91

2. Diagram of Selection and Testing Process of Experimental and Control Groups. . . . . . . . . . . . . . . . . . . . . 104

3. Mean Scores of Discrete Point Tests. . . . . . . . . . . . . 110

4. Mean Scores of Sentence Combining Tests . . . . . . . . . . 111

5. Number of Correctly Used Gerunds and Infinitives . . . . . . 115

6. Correct Usage per 100 Words of Gerunds and Infinitives . . 117

7. Ratio of Incorrect to Correct Usage of Gerunds and Infinitives. . . . . . . . . . . . . . . . . 119

8. Incorrect Usage per 100 Words of Gerunds and Infinitives. . . . . . . . . . . . . . . . . . . 119

9. Total Usage per 100 Words of Gerunds and Infinitives. . . . 120 


\section{Chapter I}

\section{Introduction}

English as a Second/Foreign Language learners experience great difficulty with the acquisition of gerunds and infinitives. In English usage, these two forms seem to frequently alternate and be interchangeable. Consequently, non-native speakers are not able to distinguish the difference in meaning between two sentences whose only variation appears to be in two different complement forms, -ing or toinfinitive. Celce-Murcia and Larsen-Freeman (1983), for instance, point out the fact that infinitives and gerunds are a problem for language learners, because most languages, such as Spanish, Italian, French, or Hebrew, "have that clauses and infinitives but no gerunds" (p. 433). Another problem is represented by the fact that ENL/ESL learners hear more infinitives and that clauses than gerunds when engaging in conversation with native English speakers. Indeed, in her study on the frequency of occurrence of these three complements, Butoyi (1978) reports that language learners find that clauses and infinitives easier than gerunds. She concludes that first language interference and frequency of occurrence in spoken English combined lead to the problems experienced by non native English speakers. 
Traditionally, English grammars have presented the selection between the two complements as arbitrary and meaningless, which cannot be mastered without memorization. On the one hand, native speakers can rely on their linguistic intuitions to grasp the different shades of meaning entailed by the two verbal nouns, although they may have problems in explaining why or in which context one may use the infinitive or gerund form. On the other hand, as a norm, non-native speakers end up learning by heart lists of verbs taking one form or the other, and as a result they are often confused by which verbs take which forms.

Today ESL/EFL teachers have a better way to approach this teaching problem. . . Bolinger (1968) points out that there seems to be an underlying semantic principle: the infinitive very often expresses something "hypothetical, future, unfulfilled," whereas the gerund typically expresses something "real, vivid, fulfilled." This principle explains why verbs like want and hope take only the infinitive (i.e., they represent future unfulfilled events) . . . This also explains why verbs like enjoy and avoid take only the gerund (i.e., you can only enjoy things you've already experienced; to avoid something is a successful fulfillment of sorts). (Celce-Murcia \& LarsenFreeman, 1983, pp. 434-435).

An important issue in ESL/ENNL teaching methodology and second language acquisition research is the extent to which the use of (semantic) rules plays a role in second language acquisition by facilitating (or interfering) with the correct acquisition of grammar (Celce-Murcia \& McIntosh, Ed., 1979). Bolinger (1968b) reminds teachers of the necessity of a balance between grammar rules and factors other than grammatical ones, such as context. However, teaching students grammar with a semantic rule may just be a better alternative to exercises only and an instructional strategy to add to the arsenal of language teaching methodologies. 
Indeed, the lack of textbooks presenting gerunds and infinitives according to the Bolinger principle seems to match the scarcity of research exploring the implementation and use of this instructional strategy. For example, more popular textbooks in ESL/ENL programs such as B. Azar's Understanding and Using English Grammar (1989) and Fundamentals of English Grammar (1985) do not attempt an explanation of the semantic differences between the use of a gerund form versus the use of an infinitive form, except for the verbs regret, remember, forget, and prefer.

This study explored the effect of teaching gerunds and infinitives with the Bolinger principle on the language acquisition process of ESL/ENNL learners. The participants in this study were non-native speakers, with the exception of the teachers. The subjects came from heterogeneous language backgrounds. They were enrolled in two colleges in Portland and planned to pursue their studies at college level in the United States.

The Problem

"Grammar exists to code meaning" (Dixon, 1991, p. 175), and each language has a different grammatical means to express a type of meaning, though some languages seem to lack certain construction types such as the sentential complementation, which is the object of this thesis. With few exceptions, grammars conceived for ESL/ENNL and undergraduate students generally explain the distinction between the gerund and infinitive as a choice that is ruled by the matrix 
verb or by idiomatic usage. Not many grammar texts (Quirk \& Greenbaum, 1984; Alexander, 1988; Teschner \& Eston, 1993) make an effort to link the grammatical forms to the meaning of the verbs, or attempt to give a more logical explanation of the use of one form instead of the other. The most common approach is to include in the grammar textbooks lists of the preceding verbs and the complement forms they take: infinitive only, gerund only, or both forms.

The Bolinger principle (Bolinger, 1968a) offers the learner the advantage of acquiring the correct usage of both complements by learning a semantic rule. In "Entailment and the Meaning of Structures" (1968a), Bolinger argues that the use of the -ing and to-infinitive complement forms do contrast in meaning, contrary to the more traditional assumption that the choice of one complement over the other would be a meaningless one. Instead, structural differences do reflect semantic differences. The Bolinger principle explains that if the to-infinitive form is chosen, then the preceding verb will entail a future meaning, implying 'potentiality or 'something projected'; on the other hand, by choosing the gerund form, the preceding verb will imply a frequent, already experienced action, entailing positive or negative feelings toward the event. For example, verbs such as detest, dislike, enjoy, and prefer, refer to actions previously experienced, because we dislike/hate something only if we have previously experienced the action: "I dislike doing grocery shopping" or "I enjoy skating". Indeed, these verbs do entail positive or negative feelings toward the actions as referring to 'something actually done' (Bolinger, 1968a, p. 123). 
As for the use of the to-infinitive form, verbs such as plan, hope, want, wish, and so forth, imply a future action, something not yet experienced, or known: "I plan to go to Italy this summer", or "I wish to go to Italy this summer". These actions represent 'something projected' as opposed to 'something actually done'(gerund). Bolinger's assumption is that each grammatical structure has a precise meaning and function; therefore, the two complement forms do express different shades of meaning.

The Bolinger principle is a "rule of thumb" that can help one to choose the correct complement clause, because it allows students to differentiate between habitual, actual (or "reified") actions and future (or "potential") actions. Corpusbased studies on the usage and frequency of occurrence of these two forms seem to reveal that infinitives are the means of complementation more frequently used by native speakers (Butoyi, 1978; Andersson, 1985; Mills, 1987; Rudanko, 1993; Aarts \& Aarts, 1995).

According to Bolinger (1968a), the complementisers -ing and to-infinitive would be introduced by transformational rules rather than existing in the base (deep structure), and in many cases the -ing and to-infinitive constructions have consistently different meanings (Huddleston, 1971). However, Kiparsky and Kiparsky (1970) proposed that, with respect to infinitival verb complements, they appear to be the result of the failure of the embedded verb to undergo person and number agreement transformations instead. In his article (1968a), Bolinger explained that three situations would account for a syntactic difference at the surface level, 
without altering the base. Of the three, the distributional entailment would determine that "the choice of something else" --the matrix verb or a semantic feature shared by the verbs-- can trigger the change in surface meaning, rather than the speaker's unruly choice. As for the -ing form, its progressive aspect is another essential feature of the gerund, which can express actual past events. Compare, for example, these two sentences:

1 I like him to be nice to you.

2 I like his being nice to you (p. 123)

where the infinitive seems to relate to the possibility of "his being nice to you", while the gerund seems to indicate an action that has already taken place in the past and that is very likely to happen again. The progressive aspect of the gerund form is evident in the 'ongoing' situation of sentence \#2. Most linguists have interpreted the gerund as progressive, perhaps because of its resemblance to the participial form.

Anticipating Bolinger's explanation of the infinitive form as entailing ' a future oriented action', Jespersen (1933) attempted a semantic interpretation of the infinitive. According to him, the particle to appeared to be used in the past to indicate movement or direction towards a goal. It seems that the particle to has retained this meaning, in its prevalent use with respect to the gerund form, and that, for this reason, the infinitive generally tends to refer to actions taking place in the future (see Fanego, 1997). As we shall see, certain groups of verbs do not behave according to Bolinger's semantic principle. However, Kiparsky and Kiparsky (1970), and Karttunen (1971) seem to have provided a semantic yardstick to account 
for those verbs which are exceptions. Using the Bolinger principle to teach English complementation can serve as a criterion with which we can guide language learners and facilitate their learning process, in particular by minimizing the traditional and tedious memorization of a verb list.

It seems that one of the pedagogical concerns in English language teaching regards what of complementation to teach first to non-native learners of English. Mills (1987), for example, has developed a set of pedagogical steps for the teaching of infinitival verb complementation, as he observes that much of the current literature on complementation contributes little to bridge the gap between theory and pedagogy. His study deals specifically with the infinitive complementation, in particular because this type of complementation appears to be the most frequently occurring in English language (Butoyi, 1978; Rudanko, 1993). Mills investigates the occurrence of the infinitives in written (academic) English within six patterns of complementation. This classification is based on Huddleston's taxonomy (1971) and on the type of matrix verb present: 1) one-place (intransitive), two-place (transitive), and three-place (ditransitive) predicates.

Mills' discussion is interesting because, though relying on the syntactic classification of gerunds and infinitives, he considers the semantic meaning of the verbs to be important in order to understand their usage. He groups the six categories of infinitival verb complementation in two ways of teaching, and suggests adopting one or the other alternative: either the processes which the sentences undergo in complementation (e.g. for insertion, raising, and deletion) or the 
superficial similarities between pairs of categories. First, Mills suggests teaching the infinitival complementation at intermediate level by explaining the presence/absence of selectional restrictions in verbs, especially those occurring with 'subjectless' infinitival constructions. Synonymy of sentences with voice transformation, ("John seems to have convinced Bill", "I believe John to have convinced Bill", p. 229), and there as surface subject/object should be taught in consecutive steps. Within the monotransitive complementation proposed by Quirk et al. (1985), Mills claims it is necessary to distinguish two different categories of verbs - 2) two-place verb with complement subject retained ("For him to do that would annoy his mother"), and 4) two-place verb with complement subject under identity with the subject ("He tried to do it", p. 228-229). The fact that these two constructions often overlap does not seem to justify their combination into one; instead, teaching the two separately would be the most pedagogically effective choice. Verbs in category 4) expressing volition could undoubtly serve as a semantic cue to help students with this categorization, because of the cognitive association (volition/non-volition). Finally, categories 1) and 2) - two-place verb with complement subject retained, complement as subject; and two-place verb with complement subject retained, complement as object - should be taught even though these constructions marked by for are rare. However, the semantic cue (or principle) associated with this category of verbs described as non-assertion verbs, would be adequate to the level of advanced students. Unfortunately, while most of the literature and research on English complementation deals with the infinitive complementation, literature on the 
gerundive complementation and the pedagogical approaches to the teaching of gerunds is not yet as extensive.

As mentioned before, Celce-Murcia \& Larsen-Freeman (1983) observe that much of the problem in learning the English sentence complementation arises, in many instances, from the lack of gerunds in most languages, which use that clauses and infinitives instead. As claimed by Vawser (1988) altogether, Celce-Murcia and Larsen-Freeman suggest that teaching the English sentence complementation with the Bolinger principle may represent a lever for both teachers and students. Therefore, it seemed appropriate to test the validity of this principle in an experimental study, and then compare these results with those obtained by Vawser in her study.

\section{The Purpose}

This thesis is in part a replication of Vawser's Master Thesis (1988) and, in part, an attempt to improve upon this method by controlling the variables involved in her study. While using Vawser's tests (Discrete Point, Sentence Combining pre and posttests, and Writing Samples) and lessons, this study focused on the two complement structures previously isolated in her research: -ing and infinitive-to complements.

The goals of this study are:

a) to compare the results of the tests from my own study to the results of Vawser's tests obtained in an experiment testing the use of gerunds and infinitives in intermediate ESL students, 
b) to verify whether or not the method employed for this experiment will result in a significant difference between the two groups with respect to their scores on the pretest and those on the posttest, and

c) to contribute to the expanding body of data on second language teaching.

\section{Statement of Research Questions and Hypotheses}

In this study, a group of adult high-intermediate and advanced ENNL students are the subjects of the experiment. They were tested using Vawser's pre and posttests - the Discrete Point, Sentence Combining, and Writing Samples - in order to compare the dependent variables of her study to those obtained with this experiment, and to measure the improvement of the Experimental Group and the efficacy of teaching gerunds and infinitives with the Bolinger principle. The Experimental and Control Groups were tested in a four-week period so as to allow them considerable time for the acquisition of the structures. Lastly, the researcher adopted Vawser's questions:

1) Will teaching gerunds and infinitives using the Bolinger principle result in any significant increase of students' ability to use these complements in discrete point tests as opposed to learning gerunds and infinitives through list memorization?

2) Will students' writing show any significant improvement in their use of gerunds and infinitives after being taught the structures with the Bolinger principle? As for the hypotheses, these too were adopted from Vawser's study: 
1) Hypothesis: Teaching ENNL students gerunds and infinitives with the Bolinger principle will result in a significant improvement in using gerunds and infinitives in their scores on the Discrete Point Posttest and Sentence Combining Posttest.

2) Hypothesis: Teaching ENNL students gerunds and infinitives with the Bolinger principle will result in a significant improvement in the use of gerunds and infinitives in writing as shown by their scores on the post-Writing Samples.

\section{$\underline{\text { Research Methodology }}$}

Two discrete point pre and posttests were given to the subjects to measure the first hypothesis. The tests and the procedure will be discussed in Chapter III.

Two writing samples pre and posttests were given to the subjects to measure the second hypothesis. These samples were not run through a statistical analysis. Instead, the number of gerunds and infinitives were counted to see whether the subjects used the items correctly or incorrectly. Also, a list of the verbs most frequently used by the subjects was obtained from their writing samples. Since the complement forms investigated in this study are those in object position, gerunds and infinitives in other positions were not counted, decreasing the number of the verbs charted. A 50-minute lesson was taught by the researcher to both Experimental and Control Groups. The only difference consisted in the semantic approach used in the Experimental Group. Both groups received the same materials and were tested and taught by the same researcher using an inductive approach. 
The causal relationship between teaching methodology, acquisition, and learning can be explored through an experimental research design. As shown by Vawser's study, this seems to be an appropriate method. In this case, a quasiexperiment was the best choice because of the limitations due to the selection of participants. The dependent variables were represented by scores on the pre and posttests that were administered before and after the treatment. The independent variable was represented by the 50-minute lesson, one lesson per group, and the review of the principle right before the posttests.

\section{$\underline{\text { Summary }}$}

The purpose of this experimental study is two-fold: 1) investigate the relationship between a teaching methodology that incorporates the Bolinger principle and the learners' acquisition of the correct usage of gerunds and infinitives, as shown by the students' test results and other collected writing samples; 2) compare the results of this study with those reported by Vawser on teaching gerunds and infinitives with the Bolinger principle.

The following chapters of this thesis consist of a review of the relevant literature on English complementation and the grammar definitions of gerund and infinitive forms provided by grammarians. We will see that a semantic contrast exists between a verb followed by a gerund and a verb followed by an infinitive. Such a contrast is exemplified as realis (gerund, past) versus irrealis (infinitive, future reference) or Bolinger's notion of reification / potentiality (1968a), and could 
imply different shades of meaning. For instance, the sentence "I plan to go to France" implies something that the speaker has not experienced yet and that is 'projected' in the future. The sentence "I enjoy skating", instead, implies an action/emotion already experienced by the speaker and therefore it is 'past' or 'in progress'. Many of the studies under inquiry seem to support Bolinger's semantic principle. Most linguists agree on the basic semantic distinction between the two complements. Some theoreticians focus on the deep structure of these complements, discussing whether two sentences with the same surface forms should be regarded as having the same configuration in the base (Stockwell, Schachter \& Partee, 1973). Others attempted a semantic reading of the two forms, though on a surface level; others yet attributed to gerunds and infinitives aspectual readings. Verbs taking gerunds or infinitives share a feature, called aspect, denoting the relation of the action to the passage of time. It makes reference to completion, duration, or repetition of actions/events. For this reason, a gerund, though referring to past events, can give an imperfective meaning to a sentential complement, while an infinitive can entail a perfective meaning instead (Wood, 1956; Bolinger, 1968a; Jorgensen, 1982; Palmer, 1974; Fanego, 1997) (Chapter II). In chapter III are outlined research methods, subjects, data collection procedures, and data analysis employed in this experiment. As for the results of the data analysis and discussion, they are outlined in chapter IV. The last two chapters include also Tables and Figures. Chapter V presents a discussion of the conclusions of this study and an indication of the strengths and limitations of the experiment. On the basis of the 
results, the researcher will indicate any implications for ESL/ENNL teachers and recommendations for future research. 


\section{Chapter II}

\section{Review of the Literature}

\section{$\underline{\text { Introduction }}$}

As Dixon (1995) notes, regarding natural languages, "a similar type of meaning may be expressed by different grammatical means in different languages. The variation is not random. Each construction type in a language has a semantic effect" (p. 175). This seems to be true for English sentential complementation as well, and in particular for the -ing and to-infinitive forms, since many language learners have difficulty in learning the use of these complement forms. Traditional grammars have presented the selection of complements in object position - the gerund -ing and infinitive to - as a mechanical choice, and some grammar textbooks still teach the two forms on such a traditional basis. Consequently, to learn the use of the two forms, ESL/ENNL students need to memorize the items without being able to attach any meaning to them, which indeed appears to be a distinctive property common to both the preceding verbs and the complementisers. This chapter will present a review of the literature on English complementation and, in particular, on the complement objects realized as -ing and to-infinitive forms. In order to 
facilitate the comprehension of the subject, this overview has been subdivided in three sections. The first section deals with the more traditional grammars and the theoretical studies on English complementation; the second section presents a few of the grammar textbooks commonly available; and the last section introduces those empirical studies that have been carried out using the Bolinger principle.

\section{Theoretical Studies}

In Essentials of English Grammar (1933) Jespersen attempts an explanation of the possible meaning of the infinitive versus the gerund forms. He claims that gerunds and infinitives often overlap, although "idiomatic usage allows only one construction" (p. 346). However, Jespersen provides lists of verbs which take the gerund or the infinitive form and claims that the use of the infinitive is "slightly more formal than the gerund" (p. 347). According to Jespersen's nexus theory, the gerund is a "nexus-substantive" whose advantage is that it can be formed from any verb. As for the infinitives in object position, he describes them as "Primaries in an infinitive-Nexus"(p. 339). A nexus would be a (semantic) link between the verbal or noun constructions and their complement forms. He explained that the verbal character of the infinitive is evident from its capacity of having objects. A nexus is a second way in which a Secondary (Substantives, Pronouns, Adverbs) can be joined to a Primary (Adjectives, Adverbs, Pronouns). Jespersen compares a junction (the barking dog) to a nexus (the dog is barking), and observes that a nexus is "more pliable" (p. 95). While an independent nexus forms a complete piece of 
communication - a sentence- a dependent nexus forms only a part of a sentence, and may be either a primary in a sentence (subject or object), a secondary (an adjunct) to a primary in a sentence, or a tertiary in a sentence. Lastly, a dependent nexus may take the forms of 1) a gerund - which is a special kind of nexus substantive; 2) an infinitive; or 3) a clause.

In A Modern English Grammar on Historical Principles (1954), part IV, Jespersen describes a nexus as "a combination implying predication and as a rule containing a subject and either a verb or a predicative or both. Besides these a nexus may contain one or more objects, often a direct and an indirect object" (p. 5). As for the gerund, Jespersen distinguishes it from the second participle or -ed form, saying that "they may both refer to any time (or to not time at all)" (p. 91) (e.g., van der Meer's definition of the gerund as "time-irrelevant", particularly for the verbs of perception, 1994; p. 478). Also, the construction found after "like" might take the participle or gerund, though this is a dubious case. In Jespersen's opinion, an infinitive would always denote a nexus (link) between the subject and the verbal idea. The author offers a semantic interpretation of the infinitive by explaining that the particle to used to express movement or direction to or towards a goal, so that the preposition would retain its usual meaning, and that "The use is often indistinguishable from the infinitive of purpose" (p. 240) (e.g., Duffley \& Tremblay, 1994, p. 571).

Wood (1956) proposes a more subtle distinction in the use of the two complements, claiming that gerunds and infinitives do not alternate without 
difference in meaning; indeed, the choice of one form over the other can imply a different reading. In particular, Wood tries to examine the semantic difference in those constructions which allow the use of either forms. According to him, the use of the infinitive would imply the existence of an agent, while the gerund would represent an activity "as it were in vacuo", so that no agent would be required. So, the sentence "To lie is wrong" would specifically refer to somebody in particular; "Lying is wrong", instead, would state a universal truth (p.11). The consequences of this basic distinction would be three: first, the two forms would not always be interchangeable as it is theoretically assumed; second, the gerund would have a much wider and freer application because it would not need an agent; third, those gerundial constructions allowing infinitives are usually in a passive form (for example, "My shirt needs mending"). Indeed, the gerund can be found after need, want, deserve, and merit. It can make reference to something general, the infinitive, instead, to something more specific. A general sense can be possible with the infinitive too, but only in a series, a succession or recurrence of a specific action. In particular, after intend, propose, forget, and remember, the infinitive form seems to be more determinant. However, Wood offers more than one explanation for the behavior of these two complements. He claims that the gerund can also be used when it makes reference to something actually occurring or that has been occurring, such as, "It's stupid talking like that" (it has just happened), and that the infinitive could be used to refer to a past occurrence, "It was stupid of him to say that" (p. 13). For example, after verbs such as start, begin, continue, and cease, the gerund 
would be necessary to indicate a particular stage in a continuing process (aspectual reading), while the infinitive would have no reference to what happened before or would happen later.

Wood also notes that after the verbs give, regret, remember, and forget the gerund can be interpreted as referring back, while the infinitive would refer forward. This distinction seems to agree with Bolinger's notion of entailment: the choice of the complementiser seems to be triggered by the semantic meaning of the verb. For example:

2 a) I regret saying he was a liar.

b) I regret to say he was a liar.

3 a) I can't remember posting that letter.

b) I can't remember to post that letter.

$4 \quad$ a) I forget writing to him.

b) I forget to write to him (Wood, p. 14).

Wood observes that the difference in meaning between the two forms, -ing and toinfinitive, cannot depend upon the choice of the complement only, but also upon the matrix verb itself. He also stresses that in some circumstances the gerund seems to be usually employed for the general purpose and the infinitive for a particular purpose. For example, think followed by the gerund would mean "have the intention", while if followed by the infinitive it would mean "did it occur to you?"(p. 15). However, as we shall see, this interpretation will be further discussed by Jorgensen (1982). 
Another relevant category of verbs discussed by Wood are like and (do) not like. With the gerund they would suggest enjoyment or repugnance; with the infinitive instead they would express desire, preference, or choice; finally, in the negative they would indicate reluctance. Wood concludes that this may be the reason why the verb dislike is used only with the gerund. He actually suggests that "with certain verbs the possibility of several shades of meaning is pre-existent" (p. 16) supporting Bolinger's notion of entailment.

Palmer $(1965 ; 1974)$, for instance, describes complement constructions as 'catenatives' (ch. 7), and seems to propose a concept very similar to Jespersen's nexus. To understand the catenatives, it is necessary to first distinguish between simple and complex clauses, the latter being those that involve more than one verb phrase, with subordination, and that can consist of several verb phrases. Catenatives are essentially complex clauses. His examples of catenatives are: He kept talking; I want to go to London; I saw John come up the street (p. 166). The constructions in which they occur are: bare infinitive, to-infinitive, -ing form, and $e n$ - form. Catenatives have a basic paradigm that is similar to that of modal auxiliaries, though catenatives can take the -ing form and are less free in their combinations than the modals. According to Palmer, with some verbs the bare infinitive and the -ing form are quite clearly related in terms of aspect (Bolinger, 1968a; Huddleston, 1971; Newmeyer, 1975; Freed, 1979). In other verbs, a difference of aspect can be seen in the contrast between the to-infinitive and -ing forms:

$5 \quad$ He started to speak, but was soon interrupted. 
6 He started speaking, and kept on for hours.

However, for Palmer the semantic distinction seems to be less clear in the verb like followed by a gerund or an infinitive:

7 I like swimming.

$8 \quad$ I like to swim (p. 172).

The -ing form appears to be "intrinsically progressive", even when there is no contrast with a non-progressive infinitive:

$9 \quad$ He kept talking.

10 He kept them talking.

Palmer notices that with some verbs, in particular with the verbs of attitude, the -ing form bears no progressive meaning to the clause:

11 I don't like them reading comics.

Since subordinate clauses function like other noun objects, they can be assimilated to objects. But, sometimes the structure can be chosen, as in: " He began to talk/ He began talking"; and sometimes, as Palmer assumes, there is no choice: "He stopped talking/ He stopped to talk" (p. 178).

However, for some of the attitude verbs the analysis in terms of the transitive verb plus verbal noun object seems more appropriate. One in particular is the verb dislike, whose few verb phrases can be explained in terms of the catenatives: "I dislike him doing that"; "I dislike him having done that" (p. 179). Palmer's classification of catenatives is presented in eight semantic subsections: futurity; causatives; reporting; perception; process; effort and achievement; attitude; and 
needing; though he adds that "any classification is bound to be arbitrary and oversimplified" (p. 189). The subclassification is also in terms of the constructions with which these verbs normally occur: 1) (NP1 $\left.\left.\left.\mathrm{V}\left[\left(\mathrm{NP}_{1}\right)\right] \mathrm{V}\right], 2\right) \mathrm{NP}_{1} \mathrm{~V}\left[\mathrm{NP}_{2} \mathrm{~V}\right], 3\right)$ $\mathrm{NP}_{1} \mathrm{~V} \mathrm{NP} 2\left[\left(\mathrm{NP}_{2}\right) \mathrm{V}\right]$, and 4) $\mathrm{NP}_{1} \mathrm{~V} \mathrm{NP_{2 }}\left[\mathrm{NP}_{1} \mathrm{~V}\right]$ (p. 195). Verbs of perception and verbs of attitude (like, hate, miss, enjoy, deplore, etc.) occur with an NP and a bare infinitive, -ing form, and -en form. With these verb phrases, tense could be marked with have, but this is less common since "our attitudes are usually towards activities irrespective of time" (p. 206) (see Van der Meer, 1994). Causatives such as have, help, let, and make are all futurity verbs, so have, make, and help can occur with the (bare) or $t o$-infinitive and -ing forms, while let occurs with a bare infinitive only. He observes that the verbs of process (keep, start, finish, cease, leave, etc.) all occur with the -ing form. Finally, the needing class takes the -ing and to-ing forms (deserve, need, want, etc.).

More relevant to our discussion is the major semantic/formal class of futurity verbs. These all refer to actions contemplated for the future, to be accomplished. Semantically, Palmer explains it in two ways: i) one plans for the performing of an action by oneself or by someone else; ii) one can involve someone in planning an action. Other semantic/formal classes are the verbs of reporting and the verbs of perception, these last ones marking aspect by the contrast of bare infinitive and -ing form. The verbs of process would account for the -ing form, while those of effort and achievement for the to-infinitive clauses (Duffley \& Tremblay, 1994; Fanego, 1997). The verbs of futurity are further classified into verbs of persuading, verbs of 
ordering, and verbs of asking. A particular example of semantic distinction between the -ing form and the to-infinitive form is represented by remember. Remember is classified amongst the homonyms, which means that the verb in this category can occur with more than one construction. So, remember with the -ing form means "to remember that one performed the action"; with the to-infinitive, it means "to remember; and therefore to perform the action":

12 I remembered doing it.

13 I remembered to do it (p. 193).

It seems clear that Palmer's semantic classification of verbs taking complements is guided by the definition of the intrinsic meaning attributed to each one of these verbs, indirectly supporting the Bolinger principle. With regards to aspect, Palmer's observation is interesting, that is, that we either like or hate something regardless of the time.

In his semantic approach to the discussion of complement forms, Bolinger (1968a) contributes to clarify the difference in meaning between verbs followed by the gerund or -ing form and those followed by the to-infinitive form. His article is an attempt to explain and describe the similarities and differences among structures, such as the -ing and to-infinitive forms, while bearing in mind the importance of explaining surface dissimilarities with deep identity. In his presentation of the "distributional entailment", Bolinger's goal is to analyze what would trigger the morphological transformation or change in a structure. Providing examples of for-to and -ing complementisers, he claims that they "are chosen for their own sake ... In 
short, for-to and -ing contrast in meaning" (p. 122). The choice between the two forms would not be mechanical, and he quotes Jespersen to support his claim, according to whom "the infinitive seems more appropriate than the gerund to denote the imaginative (unreal)" (Jespersen, 1954, p. 166), or, in Bolinger's own words, the infinitive would denote "something projected versus something actually done" (1968a, p. 123). The examples below show a difference between a future (unfulfilled) event and a past (fulfilled) action:

14 Can you remember to do that?

15 Can you remember doing that? (p. 123)

Bolinger concludes that there is a semantic contrast between the realizations of the ing and the to-infinitive complements. "It is a contrast between two aspects: reification versus hypothesis or potentiality" (p. 124). In addition, the aspectual difference between the infinitive and gerund forms would be evident in their "degree of vividness" (p. 126), so that any difference in syntactic form would always indicate a difference in meaning. Therefore, "there are no identical structures in surface grammar, but only likeness in varying degrees" (p. 127).

According to Bladon 's (1968) discussion of verbs taking the gerund -ing or the infinitive to constructions, like, love, hate, prefer, and dislike would represent a group of verbs whose governing rules are quite clear cut. However, prefer is excluded from this set of verbs controlled by the principle aligning the occurrence of the to-infinitive with the meaning of desire and the gerund form with the sense of enjoy. This fact is supported by the high frequency errors which are made among 
non-native speakers. Also, Bladon criticizes the assumption, supported by many grammarians, that the criterion for distinguishing like with the to-infinitive from like with the -ing nominal "opposes a reference to a particular occasion (expressed by the to-nominal) to a statement of general validity or habit (in which the nominal -ing is used)" (p. 203). However, such distinctions are not always applied in the practice, and one such particular example is offered by the verb dislike. With the exception of a few grammarians, this verb is generally included among those that can take both to- and -ing objects nominal. Indeed, like and dislike present semantic differences. Dislike can occur only with an -ing construction, and where the verb like is preceded by certain auxiliaries, the $t o$-infinitive would not be acceptable. For example: ${ }^{*}$ I will like to learn languages (p. 209). As for like, it usually permits both complement forms:

16 I don't like disturbing him.

17 I don't like to disturb him.

These two sentences (and all others admitting both objects nominal) would exhibit semantic differences according to the nominal selected. However, the conditions governing the selection of a to-infinitive or -ing construction are different. The relevant factors for the choice of one of the two forms "belong to different levels of linguistic description"(p. 209), such factors being on formal, semantic, syntactic, and phonetic levels. Therefore, he posits "as a tentative criterion the free substitutability of want for like whenever a to-nominal follows as object, and enjoy for like before an -ing nominal" (p. 209): 
Vt like is replaceable by $\mathrm{V}$ want

$\mathrm{Vt}$ like is replaceable by $\mathrm{V}$ enjoy
(DESIRE)

(ENJOYMENT)

Thus, selection of the feature desire will take a to-infinitive object and enjoyment will take -ing. In a sentence where Vt like is characterized as desire, a second selection should be available on the basis of whether the activity represented in the complement clause is fulfilled (as in "Do you like to fly home?") or not (as in "Would you like to fly home?") (p. 212). For example in the two sentences:

18 She lliked to have breakfast in bed (she occasionally did so).

19 She liked having breakfast in bed (she regularly did so).

by adding the phonetic factor of stress $\backslash$, the sentence represented in 18) would imply an actual enjoyment in the past. Here, the subject expresses his/her enjoyment of something rarely occurring. In 19) the enjoyment would be frequent or at least regular. As Bladon notices, the feature occasional would be realized as a toinfinitive object nominal, and the nuclear stress on the verb like; the feature frequent would be realized as the -ing nominal (p. 213).

20 He likes to go home by \car. 'firm wish'

21 He likes going home by car. 'regular enjoyment' (p. 214)

The verbs dislike and prefer do not follow this pattern, although the general criterion established by Bladon should offer a systematic and predictable framework for every syntactic and semantic context. Consequently, for the expression of a fulfilled desire, the selected feature would be the to-infinitive; for a positive, actual enjoyment that is occasional, the selected feature would be the to-infinitive; and for a 
positive/ nonpositive, actual enjoyment that is frequent, the selected feature would be the -ing construction. These conclusions seem to support Bolinger's claim of reification of the gerund (feature frequent) versus the potentiality ascribed to the toinfinitive complement, adding to this classification the feature of "occasional fulfilled action" which also take the to-complement construction. Finally, the verb like occurring with auxiliaries can take the to-infinitive with both meanings of fulfilled/ unfulfilled actions when it refers to 'desire'.

Contrary to Bladon's observations, Eagleson (1972) claims that prefer would not constitute an exception to the pattern of verbs such as like, love, hate and dislike, being basically no different in essence from those verbs. He presents these examples to justify his claim:

22 Do you prefer playing tennis?

23 I prefer watching / to watch television (p. 143).

According to Eagleson, the -ing form indicates that the speaker enjoys watching television more; the to-infinitive form informs us that tennis was not contemplated at all amongst the available choices. So prefer could be seen as verb falling in two semantic fields: one expressed by the form -ing and indicating enjoy or fulfillment; the other expressed by the to-infinitive form and indicating desire or unfulfillment. Nonetheless, in his postscript to Eagleson's article (1972) Bladon reaffirms that prefer cannot be included in that same group of verbs because it is not subject to the same co-occurrence restrictions that apply to like, love and hate. For example, one can say "He has preferred to learn languages", but not "*He has liked to learn 
languages" (p. 144). However, Bladon and Eagleson's overall descriptions of complementisers appear to support Bolinger's contrast between fulfilled and unfulfilled actions.

Kiparsky and Kiparsky (1970) use semantic criteria to differentiate English predicates that take complements into two categories: factive and nonfactive verbs. It is possible to test a factive verb by examining the presupposition associated with the complement. The presupposition is entailed in the speaker and the hearer's understanding of an utterance, whether or not $\mathrm{s} /$ he implies the truth of the statement. If the presupposition of the complement remains constant, then the predicate of the matrix verb is factive; if the presupposition changes, then the verb is nonfactive. For example: "John regrets that he told you a lie". "That he told you a lie" remains a fact, regardless of the main verb, but in "John claims that he told you a lie", "That he told you a lie" is not presupposed. Another characteristic of factives is that "presuppositions are constant under negation" (p. 150). According to Kiparsky and Kiparsky, for the set of factive and nonfactive predicates, the factive and non factive complement paradigms are in complementary distribution. The difference is in the speaker's opinion, whether or not s/he implies the truth of the statement. Also, Kiparsky and Kiparsky pose two semantic distinctions: factivity and emotivity. The verbs which presuppose that their sentential object expresses a true proposition would also presuppose that their non-sentential object refers to a specific fact:

24 I ignored an ant on my plate. 'factive'

25 I imagined an ant on my plate. 'nonfactive' (p. 167). 
As a result of this semantic/pragmatic distinction, the complements of factive predicates are in the gerund form and the complements of nonfactive predicates are in the infinitive form. It seems that Kiparsky and Kiparsky' semantic parameter can be used to explain the use of gerunds or infinitives with verbs that apparently contradict Bolinger's principle and take only infinitive complements.

Karttunen $(1970,1971)$ as well provides her important semantic distinction among predicates that take infinitive complements: the implicative and nonimplicative verbs. Non-implicative verbs are distinct from factive verbs. Other than manage, remember, and bother, other implicative verbs are get, dare, care, and many others. Non-implicative verbs are: agree, decide, want, hope, promise, intend, try, and so forth. For example:

26 ?John managed to solve the problem, but he didn't solve it.

27 John hoped to solve the problem, but he didn't solve it (p. 342).

From the first example we see that there is an implication between the matrix verb with manage and the proposition containing the complement. If the main sentence is true, then the complement must also be true. Such a relationship does not hold if the main verb is hope or like, which are non-factive, and could be described as volitional verbs. On the other hand, it is characteristic of factive verbs that a negative main sentence does not affect the presupposition expressed in the complement. Instead, a negative sentence with an implicative verb implies the negation of its complement: 28 John didn't manage to solve the problem.

29 John didn't solve the problem. 
Karttunen explains that there is a "common feature typical of the suppositions associated with implicative verbs" (p. 352), that is, some necessary and sufficient condition in the main verb determining whether the event described in the complement took place. Also, there is a subcategory of negative implicatives such as forget, fail, neglect, decline, avoid, refrain that incorporate negation. Some other verbs may sometimes be used in an implicative and sometimes in a non-implicative sense. They are positive implicatives such as choose, be able, can, be in the position etc ..., described as Only If-Verbs; or negative implicatives such as refuse, which are used with "the weaker presupposition" (p. 358). Finally, a third category of verbs, cause, make, force, prevent, and dissuade, or If-Verbs, would express a sufficient but not a necessary condition for the truth of the complement. Implicative verbs are a special class of verbs that generally take the infinitive, and imply either the truth or the falsity of their complements. As a specific class of verbs taking the infinitive as their complement, they seem to complement Bolinger's semantic principle.

A syntactic analysis of complementation with gerunds and infinitives has been carried out by Stockwell et al. (1973). For their description of sentential complementation - gerundivization and infinitivalization (gerunds and infinitives as objects of sentences), the authors rely on Kiparsky and Kiparsky's (1970) account of factive and non-factive verbs.

Infinitivalization, the to- $\mathrm{V}$ form, seems to be a secondary outcome of numerous processes that leave the verb subjectless. There are also infinitival 
nominalizations derived from 'emotive' predicates. For example: "I regretted the fact that Frederick left early". According to Stockwell et al., the optional rule of FACT-DELETION is applied right after the objectivalization and subjectivalization rules:

30 I regretted [the fact of] Mary's leaving early.

31 I regretted Mary's leaving early (p. 547).

In dialects where regret is an emotive verb, the rules of FOR-INSERTION and TOREPLACE-AUX apply, obtaining:

32 John regretted for Mary to leave early (p. 548).

However, in the authors' dialect the sentence above seems to be ungrammatical. Therefore, since the grammaticality or ungrammaticality of sentences seems to be determined by the speakers' dialects, Stockwell et al. concluded that verbs such as regret, resent, and deplore would represent a "marked class" of verbs, which means that they would be semantically emotive but syntactically non-emotive.

Stockwell et al. present gerundives (the derivation of gerund forms) grouped into two classes. In the second class, the Head-deletion gerundives ("I regretted (the fact of his) leaving early", and "The activity of hunting polar bears is not fun") (p. 506), the head-noun "the action" is deleted. This class exemplifies the class of gerunds found in object and subject position. According to Stockwell et al., the gerundivization process can be explained with the presence of a preposition, in the deep structure, which would govern the rule of gerund formation. A peculiar class of gerundives are the adverbial gerundives (for instance, "I went hunting", "I kept 
running"), which do not fit among the head-deletion gerundives and, according to Stockwell et al., do not seem to be generated by the rules of their grammar. Another important parameter in their analysis of complementation is the distinction between factive/non-factive predicates, as proposed by Kiparsky and Kiparsky (1970), and which Stockwell et al. drew upon. According to Kiparsky and Kiparsky, nominalizations should not to be considered arbitrary linguistic processes, instead, they would depend on semantic features present in the governing items (entailment). Also, infinitival nominalizations would derive from non-factive predicates while gerundive nominalizations would derive from factive predicates, since "The surface contrast between infinitivals and gerundives depends on factivity in the deeper structure" (p. 562).

Stockwell et al. agree with Bolinger's (1968a) analysis of the semantic contrast between complement structures, and quote the examples he provided with "remember":

33 a) Can you remember doing that? (Can you remember "the fact of" doing that?)

b) Can you remember to do that? (Bolinger, 1968a, p. 123)

although, according to Stockwell et al., these examples would not give a satisfactory explanation of sentences with the modal would:

34 ? It would have been nice knowing you.

35 ? It would be nice playing golf in the rain. 
Even though gerundive and infinitive complements may present surface contrasts, gerundive formation is just one of the many surface possibilities in factive constructions. "The claim that these examples with gerundives are factive [and correspond to Bolinger's notion of reified] creates new semantic problems"(p. 563), because it is not the fact of knowing somebody or playing golf in the rain that are nice, but the actions themselves. Consequently, the deep structure of gerundives seems to require deep-structure Head-nouns other than "the fact", contrary to what Kiparsky and Kiparsky claimed.

Since "the fact" is not possible with gerundives, therefore "the fact" is replaced with the Head-noun "the action/event" in the deep structure. In this example:

36 a) I continued working.

Stockwell et al. claim that the head-noun action/activity is present in the deep structure:

b) I continued (the action of) working (p. 565).

Their interpretation seems to agree with Menzel's claim (1975) that infinitives, although actions, could not take the head noun action; gerunds are action as well, but they can take the head-noun action instead. With respect to the See-class verbs, Stockwell et al. seem to interpret the -ing form as semantically progressive:

37 a) I saw him working $=$ I saw him while working.

b) I saw him work = I saw him while working (p. 565). In these examples: 
38 a) I saw him dying.

b) I saw him dye.

39 a) I heard it falling/fall.

b) I heard the earth trembling (p. 566).

Dying and falling are perceived as in process or as denoting an imperfective aspect (Newmeyer, 1975; Freed, 1979). Their meaning could also be perceived as the beginning (I felt the earth trembling) or as the perfective aspect of the end (die, fall). The perception verbs too, observe, notice, etc., can only take gerundives.

The Begin-class - begin, cease, continue, finish, and start - is described as an "overt aspect-marking system" (p. 566; see also Freed, 1979). Indeed, the sentence "He began/ ceased/ continued/ finished/ started working" can be paraphrased by "His working began/ ceased/ continued/ finished/ started" (p. 567). This distinction seems to match Freed's (1979) analysis of the Begin-class verbs as aspectualizers. According to Freed (e.g. Newmeyer, 1975) this class of verbs can refer to the situation-internal time of an event, in contrast to the situation-external time of other aspectualizers. However, in order to find a satisfactory explanation of gerundivization, Stockwell et al. assumed the head-noun derivation as correct. Yet, according to the authors, this derivation:

40 He began (the activity of) working.

would not account for the progressive with the See-class verbs.

In her approach to the grammar of complementation, Freed (1979) employs analytic techniques to explain the temporal nature of 12 aspectual verbs, divided in 
three groups: 1) begin, start, continue, and keep; 2) resume, repeat, stop, and quit; 3) cease, finish, end, and complete. In her study, the various verbs and their complement structures are considered for their "associated presuppositions and consequences (entailments)" (Freed, 1979, Preface). In particular, she defines the complement structures of these aspectual verbs as "events", which is a semantic category consisting of different temporal segments. Freed is concerned with the interrelatedness of syntax and semantic content, though on a surface level only. The group of 12 verbs analyzed are referred to as aspectualizers because they give an aspectual or internal-temporal reading to the sentence. "Aspect" is a notion of time referring to the internal temporal structure of events and activities. It is a term describing the temporal quality of an event, such as inception, repetition, completion, duration, punctuality, etc . . Overall, various verbs are described according to their associated set of presuppositions and consequences, and according to the context in which they occurred.

Freed's aspectual analysis is based on data collected from nine "dime novels" (p. 21). The difference between written and spoken language, however, is not at issue, because Freed believes that language does not operate randomly, and that speakers use words in specific and consistent ways. In order for the aspectualizers to operate, certain conditions must be present which will determine the differences between Activities, Accomplishments, Achievements, States, and Series. For example, the fact that a verb is an accomplishment or a series is determined by its presuppositions and consequence relations. To verify the presuppositions and 
consequences entailed by a verb, Freed provides test frames that allow an aspectual/ semantic reading of the sentence. The following is an example for testing whether or not a verb is an Achievement:

NP V-ed at (Time) or At What Time did NP VP?

NP V-ed at (Place) or Where did NP VP?

The sentence provided for the test frame is "Finding one's coat":

$41 *$ I started finding my coat at $5 o^{\prime}$ clock.

$42 *$ I stopped finding my coat at 5 o'clock.

$43 *$ I finished finding my coat at 5 o'clock (p. 56).

"To find something" is an achievement term that cannot occur in the progressive. The same test frames can be applied to different verbs to determine their terms.

In her analysis, Freed focuses on two aspects of verb complementation that had been neglected by previous studies. First, the semantic difference between the to- $\mathrm{V}$ and the $\mathrm{V}$-ing forms; and second, the semantic distinction between the verbs indicating initiation (begin, start), duration (continue, keep, repeat), and those referring to cessation of an activity (stop, cease, quit, finish, end). Begin and start, for example, are found to be identical with respect to their presuppositions, but different with respect to their consequences. Freed claims that begin would refer to the initial temporal segment of the nucleus of an event, while start would refer to the onset of an event. In fact, someone can start to do something and not accomplish the action undertaken. For example: "Henry began to sneeze but quickly regained his composure after sneezing only once" (p. 72). Freed reports that, in natural language, 
native speakers would choose start for sentences in which the action is declared untrue or is not immediately accomplished. So, start followed by the infinitive would entail the "non-initiation of the event" (p. 72), while the same verb followed by the gerund would be syntactically and semantically related to the "be-prog operator" or -ing form. Consequently, start/ begin followed by the to- $\mathrm{V}$ form would have a 'generic' reading, whereas these verbs followed by the -ing form would have a 'durative' reading.

Freed also claims that Bolinger's description of the verbs taking sentential complements, though "not entirely appropriate for the aspectualizers in question, has certain important similarities to their characteristics" (p. 155). Bolinger's (1968a) semantic principle seems to be supported by Freed's analysis, since she attributes to the gerund a durative reading as referring to an actual event, and ascribes to the infinitive the idea of a generic reading as referring to past or future events, but more specifically, to future events.

According to Freed, that there is a strong correlation between the syntactic and semantic forms of the infinitive and the gerund. In particular, the infinitive form occurring with start, begin, continue or cease would have a generic reading, that is, a repetition of the event at different moments in as much as its temporal nature would be intermittent. However, she concludes that the infinitive form ultimately refers to some future occurrence of the event:

44 a) Linda remembered telling him the news.

b) Linda remembered to tell him the news. 
In fact, in sentence 44 a) there is reference to past events, while in sentence $44 b$ ) there is reference to future events. Also, the gerund form would have a durative reading since it may refer to the unspecified duration of an event and would suggest "a single event that is in progress or is initiated at the time that begin, start, continue, or cease operate" (p. 152). These distinctions are true for the two aspectualizers start and begin. Both verbs presuppose the prior non-occurrence of the events and, consequently, they make reference to the future occurrence of the event. As mentioned, start would refer to the onset of the event, while begin would refer to the nucleus of the event. On the other hand, finish and resume seem to rule out the to-V form because finish seems to refer to the coda of the event, while resume implies the resumption of an event from the nucleus on. Likewise, stop, quit, and keep would exclude the to-V form as each would refer to the nuclear activity of the events named. Begin, start, continue, keep, resume, and repeat would entail the occurrence of the event. Stop, quit, cease, finish, end, and complete would imply instead the non-occurrence or cessation of the event.

Newmeyer (1975) describes the syntax of the English aspectual verbs as a subclass of verbs having the surface form of verbs, adjectives, and modal auxiliaries. Aspectual verbs are lexical items "whose semantic role is to function as one-place predicates of arguments which contain entire propositions" (p. 8). For example: 45

a) John happened to annoy Bill.

b) John tried to annoy Bill (p. 8). 
In 45 a) the logical subject of happen is an event, the fact that John is annoying Bill. Try in 45 b) represents a two-place predicate, instead, because John is one argument and the proposition 'John annoyed Bill' is the other argument. Therefore, try does not appear to be an aspectual verb. Aspectuals are instead chance, occur, and turn out. These verbs would be predications upon either lexical items such as John, Bill etc. . . and also upon propositions. Therefore, their arguments can embed propositions.

A particular class of aspectuals analyzed in Newmeyer's study is the Beginclass (e.g. Huddleston, 1971; Stockwell et al., 1973; Freed, 1979), whose verbs can entail initiation, duration, and cessation, and can state whether or not a proposition occurred within one or more time segments. This class includes begin, start, and commence; stop, finish, and end; keep, and continue. According to Newmeyer, "These verbs manifest the same semantic co-occurrence restrictions with respect to tense, aspect, and adverbials as the verbs of the happen-class" (p. 25), which are described by Karttunen $(1970,1971)$ as "implicative verbs". The Begin-class verbs are all intransitive in their "remote structures", which is an abstract representation in an intermediate stage between surface structure and semantic representation. The Begin-class verbs can embed their subjects and can have causative aspectual reading. For example:

46 a) The major began the fair.

b) The major caused the fair to begin.

47 a) Tom started the car. 
b) Tom caused the car to start (p. 59).

It seems that the underlying structures of sentences 46 a) and 47 a) are similar to those underlying sentences $46 \mathrm{~b}$ ) and $47 \mathrm{~b}$ ). These sentences would be derived from a "remote structure" in which the aspectual is governed by a verb of causation, is intransitive, and subject embedding.

The behavior of the Begin-class verbs when causative is justified with the property of "factivity", as discussed by Kiparsky and Kiparsky (1970). Newmeyer provides a list of the factive and non-factive Begin-class verbs according to which stop, resume, continue, finish, and keep are factive; and begin, start and keep are non-factive. Keep, for instance, can be both factive and non-factive. Stop is factive because it is evident that one presupposes that the action was already taking place before ceasing completely.

$48 \quad$ Ira stopped cheating on exams.

49 Ira began cheating on exams.

In sentence \# 48, the speaker presupposes the truth of the complement. In sentence \# 49 , the speaker is just observing the initiation of the activity. Therefore, begin is a non-factive verb. Stop is a factive verb. It seems that Kiparsky and Kiparsky discuss only factive predicates taking simple noun phrases as subjects, neglecting predicates taking complex noun phrases, such as, it is significant, odd, tragic etc. Nonetheless, other predicates such as stop can be either factive, and require complex subjects, or do not permit the noun "fact" to be the head of a sentential complement.

Consequently, Newmeyer assumes as incorrect the Kiparsky and Kiparsky's claim 
that factive verbs are headed by the noun "fact". Instead, the feature of factivity and the evidence of a higher causative verb would explain the distribution of the causative aspectuals. For example, the verb cause can be both factive and nonfactive in the sentences below:

50 John caused Bill's winning.

51 John caused Bill to win (p. 69).

In sentence \# 50, cause takes a gerund complement and is factive. Indeed, the presence of the -ing complement seems to indicate an aspectual difference that "brings the action more sharply in focus" (Bolinger, 1968a, p. 126). If we negate the sentence, we still would hold the same presupposition for true. Sentence \#51 simply states that Bill won, but it does not presuppose the event. Therefore, according to Newmeyer, there would be two verbs cause, two verbs keep, and one verb stop (factive), so that cause in the matrix sentence combined with keep or stop in the embedded sentence could produce six possible combinations.

Seemingly, the combination of a specific complement form with the aspectual property of its preceding verb can provide a semantic/aspectual reading of the sentence, as anticipated by Bolinger (1968a) and discussed at length by Newmeyer (1975), Freed (1979), and Comrie (1976). Comrie, for example, describes aspects as "different ways of viewing the internal temporal constituency of a situation" (p. 3), relating to the internal temporal constituency of a situation. Furthermore, aspect would be differentiated form tense, a deictic category which can locate situations in time. 
Tregidgo's (1980) article focuses on the contrast of meaning between gerunds and infinitives with reference to the tense in those constructions that permit both. According to Tregidgo, the gerund form would be generally used for events or states already in existence, whereas the infinitive would be forward-looking, referring to something future:

a) I don't remember locking the door.

b) I didn't remember to lock the door.

a) I regret saying it. / b) I regret to say it.

a) Try being nice to her. / b) Try to be nice to her (p. 46).

In the sentences with the gerund, the event on which the form operates has already taken place in the past. In those with the infinitive, the event implies reference to something that has not happened yet (therefore, potential or unfulfilled; Bolinger, 1968a). This rule is considered valid for the verbs like, love, prefer, hate, and can't bear, as well. However, if the state or activity is currently in existence, like + ing form is preferred. It seems to reveal the speaker's feelings, something not possible with the infinitive, which can express instead the speaker's habitual choice or preference. According to the author, the infinitive is more "forward-looking" than the gerund (Wood, 1956; Bolinger, 1968a; Jorgensen, 1982) since it implies a choice or a tendency towards a certain action or change of state. A specific example is the verb cease, which apparently can take both forms, while, instead, cease + the gerund is ungrammatical with state-verbs:

55 One day the world may cease to exist. 
56 *One day the world may cease existing (p. 47).

Likewise, the verb continue seems to occur with gerunds only:

57 Stop now, and continue writing your report at two clock.

58 He paused to blow his nose, and then continued speaking.

When the meaning of cease is 'not stop', then continue can take both forms without any apparent contradiction:

59 During the strike the office staff continued working / to work.

When we want to refer to the duration of a state, continue can be followed by the infinitive regardless of whether the continuation is habitual. For example: "He continued to be ill"; "I shall continue to believe his story" etc. . . (p. 47) Continue could be used with the progressive tense, even though the double gerund is preferably eliminated for euphonic reasons. Thus, continue + ing form possesses the meaning of 'resume' or 'stop', indicating an action that is occurring. It cannot be used in the Present Tense, unless the action is habitual. While continue + infinitive can refer to both an action-verb and a state-verb. It can be used in any tense, but the action or state referred to would remain unchanged. However, it seems evident that Tregidgo's analysis of the two complement forms supports Bolinger's distinction between reified/concrete actions (gerund) and potential actions (infinitive), as a contrast between habitual choice or preference -gerund form and the 'forward looking' feature of the infinitive form (see also Mair, 1990).

A similar study has been carried out by Jorgensen (1982), this time to describe the patterns of the verb think of + gerund and think + to-infinitive in 
current usage. These two patterns can generally refer either to past intentions/ideas (gerund) or present/future intentions (to-infinitive). However, though interchangeable, they seem to present different readings with respect to the aspectual time-frame. In his discussion of the two complements in a previous article, Wood (1956) claims that the pattern think of + gerund (to call to mind) would presuppose the actual realization of an action in the past, while the pattern think + to-infinitive would express the hypothetical nature of the event. Wood's claims seem to substantiate Bolinger' semantic principle. However, contrary to Wood's analysis, Jorgensen's data (1982) suggest that the pattern think of + gerund expresses at least three different notions: the intention or the idea of doing something (". . his mother could not bear to think of sending her away, . . . "); be conscious of ("I never thought of being jealous"); and reference to past happenings ("He thought of being able to walk back and forth in the cell . . " (p. 55). Think + to-infinitive can be sometimes substituted with the impersonal occur to + infinitive, which has two slightly different values, in one of which it is not interchangeable with think + toinfinitive. Examples of occur + infinitive from the data seem to indicate, according to Jorgensen, an action or state of mind which was the result of an impulse. In these cases, think + to-infinitive would have as a consequence the actual accomplishment of the action, while the pattern think of + gerund would express the idea or intention of doing something, without necessarily accomplishing the action.

Jorgensen makes a distinction between the two patterns as to whether the tense in which they occur is Simple Present or Past Tense. Think in the Present 
Tense would require the gerund, for instance. If it occurs in the Present Tense to indicate an habitual, usual action, or a universal truth, then it would be followed by the to-infinitive. For example:

$60 " .$. but a boy who thinks to phone and write regularly when at camp or away from home ... these things are no small sign" (p. 57).

However, there seems to be an aspectual difference between the immediate time ("Is she thinking of getting married?") the general time ("I wonder if it is only sex when I think of getting married"), and the all-inclusive time, according to Jorgensen (p. 57). Then, think of + gerund in the past would express the mere thought or intention of doing something, and its use would be excluded from those contexts in which the action did not actually occur.

Jorgensen agrees with Wood (1956) on the fact that the two patterns seem to be interchangeable, without obtaining any substantial difference in meaning. However, Wood also claims that the gerund could have a general abstract application, while the infinitive would express a more concrete, particular event. He argues that the infinitive only can refer to particular occasions and agents, while the gerund can be used to express an action in the abstract. On the contrary, for Jorgensen both constructions can refer to particular occasions and to particular agents, and he concludes that the two patterns seem to be at variance with those proposed by Wood. When used to indicate "to call to mind", think of + gerund expresses the actual realization in the past, while think + to-infinitive seems to 
express something hypothetical. In many cases the patterns think + to-infinitive or gerund seem to alternate freely.

Although limited to the patterns of think of / think to, Jorgensen's discussion of their complementation appears to substantiate Bolinger's principle. Indeed, as Jorgensen observes, the verb think followed by the gerund would imply the actual realization of the action in the past (also, being conscious of something or having the intention), while think followed by the infinitive would express something hypothetical or potential. In addition, both complements can refer to particular agents and situations.

Quirk, Greenbaum, Leech \& Svartvik's A Grammar of Contemporary English $(1974,1986)$ offers a more formal systematic description of different types of coordination or complementation: intensive, monotransitive, ditransitive, and complex transitive coordinations. The monotransitive complementation would represent the most common subtypes of coordination, such as the Noun Phrase Objects, which have a number of semantic functions. As we know, finite-clause objects and non-finite clause objects can be with subjects or without subjects. According to the authors, the infinitive and participle (gerund) constructions with class $\mathrm{C}$ verbs (denoting assumption, knowledge, etc.) which take either the infinitive or the participle (enjoy, expect), would usually present a difference in meaning between them, as "the participle construction generally implies 'fulfillment', and the infinitive construction 'potentiality' "(p. 835) (e.g. Bolinger, 1968a):

61 He enjoys visiting/ *to visit his mother in law. 
62 He expects *visiting/ to visit his mother in law.

This rule is also effective in verbs where the choice is not obligatory:

63 He started speaking and kept on for more than an hour.

64 He started to speak but stopped because she objected.

Another factor influencing the choice is aspect (Newmeyer, 1975; Freed, 1979):

65 I heard the door slamming all night long.

66 I heard the door slam just after midnight.

Briefly noticing the present/future verb contrast with remember, Quirk et al. distinguish between an Emotive class of verbs, forget and prefer, and a Process class of verbs, begin, continue, and cease (p. 836), following the semantic classification already presented by Palmer (1974). Both classes would take the to-infinitive or -ing participle without subject. Two classes of verbs, such as dislike, hate, like, don't mind, notice, observe, etc. (class a), verbs of perception, and verbs like feel, find, imagine, which take the bare infinitive (class b), would take the -ing participle with subject. Class a) verbs are described as a subtype of ditransitive complementation ("I asked him a question/to answer"); class b) verbs are instead monotransitive verbs: Class b) I disliked his smoking/ the fact that he smoked/ *him to be a smoker. Class c) I found him to be a smoker/ him a smoker/ him smoking.

The two constructions would be semantically distinct: the verbs in class b) would denote cause, intent, etc.; the verbs in class c) would denote assumption, knowledge, etc. (p. 838). The to-infinitive nominal clause can occur as the subject, direct object, subject complement, appositive, and adjectival complement of a phrase. For 
example: "He likes everyone to be happy." The -ing nominal clause is called by the authors 'participial clause', and it can occur in subject, object, subject complement, appositive, prepositional complement, and adjectival complement positions.

Mostly important, Quirk et al. offer an adequate explanation of different types of complementation. They justify the choice of participle or infinitive complementisers suggesting an opposition between 'fulfillment' and 'potentiality' (p. 835), which supports Bolinger's claim.

In his systematic explanation of the semantics of the English verbal phrase, Leech (1987) posits a contrast between factual and theoretical meaning. He explains that theoretical meaning would treat something as an "idea", while "factual" meaning would treat the subject of the sentence as a possible fact. Leech provides examples with the modals "may" and "can", but the factual/theoretical contrast was evident in constructions such as -ing and infinitive complements:

67 It's a pity (for Bill) to refuse such an offer - IDEA

68 It's a pity that Bill refused such an offer - FACT

69 It's nice to be young - IDEA

70 It's nice being young - FACT (p. 113).

Leech makes several observations: first, the theoretical examples 67) and 69) are construed with the infinitive, and the factual sentences 68) and 70) contain a thatclause and a verb -ing constructions. Second, "the factual sentences imply the truth of the statements they contain, whereas the theoretical sentences do not" (p. 114). Sentence 68) tells us that Bill did refuse the offer. Sentence 67) does not tell us 
whether Bill refused the offer or not. According to Leech, the factual sentence is "truth-committed" whereas the theoretical sentence is "truth-neutral". However, Leech adds that these observations could be helpful hints and that they do not represent definite conclusions. Yet, his explanations of factual and theoretical meaning of English complements seem to substantiate Bolinger's semantic interpretation of -ing and to-infinitive constructions.

Meaning and grammar are not in a one-to-one relationship in linguistic structure. According to Jackson (1990), there are two systems operating in language: a semantic system (meaning) and a grammatical system (form). In his semantic and grammatical analysis, meanings are categorized as events, actions, and states and would correspond to 'situation types' (p. 8). They would represent the general content of the messages. Events may refer to things that happen without a stated human instigator. Actions would be agentive; events non-agentive. States may refer to the "way people or things are" (p. 9) and are usually verbs. Jackson's argument is that syntax (form) and semantics (meaning) interweave in the structure of language and, consequently, a grammatical description should take account of both aspects.

In his discussion of non-finite clauses, Jackson presents a selection of situation types where "included propositions"(p. 174) would occur as one of the participants of the situation. These situation types refer to the beginning, ending or continuing of some action or process, and an included proposition may refer to the action or process that is starting or finishing:

71 The percolator in the living room started making bubbling noises. 
72 After a week she stopped writing letters altogether.

73 She suddenly began to talk about bicycles.

74 Bell continued to squint into the distance (p. 174).

The participant of these situation types has either an agentive role (she in $\# 72$ and \#73) or an affected role as the entity beginning (percolator). The action or process that has begun has an eventive role and has the form of an included proposition. This may take either an -ing clause (\#71 and \#72) construction or an infinitive clause (\#73 and \#74) construction. Verbs such as liking, preferring and hating, are defined as "private state" situation types. There are four types of 'private state' verbs - know, like, hear, and hurt - that may refer to subjective states of mind and feeling:

75 I like to wrestle sometimes.

76 She likes wearing it.

77 He naturally preferred to carry it with the sealed packet to Slade.

78 He hated having to hurt her (p. 175).

Jackson explains that the infinitive clauses in \# 75 and \# 77 and the present participle clauses in \# 76 and \# 78 would represent the eventive included proposition. In other examples with the verbs consenting and refusing, the included proposition with the eventive role is in the form of an infinitive clause:

79 The chairman refuses to forecast future business.

80 They consented to take a fourteen-week course (p. 176).

However, Jackson notices that the included proposition would vary with the meaning of the situation type. Therefore, the verbs start / stop and like / prefer would have 
infinitive or participle clauses according to the verb type involved. Jackson's discussion of complementation seems to be supported by Kempson \& Quirk's (1971) claim of a latent contrast in the meaning of words, which, as we shall see in the last section of this chapter, may be activated by the different combination and distribution of lexical items.

Mair's syntactic study of the to-infinitival complement clauses is a functionalist approach to the English complementation (1990). We learn that the toinfinitive complement clause is the most frequent type of non-finite complement clauses (see Butoyi, 1978), and that it is a widely used strategy in written and spoken English since it would perform a function that cannot be fulfilled by other types of clauses. Mair recognizes the potential for variation in non-finite clauses, as attested by Kiparsky and Kiparsky' (1970) and Stockwell et al.' s (1973) studies, such as the problematic grammaticalness of the for $+\mathrm{NP}+$ to-infinitive with emotive predicates, which is assumed to be ungrammatical by Stockwell et al.

Mair's discussion deals with two main types of infinitival complement clauses: infinitival subject clauses, and to-infinitival clauses as complement of transitive verbs. This second type would include three major structural types: infinitival clauses without overt subjects; infinitival clauses with raised subjects; and for- infinitival object clauses. Mair observes, (e.g. Stockwell et al., 1973) that complex predicates, which would be termed 'emotive' according to Kiparsky and Kiparsky (1970), would depend on complex expressions and should be regarded as genuine complement clauses. For example: 
81 "I am not in any position to say whether it would be cheaper".

82 "And most people here believe that Mr Gordon Walker will have a

difficult task to defend his 3, 544 majority successfully this year" (p. 96).

These complex predicates represent an open class that deserves further investigationwithinn the English complementation.

However, Mair's observations on the meaning of the to-infinitive is substantiated by Bolinger' (1968a), Freed' (1979), and Stockwell et al. 's (1973) analyses. Mair claims that after verbs such as remember, forget, regret, try, and verbs of liking and disliking the to-infinitive clause would imply a "future-oriented potential modality" (p. 102), a modality not overtly marked. Also, matrix verbs allowing subjectless infinitives, such as agree, aim, aspire, arrange, beg, decide, expect, intend, plan, try, want etc. . , should be regarded as "forward-looking", and if not forward-looking, verbs such as remember and regret would take the infinitive complement only if understood as forward-looking (see Huddleston, 1971; Tregidgo, 1980). Like, hate, love, and prefer, though they are not forward-looking, can be transformed into forward-looking by using the Conditional form: "I would like/hate/love/prefer to do it now". According to Mair's generalization, "Infinitival complements do not usually refer to states of affairs anterior to their matrix clauses" (p. 103). This makes sense if one considers the fact that the infinitive seems to refer to future events - unfulfilled actions, and for this reason cannot temporally precede the events of the main clause. An exception to this generalization are the verbs claim, profess, affect, and pretend. For example: 
83 "She claims to be/ to have been a doctor" (p. 103).

Mair's syntactic and semantic characterization of the infinitive complement structures shows that there is a "gradience" amongst all possible forms (see also Quirk et al., 1974), so that the choice of one form over the other would be the result of a "trade-off" between syntactic correctness and efficient communication.

Verbs of perception such as feel, notice, observe, overhear, perceive, see, and watch seem to operate, according to van der Meer (1994), by alternating between Static and Dynamic constructions. Van der Meer does not agree with Quirk et al. 's (1985) analysis of the two complements. These authors ascribe to the -ing form a "progressive meaning" (the happening has duration; is limited; and is not necessarily complete), so that the difference between the two forms would be due to the inherent progressive meaning of the -ing form. As we learned, Stockwell et al. (1973), attribute to the -ing form, following the See-class verbs, a progressive meaning. The same is claimed by Newmeyer (1975) and Freed (1979) in considering the aspectual meaning of the gerund form. Quirk et al. (1974), for instance, are actually criticized by van der Meer for ascribing a 'progressive' meaning to the gerund form. Van der Meer investigates the occurrences of the verbs of perception choosing the verb see as representative of this class of verbs, since it is a highly frequent verb. First, he establishes that, with the infinitive, there is usually a relation between the objects observed and simultaneity between the observation of the object and the observation of the complement. Also, the use of the bare infinitive implies that the event is observed to its conclusion. For example: 
84 I saw him leave.

85 I saw him leaving (p. 470).

In both constructions, there is a time overlap between observation of the object and observation of the complement, and van der Meer assumes that the complement verbs can refer to happenings only (involving change or development). He questions whether the two forms are interchangeable without altering the meaning. Apparently, the examples from the corpus show that they are not, and that in the object with -ing constructions we find only happening verbs. However, in this example:

86 . . . the other car was driven by Mr Evelyn Jones, who saw Judge Evans in the driving seat of his car looking dazed (p. 471).

look is a non-happening verb, and the -ing participle seems to refer to the object perceived as being in a static situation. Yet, it is an example of SVOC construction. However, substituting the -ing participle with a bare infinitive in these sentence would not work:

87 . . . he sensed their fear, saw Meg's sharp, shadowed profile, saw Belle

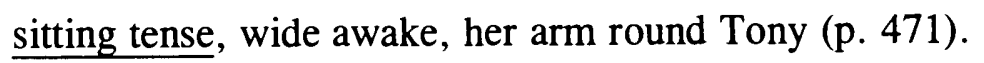

Here, a bare infinitive would not be possible, since the -ing form and the bare infinitive are syntactically different, according to van der Meer. Consequently, the to-infinitive construction would not be a SVOC construction. The evidence is provided by the morphology of the two forms: the bare infinitive is a stem, while the gerund adds a semantic element and changes the verb so as to activate other 
properties of the verb. The -ing form combines with other complements in coordination, while the bare infinitive cannot. Other evidence is provided by the fact that nothing can intervene between the bare infinitive and the object, while the -ing form allows this construction. In order to explain the semantic differences between the two forms, van der Meer presents two hypotheses: first, the bare infinitive would not be an object complement; second, the bare infinitive would be an object complement, but with special syntactic characteristics.

In the first case, van der Meer assumes that the object with bare infinitive is an $\mathrm{O}$ in an SVO configuration. By using the passive form, the construction with the infinitive does not appear to be a syntactic unit:

88 He was seen to leave the building.

89 People saw him leave the building (p. 474).

The presence of the particle to before the infinitive points out that the bare infinitive cannot stand alone in these contexts. The constituent object is not a syntactic unit because it cannot become the subject of a passive sentence and cannot be extraposed: $90 *$ Him leave, I did not see (p. 475).

So, the author supports the $\mathrm{OX}(\mathrm{X}=$ infinitive $)$ hypothesis, claiming that there is a sufficient degree of structural similarity between the to-infinitive and the -ing forms.

As for his second hypothesis, his data show that the infinitive seems to possess special syntactic characteristics: it is attached to the preceding noun phrase and cannot easily be coordinated with other non-verbal complements. It has a more restricted nature, then, and a perfective character, although it can be potentially 
imperfective. The infinitive seems to refer to the unmodified meaning of the verb, giving a dynamic picture of the activity, and would imply a holistic meaning, without imposing restrictions on it. Instead, the -ing form would represent the static, frozen picture of the action and would modify the verb and impose restrictions, indicating that not all stages of the event were realized. In the constructions found in the corpus, a coordination with an infinitive followed by a gerund seems possible, but not the opposite. This does not seem to be entirely true, since the dialects of native speakers show a greater variance. For example, an English woman born and raised in Toronto, Canada, produced a sentence using a gerund followed by an infinitive during a conversation: "The Dalai Lama saw the Chinese slaughtering the Monks and take over" (researcher's personal communication). Here, the infinitive appears to complete the action described in the first predicate so as to indicate that 'all the stages of the event were completed'. In conclusion, it seems that van der Meer's generalization as to the usage of a gerund or an infinitive can be valid only in specific contexts.

Van der Meer concludes that the to-infinitive and the -ing forms would be syntactically similar, and the analysis should be for both OC. This seems to be confirmed from the fact that those verbs that are inherently static do not take the gerund form (sit, lay, look), although these verbs imply a beginning and an end, and behave as being bounded events. In particular, van der Meer claims that the -ing form would be a de-verbalizing suffix, whose properties are timeless or timeirrelevant, and it would be Static, indicating an activity that is a non-finite state of 
affairs. On the other hand, the to-infinitive would be Dynamic, indicating an activity as ongoing, having an initiation phase and a completion phase. The conclusions reached by van der Meer do not seem to substantiate Bolinger's principle as van der Meer ascribes to the infinitive a dynamic feature and to the gerund a static state of affairs. However, van der Meer's dynamic infinitive seems to imply that the complement form can also denote a future activity, while the static gerund does express a non-finite state of affairs if we do refer to actions that cannot be considered completed, but only 'imperfective'. For example: "I like going in the mountains". Here, the action makes reference to the habit of going in the mountains, that is, a repetitive predication that cannot be considered accomplished, in that it still has actual consequences on the speaker's state of mind. Indeed, as Palmer (1974) observes, we like something regardless of the time (static feature).

Duffley \& Tremblay's (1994) article deals specifically with the to-infinitive and -ing forms as complements of verbs of effort. This argument has practical value for ESL teachers, especially when it comes to the difference in meaning between try + infinitive and try + -ing form. Generally, when followed by the infinitive, try would mean 'to make an attempt', without certainty that the action had been accomplished. Followed by the -ing form, try would mean that the event was performed, but this is not true in all the cases. Duffley and Tremblay also investigate the reasons why attempt is almost exclusively construed with to; why, when followed by the -ing form, the difference in meaning does not manifest; and whether there is any general principle that could account for the different meanings the forms 
impose on the verb try, chosen as representative of the verbs of effort. Various authors have proposed principles based on usage in English. For example, Tregidgo (1980) claims that the -ing is used for events whose occurrence precedes or coincides with that of the main verb. The infinitive, instead, would be used for verbs expressing "forward looking" events. More restrictive explanations hold that gerunds imply sameness or simultaneity of time, as already observed by van der Meer (1984). As to the question of why try + ing implies simultaneity, while try + to does not remains unsolved. However, there seems to be a syntactic difference between the two complements: first, the -ing cannot appear in subject position in a passive sentence while the to-infinitive can:

91 Being nice to her had already been tried.

$92 *$ To get to sleep had already been tried (p. 569).

Second, the -ing form can be substituted with the nominal pronouns it or that; the infinitive cannot. Third, the to-infinitive construction allows adverbs of manner between it and try. The -ing form cannot occur with this structure:

93 . . . trying desperately to translate Grimm's Fairy Tales ...

$94 *$ He tried desperately translating Grimm's Fairy Tales (p. 569).

The examples from the corpus show that the -ing form acts like a noun direct object, allowing an adverbial between try and the complement:

95 She tried for a time helping in a youth club, but found it was not a success. 
As for the syntactic role of the to-infinitive, it can act like a prepositional phrase with an adverbial function with respect to the main verb. For example:

96 He tried to open the door.

97 Then I tried to as well (p. 570).

Jespersen (1933) previously observed that the value of the particle to is that of a preposition indicating movement towards a goal or an object. With respect to the meaning of the to form, Tregidgo (1980) too regards it as an infinitive marker that can function as a preposition after try. In particular, it has a future meaning, denoting the goal of trying but also the notion of movement from "a before-position to an after-position in time" (p. 571), therefore, supporting Bolinger's principle. On the other hand, the relation of the -ing form to try is that of a noun direct object. It would not stand in a temporal relation with respect to the main verb. Therefore, depending on the meaning of the governing verb, it may imply notions of consequence, simultaneity, or anteriority in the same way as a noun direct object. For example, compare the sentence "I am considering moving to New York", with "I am considering a move" (p. 572).

According to the authors, try + -ing seems to indicate simultaneity because it evokes 'that which is tried', like a noun direct object would. In addition, try +- ing seems to imply that the realization of the event could be a means to another end. Of other verbs of effort, such as struggle, strive, labor, and endeavor, none of them can be used with a noun direct object, supporting the fact that the infinitive is not a direct object in a sentence with these verbs. Attempt, for example, can be construed 
with both forms, but the meaning associated with these is not evident, because its inherent semantic meaning already implies "to make an effort to do, accomplish, solve or effect". In fact, only seven instances of attempt + -ing form were found in the corpus. Two facts could explain this occurrence: first, the strong similarity of the constructions with the infinitive and the gerund; and second, the general preference for the infinitive rather than the gerund. Since the lexical meaning of attempt implies the notion of effort aimed at attaining a goal, attempt + infinitive resulted to be the most frequent construction. On the other hand, the notion of effort would not be inherent in the meaning of try, considered as the prototypical verb of effort. Try, instead, would imply the notion of effort when occurring with other lexemes, such as the $t o$-infinitive.

However, Fanego (1997), who has carried out a historical study on the patterns of complementation with the verbs of effort, reaches conclusions that are different from Duffley \& Tremblay's. In particular, she does not agree with their reading of try as "make an effort" as the product of the combination of the verb with the particle or preposition to. Second, she investigates the opposition of to: ing as historically meaningful and not arbitrary, and the factors triggering the choice of the -ing form after the verb attempt. Her data suggest that try + infinitive dates back to the sixteenth century and that it developed from try followed by a NP, with the meaning of attempt to do, perform or accomplish. For example: "All kind of worke seemeth to be hard before we doe try it" (p. 62). Consequently, as Fanego claims, Duffley and Tremblay 's assumption is incorrect. As for the status of the opposition 
to : ing, her data -covering the years $1400-1760$ - reveal that from the seventeenth century on the -ing form began to be used in object position as an alternative to infinitival complements. By the middle of the eighteenth century -ing forms had supplanted the to-infinitive complements, especially with verbs of avoiding and forbearing; verbs of declining and refusing; emotive verbs; verbs of intention; and verbs of suffering and bearing. Verbs of effort resisted this tendency and collocated exclusively with the infinitive. However, with the verb remember the opposition to : ing appeared to be meaningful, serving the purpose of distinguishing between two different readings of the same verb. Indeed, remember and forget became semantically related: the -ing form referred to real events that happened in the past, so that it signaled performance of the action, in contrast with the infinitive, which signaled future-time reference, implying potentiality rather than performance (e.g. Bolinger, 1968a). The semantic overlap between remember and forget could explain the diffusion of the opposition to : ing to the other verbs.

As for the verbs of effort, endeavor, labor, and strive were not affected by the tendency to alternate gerund and infinitive forms 'with the exception of attempt. Its use with the gerund form may be due to the avoidance of two consecutive infinitives. Also, speech-based texts probably promoted the use of the gerund during the eighteenth century: ". . . it was not safe for me to attempt doing him any good" (p. 65). In conclusion, Fanego claims that the opposition to : ing was certainly meaningful with remember and forget, but not with all the verbs of effort, which would alternate the two forms whenever triggered by the syntactic environment, 
since the -ing and to forms would be just contextual variants. Thus, attempt + ing and attempt + infinitive would be "exactly synonymous", rather than "quasi synonymous"(p. 66) as Duffley and Tremblay assume.

As we can see, the opposition between the gerund and infinitive forms did not arise as an arbitrary or meaningless one; instead, as Fanego demonstrates, especially for remember and forget, they indicate an opposition between past events (gerund) and future ones (infinitive), and confirm the semantic principle claimed by Bolinger (1968a) and many other linguists.

An interesting insight on semantic principles into English complementation is offered by Dixon (1995). Dixon groups the words of any language into a number of lexical classes called "semantic types" (p. 175). Semantic types have a common meaning component and share some grammatical properties. The semantic types expressing MOTION (go, throw) AFFECT (cut, burn) ATTENTION (see, hear) and SPEAKING (say, ask, tell) are associated with the verb class. Dixon groups verbs into Primary and Secondary verbs. Primary verbs are divided into Primary-A verbs and Primary-B verbs. Primary verbs make up a complete sentence with noun phrases filling their argument slots; all Secondary verbs relate to some action or state and require a grammatical link (Jespersen's nexus, 1933) to another verb (p. 176). According to Dixon, every language possesses some grammatical means for expressing secondary concepts. Some languages lack complements to express secondary concepts. Therefore, they must use what Dixon calls "complementation strategies" in order to obtain the required meaning. However, there is a critical 
difference between Primary and Secondary Verbs, because "Secondary verbs encode meanings that relate to some other verb" (p. 178). Their meanings can be expressed as "verbal lexemes", affixes, verbal modifiers, or clausal particles. For instance, in English these two sentences have the same surface syntax but different semantic interpretations:

98 They began building the wall.

99 They discussed building the wall.

Sentence 98) describes an activity of building; sentence 99) describes a discussion whose topic is the building of a wall (p. 178).

There are different ways in which languages code the link between secondary or primary-B verbs and a second verb. Amongst the various types of complements in English, the most popular way of linking two verbs is represented by one clause filling a syntactic slot (subject, object) in the other clause. This is the complement clause construction. Dixon explains that of the three main kinds of complement, toand -ing complements can have their subjects omitted but have limited tense-aspect possibilities (p. 184). While a that-complement can refer to an activity or event as a simple unit, with respect to a single fact, an -ing complement "refers to an activity as extended in time, noting the way in which it unfolds", ultimately supporting the aspectual/ temporal reading of the activity (p. 185):

100 I heard [that America had beaten France].

101 I heard [America beating France]. 
As to the infinitive complement, there are two main subtypes of to complement: the 'modal' type and the 'judgment' type. 'Modal'-to complements relate to the subject of the complement clause. Here, the subject gets involved in the activity or state that is being referred to by the main clause. The subject of a 'Judgement' to complements expresses a judgement or opinion about the subject of the complement-clause predicate. Although a 'modal' to construction can have a similar meaning to a that clause with a modal, they never have exactly the same meaning:

102 I remembered that I should lock the door (but then I decided not to).

103 I remembered to lock the door (but someone prevented me from locking the door).

Sentence 102) records a fact; sentence 103) refers to the potentiality of the subject's action (p. 186).

Negation, modals, and aspectuals provide modification of a verb while sharing the same subject or object. Aspectuals such as begin, start, finish, continue, try, and attempt function as full verbs. Most aspectual verbs take both to- and -ing complements, with a difference in meaning:

104 John tried to drive the car (but somebody stopped him).

105 John tried driving the car (but he could not perform well) (p. 187).

The -ing complement indicates that John drove for some time; the to-complement means that he attempted to get involved in the activity but was prevented from doing it. Finish is confined to an -ing complement. It contrasts with cease that takes both complements. According to Dixon, finish has 'object orientation', cease has 'subject 
orientation' (p. 187). Dixon 's subdivision of verbs according to semantic types creates a link between the semantic interpretation of the type of verb in the main clause and the choice of complements. For example, the 'wanting' type, want, wish, desire, hope, etc., take a to-complement referring to something that the speaker can achieve by doing. Verbs of the 'making' type consist of three subclasses: a) make, force, cause, let, allow, permit, which imply "some positive effort on the part of the main clause subject to accomplish something" and are restricted to to-complements (Karttunen's "If-Verbs", 1970); b) stop, prevent, spare, save, which "imply a definite effort to avoid something happening" and use a variety of -ing clauses; and c) ensure, which takes a that complement (p. 188). A semantic interpretation is given for each class of verbs: the 'attention' and 'thinking' types, taking -ing, that and 'judgement' to complements; the 'speaking' type, and the 'liking' type.

Dixon concludes that in natural languages there would be at least two types of complement clause or strategy of complementation: one with "potential" (or irrealis) meaning, "referring to something that has not happened, but which people intend or want should happen" ... and one with "actual" (or realis) meaning "referring to some existing or certain event or state" (1995, p. 213). Many languages, like English, would distinguish between at least two actual constructions, one referring to an activity "as it extends in time" (English -ing complement), and the other referring to "the fact of something happening" (English that and wh-clause) (p. 214). So, each semantic type has a semantic value, which shows the interdependence of the grammatical and semantic structure -form and meaning- of natural languages. 
All of the authors presented in this section agree on the basic distinction between future and past actions of verbs as implied by the infinitive and gerund forms: potentiality versus reification (Bolinger, 1968a), and the irrealis versus realis (Dixon, 1991), or idea versus fact (Leech 1987). Kiparsky and Kiparsky (1970), and Karttunen $(1970,1971)$ distinguish between factive, non-factive, and implicative verbs. For these verbs, the choice of complementisers is determined by the matrix verb and the truth of its presupposition, rather than by features such as desire or enjoyment. However, there are historical facts and linguistic analyses that might account for the behavior of these two complements.

First of all, the opposition to : ing is historically meaningful as an opposition, especially for verbs such as forget, remember, and regret. In addition, the fact that this opposition had spread to other verbs appears to support Bolinger's argument. Secondly, both complements can entail different features (perfective, imperfective, fulfillment/unfulfillment, enjoyment, etc.) that are activated according to the context or the preceding verbs themselves. On the one hand, although the gerund form can indicate a progressive or imperfective meaning with perception verbs, the action is generally intended as just happened, therefore referring to a past action already experienced. On the other hand, the infinitive form generally refers to future, 'projected' actions, with exception only to the perception verbs (see, observe, watch, etc.) for which the use of an infinitive implies a perfective meaning and refers to the whole action. Finally, the complement -ing and to-infinitive forms are not the only factors triggering the choice of one complementiser over the other. Indeed, verbs 
such as end, begin, cease, continue, finish, start, keep, etc. seem to represent an "overt aspect marking system": they share the feature aspect and determine the internal-time situation of the sentential complement. For example, begin will take the gerund form, while start will be followed by the infinitive form. In fact, begin describes the onset of the nucleus of the action; whereas start refers to the onset of the action described in the complement. Overall, these observations indicate that the gerund can generally make reference to actions already happening, while the infinitive can imply future, not yet initiated actions or can express general preferences.

\section{$\underline{\text { Grammar Textbooks }}$}

The following texts represent a sample of general grammar textbooks for college and university students and some textbooks for ESL/EFL students.

In their University Grammar of English $(1974,1986)$, Quirk et al. present the transitive complementation according to their Grammar of Contemporary

English,(1972) but without the extensive theoretical discussion of the original work. As direct objects of verbs, non-finite clauses can have a subject or be subjectless. In the subjectless non-finite clauses, the verb can take either a to-infinitive or a gerund (participial) form. For example: "John longed *doing/ to do homework"; "John denied having stolen/*to have stolen the money"; and "John began to write/ writing a letter" (p. 361). They notice that when both constructions are permitted the choice is influenced by an aspectual difference such as the progressive aspect (Newmeyer, 
1975), and that "The participle construction generally implies 'fulfillment' and the infinitive construction 'potentiality'":

106 a) He started speaking and kept on for more than an hour.

b) He started to speak but stopped because she objected (p. 362)

Quirk et al.'s observations on the English complements clearly support Bolinger's principle, as they attribute to the gerund a sense of fulfillment and to the infinitive a sense of potentiality. Also, they agree with Wood', Tregidgo', Jorgensen', Newmeyer', and Freed's claims on the semantic and aspectual differences of the two complements.

Young's grammar book (1980) is intended for elementary students in higher education and to help them prepare to pursue the subject to more advanced levels. Young's English grammar is partly based upon the theoretical model of systemic grammar. However, none of the traditional lists of verbs taking a gerund or an infinitive or both is to be found.

Verbal behavior is explained as patterned on different levels of language which are simultaneous and interrelated. These levels are: phonology, the pattern of sound, discourse, and the pattern of linguistic action. As for the structure of a clause, Young terms the verb Predicator $\mathrm{P}$, the subject $\mathrm{S}$, the complement $\mathrm{C}$, and so forth. The occurrence of one Predicator appearing dependently on another Predicator is termed Phase, one of the few processes of sentential complementation:

107 I | wanted | to give | them | a present
S P
$\mathrm{P} \quad \mathrm{Co}$
Co
(p. 137). 
In the sentence above, of the two verbal groups the second Predicator represents the non-finite clause, which, according to Young, can be introduced by the to-infinitive form, the -ing form, and the -en past participle form. The occurrence of the second predicator in the clause is in Phase with the first one, and depends on the selection of the main verb, that is, its choice of a to-, -ing, or -en complement form. So, remember allows a phase construction, but a verb like walk does not. Of course, there are clauses with more than two Predicators. A special case are the two verbs want and need. In some instances the -ing form phase can be substituted for a passive $t o$-form or an -en form:

108 These shoes need their soles repaired/repairing.

109 These shoes need to be repaired/repairing (p. 140-141).

It seems that after need and want the -ing form of the second verb has a different syntactic value from the usual one, that is, it would perform a different function in which it has the value of a noun (Verbal Noun). The object clauses, included in the complex verbal groups of the non-finite clauses, can occur in bound clauses, as a second predicator in a clause, and in rankshifted clauses. Rankshift is a recursive phenomenon, in which a unit can be shifted down in the clause and be posited below the label of its own rank. Some verbs in the verbal group would form a tightly constructed unit, because there is a connection between one predicator and the second one, others, like those in phase structure, would not.

In a phase structure each predicator is described for each voice. Therefore, the following sentence has two Predicators: 
110 I heard (P) them opening (P) the door (p. 184).

Many predicators such as may, be able, and be going have some of the properties of auxiliaries and can acquire "aspectual meaning" whenever they occur with auxiliaries. They can show aspectual contrast by the structure of the predicator. For example:

111 He kept breaking the record (repeatedly).

112 They have stopped enforcing this law (cessation of action) (p. 185).

This contrast is described as 'prospective vs non-prospective' (p. 189) and while the to-form realizes the first contrast, the -ing form realizes the second one. This contrast could be interpreted as future (prospective) vs past (non-prospective). These meanings can be detected in phase structures too:

113 I tried to close the window.

114 I tried closing the window (p. 189).

It seems that in the first clause the closing of the window would be the goal; in the second one the window gets closed but the room is still cold. Young claims that as long as one can choose between the two forms, then there is a clear distinction of meaning.

However, as a means of complementation Rankshift and Phase can be a source of ambiguity, but the difference in meaning between the two structures would be very slight. Young explains that when a possessive pronoun cannot be inserted, the sentence must be understood as a Phase. When a possessive and a non-possessive are allowed, the two forms should be considered interchangeable. According to 
Young, "there is in this area of English grammar a great deal of purely arbitrary complexity . . . it is difficult to find more than fragmentary connections between meaning and form"(p. 142). His conclusion seems to neglect the fact that numerous studies have sustained that, indeed, there is a semantic relation between meaning and form. However, Young's grammar is still traditional in its presentation of complementation and lacks any explanation about the usage of gerunds and infinitives.

Celce-Murcia and Larsen-Freeman (1983) suggested teaching the use of gerunds and infinitives to ESL students by using the semantic principle put forth by Bolinger (1968a), while making a distinction between factive verbs, non-factive verbs (Kiparsky and Kiparsky, 1970), and implicative verbs (Karttunen, 1971). This approach to the study of English complementation would facilitate understanding the difference in meaning between the two forms with "at least six of the verbs that take both infinitives and gerunds" (p. 436). Celce-Murcia and Larsen-Freeman provide examples showing the subtle potential difference in meaning between the two constructions:

125 I like camping in the mountains (more immediate, more vivid).

126 I like to camp in the mountains (more remote, more objective).

In the first example, I might actually be in the mountains when I utter this sentence. In the second example, I am referring to the fact that the atmosphere in the mountains is peaceful, and that I do like it (or it can be said to represent a general statement with respect to preferences). According to Celce-Murcia and Larsen- 
Freeman, the Bolinger principle would work for many verbs, but it would be unable to explain the grammatical behavior of 'factive' and 'implicative' verbs, which indeed seem to contradict Bolinger.

Van Ek \& Robat' s (1984) The Student's Grammar of English draws upon various sources, amongst them Quirk et alia's Grammar of Contemporary English (1972, 1985). Van Ek and Robat's grammar is conceived as a linguistic grammar for university students at undergraduate level. The authors try to combine descriptive and pedagogical adequacy, while at the same time presenting an explicit and comprehensive model of grammar for students. As for the description of verb complementation, van Ek and Robat choose those verbs which seem to be more frequent in the language. They adopt Quirk et al. 's system of textual division, in particular the classification of complements according to whether they occur with transitive, intransitive, monotransitive, and ditransitive verbs. Complements to monotransitive verbs can occur with the -ing form, the to-infinitive form, and the bare infinitive with and without overt subjects. As for the complements to complex transitive verbs, they can occur with a direct object and a second complement in a non-finite clause (direct object + bare infinitive, to-infinitive, or -ing participle). Of course, the other non-finite forms are not examined here since they are not the object of our inquiry.

Avoid, deny, stand, imagine, hate, and begin are described as monotransitive verbs taking the -ing participle without overt subjects. See, mind, prevent, and find are classified amongst the monotransitive verbs taking the -ing participle with overt 
subjects. With respect to the verbs of 'physical perception', feel, hear, notice, see and watch, the authors note that they can occur with both complements and that the difference between the two is one of aspect (Newmeyer, 1975; Freed, 1979):

127 I saw him cross the street.

128 I saw him crossing the street (p. 311).

Other monotransitive verbs such as mind, prevent, remember, and stop can occur with a possessive determiner. Mind, in particular, is often found with negative and interrogative clauses:

129 I don't mind your staying here.

130 Would you mind closing the window? (p. 312)

As for the monotransitive verbs with the to-infinitive without overt subject, their subjects are usually the same as the main/higher clause. But, contrary to the verb like, order and know cannot occur without an overt subject. Within this class, two subclasses are distinguished: the first subclass of verbs can take the infinitive; in the second one, the verbs are not allowed to have both complements:

131 I managed to find a solution.

$132 * I$ managed finding a solution (p. 313).

To simplify the complex classification, the authors provide the students with a list of these three subclasses: the to-infinitive clause only; the -ing participle clause only; and the to-infinitive clause or -ing participle clause. Not many verbs can take both forms. Need, for example, used with the sense of require can occur with either 
complement: "This room needs cleaning" or "This room needs to be cleaned", its passive counterpart.

Van Ek and Robat recognize that, although some verbs seem to be interchangeable with respect to their complement forms, others do show distinct semantic differences. This is better exemplified with the verbs regret and remember. With remember, the to-infinitive can refer to future events, while the -ing participle can refer to 'present remembrance' (see also Fanego, 1997):

133 Please remember to post this letter for me (don't forget).

134 I remember posting the letter for you about four weeks ago.

On the other hand, the to-infinitive form with regret can refer to the present; the -ing form, instead, to the past:

135 I regret to say I don't see what you mean.

136 I regret asking him for help (p. 314).

However, with verbs indicating "emotional attitudes", such as like, hate, prefer, and so forth, the -ing participle is preferred either way, while the to-infinitive is used for particular occasions (Wood, 1956; Jorgensen, 1982). Start and begin seem to be an ambiguous pair, as it appears difficult to find an explanation as to when to choose one complement over the other. As previous grammarians did, van Ek and Robat interpret the -ing participle following start as denoting 1) an action in progress or 2) its duration; when occurring with the to-infinitive, begin is classified as a semiauxiliary. Their grammar includes a list of subclasses of verbs for which the syntactic classification and the semantic differences seem to match. This list includes 
1) expect, like, want, and wish, described as volitional verbs and taking the toinfinitive with or without overt subject; and 2) advise, allow, cause, encourage, order, permit, and require, described as causation verbs and taking the to-infinitive clause with overt subject only. This group is in turn subdivided in a) various infinitives, and b) believe, feel, know, and show, described as verbs of cognition and demonstration, and generally taking the infinitive to be. See, hear and watch are included in the monotransitive verbs with a bare infinitive. Among the complex transitive verbs taking direct objects and a non-finite clause, have, help, let and make take a bare infinitive; verbs of volition or causation take the to + infinitive form; and the verbs have, get, keep and leave take the -ing participle form.

Van Ek and Robat's presentation of the English grammar is clear, and their discussion of the semantic differences between the two forms (gerund and infinitive) appears to support the Bolinger principle. In particular, their classification of volitional and causation verbs, and verbs of cognition and demonstration could represent a significative semantic cue for associating them with the correct complement.

Huddleston (1988)'s English Grammar: An Outline is intended for an elementary course in English within a linguistics programme. With respect to the non-finite clauses, the -ing and to-infinitive object clauses, they are all found in catenative constructions (Palmer, 1974), and the choice among the four constructions is determined by whether the verb is a modal operator (may, can); a sensory perception verb (see, hear); or a passive, but many of the most common 
complements are the to-infinitival and the present-participial forms. However, according to Huddleston, the most important factor of verb meaning seems to involve modality. He explains this factor as a tendency for the gerund, or present participial, to be associated with actuality or factuality. He adds that the infinitival tends to be associated with non-actuality or non-factuality:

137 He hoped to read it.

138 He enjoyed reading it (p. 165).

Sentence \# 138 implies "He read it", referring to the fact that he did read it (factual), whereas sentence \# 137 does not imply the fact that he read it, and therefore it is non-factual. Huddleston applies the same semantic distinction to verbs such as remember and try, and attempts to analyze the semantic relationships between the verbs manage and happen and their subjects. Also, non-finite clauses can be dependent in adjectival structures, presenting an alternation between raising and nonraising constructions:

139 It was likely that Ed would win the race - Ed was likely to win the race (Raising).

140 Ed was eager to win the race (Non-raising) (p. 167).

and they can be dependent on NP structure, where we find to-infinitivals and participials that function as a modifier. Indeed, Huddleston claims the existence of a semantic distinction between factuality (gerund) and non-factuality (infinitive), therefore supporting the Bolinger principle (1968a) and Kiparsky and Kiparsky's syntactic analysis of these complement forms (1970). 
Azar's Fundamentals of English Grammar (1985) is a textbook designed for mid-level students. The presentation of gerunds and infinitives is chiefly provided through charts and lists, since the preceding verbs, as Azar explains, can generally take one form or the other, without much difference in its meaning (for instance, the verb begin). The activities, nonetheless, are helpful in providing some context. Unfortunately, no attempt is made to any semantic classification of verbs taking gerunds or infinitives. The examples used by Azar to explain the rules are isolated sentences that are void of context, while the Notes at the bottom of the page appear to be not very useful after all.

Some attempt at context-based activities, instead, is present in Azar's Understanding and Using English Grammar (1989), conceived for upper-level students of English. It is a developmental skills text: though the textbook's focus is on grammar, it also aims to promoting the development of all language skills. The exercises, indeed, promote the four skills, as each is directed toward listening, oral production, writing, and reading. Here, the chapter on gerunds and infinitives includes a useful list of adverbial gerundives -the verb go followed by a gerund (go shopping, fishing, running, etc.). In particular, Azar groups the verbs remember, forget, regret, try, and prefer into one category, whose verbs do show different meanings according to the complement they take, thus supporting the Bolinger principle. For instance, regret: when used with the gerund it means that one regrets an event happened in the past; when taking the infinitive, instead, it refers to an (immediate) future action. 
However, Azar claims that no difference exists between begin followed by a gerund or begin followed by an infinitive. For example, there would not be any difference between "I started working" and "I started to work". Indeed, as we learned in the previous section, the two constructions can have different meanings. In the first one, the meaning intended is 'continuous' or 'progressive', "I started working and kept working until lunch-break". In the second, the action could not be accomplished, because "I started to work, but then an emergency call made me leave". At any rate, Azar's texts are quite popular, probably because of the clear presentation and the organization of the topics in visual charts.

Teschner \& Eston's (1993) undergraduate textbook appears to be a useful source of reference amongst the available English textbooks. They notice that for many native speakers, the acquisition of the three-way complementation system is a very difficult one, particularly if the complementation system in their native language is simpler or functions in a different way (see Dixon, 1995). The authors classify sentential complements into three types. They list the verbs that can take all three types of complementation: those that allow only infinitive complements; those that allow only gerund complements; and those that allow either infinitive complements or gerund complements only. However, they observe that not all permissible types of complement sentences elicit the same meaning (p. 276). Teschner \& Eston's textbook includes an appendix of 50 verbs that are organized according to the various subordinate-clause patterns that the matrix verbs can cooccur with. Sample sentences are provided. 
Smalley's Refining Composition Skills: Rhetoric and Grammar (1995) is a high intermediate to advanced level writing text for academically bound ESL/EFL students. It prepares students to write with more depth and complexity on academic topics. For this reason, each chapter is organized around a current or relevant theme. The grammar points are explained and practiced in the Grammar Review Units. A review of gerunds and infinitives is presented in Appendix, as a useful tool in writing about a process. The Grammar Review explains that gerunds and infinitives are mostly found in object position, and there is an attempt to semantic explanations. Remember and stop, for instance are presented as verbs whose meaning changes according to whether they are followed by a gerund or an infinitive. However, according to the authors, verbs of observation (perception verbs) are usually followed by the to-less infinitive, and there are not examples of these verbs followed by a gerund. In the Appendix, a review of gerunds and infinitives provides contextualized exercises, which are accompanied by the traditional lists of verbs taking the gerund, the infinitive, or both. As for the verbs followed by either a gerund or an infinitive, the authors explain that some verbs do change meaning if followed by a gerund or an infinitive (for example, the verb remember; Bolinger, 1968a). Moreover, the fact that the exercises are highly contextualized clearly stresses the importance of context in writing.

Thewlis's Grammar Dimensions 3. Form, Meaning, and Use (1997) is a high intermediate grammar textbook designed to introduce ESL/EFL students to the form, meaning, and use of English grammatical structures. Each unit introduces the 
grammar structure within a communicative orientation. 'Focus Boxes' (charts) and contextualized exercises present students the relevant form, meaning, and use of the target form. ". . . in Grammar Dimensions, we strive to have students develop the skill of 'grammaring'- the ability to use structures accurately, meaningfully, and appropriately" (p. xx). Reading, writing, and listening are developed in each unit, after which a quiz helps teachers to assess the students' learning. The topic on gerunds and infinitives is divided in two units. In particular, the section called Focus on Meaning explains the choice of infinitives versus gerunds according to the Bolinger Principle: "Infinitives usually refer to the possibility of an action occurring. The action has not happened yet". As for the gerunds, they "usually refer to an action that has already started or has already been experienced" (p. 112). Therefore, verbs of desire such as hope, wish, plan, want, etc., refer to the fact that the action has not been experienced yet and these verbs are usually followed by infinitives. As for some verbs of emotion, e.g., enjoy, appreciate, etc., they refer to the fact that the emotion itself has already been experienced and for this reason these verbs take the gerund. With other verbs of emotion, such as like, love, hate, and can't stand, the use of a gerund or an infinitive will provide the same meaning. Finally, forget, try, remember, and stop are presented as a group of verbs that do have different meanings, according to the complement form that they take.

Amongst the grammar textbooks presented in this section, Grammar 
Dimensions 3 (1997) appears to be the one that is more thoroughly organized for the non-native learner. The focus on form, meaning, and use combined with the contextualized activities makes this book one of the most helpful tools for students learning the two grammatical structures. The emphasis on appropriateness provides learners with important clues to culture learning as well.

Inevitably, in more traditional textbooks (e.g., Azar's Fundamentals of English Grammar, 1985) the authors' recourse to exhaustive lists of verbs to explain which form occurs with which verb seems inevitable. However, the majority of them (Thewlis, 1997; Huddleston, 1988; van Ek \& Robat, 1984; Quirk et al., 1985) agree on the semantic distinction in the use of the infinitive form for non-factual actions, and of the gerund form with past or factual actions. However, as we shall see in the following section, some verbs are not ruled by the meaning of the matrix verb, disallowing any semantic contrast between a gerund or an infinitive form. Since it would not be possible to put all verbs under a single criterion, it appears that students and teachers need to also rely on handy classifications that make sense.

\section{$\underline{\text { Empirical Studies }}$}

Kempson \& Quirk (1971) accomplished a series of tests in order to find out whether or not a latent contrast could be present in certain grammatical variants. According to Kempson and Quirk, in any linguistic system "in a given item, one or more semantic features can be regarded as latent, i.e. susceptible of being activated in some contexts and suppressed in others" (p. 548). Therefore, the contrast between 
the infinitive and gerund would result from the activation of a feature which is suppressed in other environments or contexts. For example:

141 I heard the door slam all night long.

142 I heard the door slamming just after midnight (p. 569).

These two test sentences show a latent aspectual contrast between infinitive and gerund. For the sentence supporting a durative or iterative interpretation, native speakers of British-English chose the present participle (\#142). Instead, in the sentence implying an effective or punctual action, they chose the bare infinitive (\#141).

However, there are some verbs where latency is disallowed. In particular, the verb remember can take either the infinitive or gerund, and its action would be independent of the temporal or aspectual value of the matrix verb. Consequently, it is difficult to detect a sense of fulfillment in these examples:

143 I remembered visiting her

144 I remembered to visit her (p. 555)

Kempson and Quirk analyze and discuss the ambiguity of these two sentences and how this could affect the subject's response to the tests; indeed, creating plausible contexts for test sentences means creating the conditions able to activate a latent contrast. The third test showed a latent aspectual contrast between the infinitive and present participle, where the present participle or gerund implied a "durative or iterative interpretation" and the infinitive referred to an "effective or punctual action" (pp. 552-553). 
The interdependence of grammar and semantics was investigated by So van Nguyen (1973) in his study of native American usage of gerunds and infinitives. In particular, Nguyen investigated whether or not there was a difference in meaning between the two types of complement and under what conditions one form might prevail over the other. The test was administered to 232 native speakers of American English during a two-week period. Thirty-two highly educated native speakers of American English took the pilot test and contributed to its evaluation and improvement. In his review of traditional grammars, Nguyen notices that authors of grammars do not usually go beyond the description of the linguistic facts observed, and consequently their methodology would be descriptive rather then explanatory.

Nguyen applied the Bolinger principle to his study, according to which the use of gerund or infinitive varied with respect to the meaning and syntactic similarity of their matrix verbs. However, some verbs appeared to be less predictable than others. For example, the small group of "emotive verbs" was confusing as to its semantic content. With these verbs, the infinitive would refer to a particular occasion and the gerund to a general statement:

145 She loves ... tennis and practices it everyday.
A. playing $102(44 \%)$
B. to play 130 (p. 140).

Nguyen observed that "the generic quality of the gerund and its prominent abstract noun-like character probably explains why this form is said to be preferred in making general statements" (p. 31). Indeed, 38 out of 50 items on the test showed 
that the contrast between the two selections was significant and that there existed a meaning difference between the two constructions in each contrastive pair. The test items were made up of different categories:

1) Hypothesis or Potentiality versus reification

2) Effective or Punctual Action/ Durative or Iterative action

3) Implied sense of finality or determination/ No sense of finality The testing involving 38 out of 50 items provided sufficient evidence that the Bolinger principle "did operate in guiding the subjects' selection of infinitive and gerund, especially after . . . "remember, forget, regret, try, prefer, and sense" (p. 145). Finally, the results of two out of three contrastive pairs of test sentences designed to test the contrast between gerund and infinitive after the sensory verbs show that the infinitive was used "for an effective or punctual action" and that the gerund served "for a durative or iterative action" (p. 146).

Nguyen concluded that the Bolinger principle should be used as a general guiding criterion in teaching to differentiate subtleties in meaning, as they are perceived in the usage of the speakers. Especially with emotive verbs (love, like, hate) or aspectual verbs (begin, start) the semantic distinction between the infinitive and the gerund is not always as clear as with "remember, forget, and try". "As a consequence, only the verbs after which significant contrast exists - between the infinitive and gerund constructions - should be taught in ESL classes" (p. 150). As a solution, teachers should avoid getting into complicated explanations and teach only the construction that seems to be preferred by native speakers. 
Nguyen's conclusions are not far from reality with respect to the actual teaching of these complement forms. Indeed, the Bolinger principle can be useful in differentiating subtleties of meaning amongst small groups of verbs, such as remember, regret, forget, or try. However, with like and love (emotive verbs) that can take the form of both gerunds and infinitives, because they mostly express preferences, the Bolinger principle might not be as helpful to learners.

According to the results of Butoyi's correlational study (1978), there would be an accuracy order of English sentential complements which are common amongst speakers of the different language groups - Spanish, Persian, and Japanese - that participated in her experiment. She attempts to investigate the influence of the subjects' native language on English accuracy order of six English structures: thatclause (I know that he left); infinitive NP (I want him to leave); infinitive Equi-NP (I want to live); infinitive NP-to Deletion (I let him leave); possessive -ing (I resent his leaving); and gerund (I resent leaving). A written multiple choice and translation tests were administered to 169 students of English as a Second Language at the University of California in Los Angeles. The accuracy orders were compared using Spearman Rank order correlations. Anderson's (1977) study and Butoyi's results were found to be significantly similar. It appeared that the that-clauses were easiest to learn, and that the infinitive and gerund constructions were more difficult. Butoyi concluded that "The accuracy with which the six focus complement types are selected by ESL learners seems to have relatively little to do with language background or type of testing instrument" (p. 53). The results indicated that gerunds 
should be presented before possessive gerunds. Since a common order of complements could not be explained through the learners' native language, Butoyi concludes that "the only viable explanation for the common order has been frequency of occurrence in native English speaker speech" (p. 63), and that the infinitive form actually seems to occur more frequently than gerunds (see Rudanko, 1993). Another possible determinant factor of the accuracy order could be "instructional factors"(p. 57).

Vawser (1988) carried out an experimental study which tested the use of gerund -ing and to-infinitive among non-native speakers of English. A group of 101 mid- to upper-intermediate ESL students, representing 25 different language backgrounds, were the subjects of her study. Vawser's prediction was that teaching ESL students gerunds and infinitives by using the Bolinger principle would result in significant improvement in the students' discrete point tests and in their use of gerunds and infinitives in writing as well. The t-tests showed that the experimental group improved significantly over the control group. The researcher used three pretests and three posttests, and formulated a 50-minute lesson for both groups. The pretest was followed by an explanation of how gerunds and infinitives are formed. The first pretest - Discrete Point Test, consisted of 20 fill-in-the blank sentences. For example: "The defefendant admitted (steal) the car". The students chose whether to use the gerund or infinitive construction. The second pretest Sentence Combining Test - was a 20-point test. It consisted of two sentences that the students needed to combine in one sentence by using the gerund or the infinitive. 
The third pretest - Writing Sample Test- was a free writing test. The Discrete Point and the Sentence Combining posttests tested the same structures. Also, all the preceding verbs in both tests all fit the Bolinger principle. Only the Writing Sample posttest had a similar yet different topic. The researcher carried out a pilot study with a group of non-native residents, which contributed to the revision of the tests. Finally, the results show that by using the Bolinger principle the improvement for the Experimental Group was significantly greater (12\% over $3 \%$ for the Control Group), and she recommends the incorporation of the Bolinger principle in teaching complements to ESL students.

\section{$\underline{\text { Summary }}$}

A review of the literature shows that there is still a dispute about the use of gerunds and infinitives in object position. The review of grammar definitions reveals an abundance of distinctions between the two complements mostly based on idiomatic expressions, or formal/informal registers. More recent literature seems to focus on specific patterns, or complements - a third of the studies deals with the toinfinitive form and its frequency of occurrence. The choice of one complement over the other is also determined by the presuppositions and their consequences associated with the context. However, as the Empirical Studies suggest, in general any future meaning ('potentiality') seems to be attributed to the infinitive form, while any sense of a 'reified' action is ascribed to the gerund form. Consequently, the Bolinger Principle appears to be supported. 
Yet, there are verbs, such as the implicative verbs, which do not fit this principle, although they seem to complement this semantic rule. For the factive verbs, for instance, there is no match between their meaning and the complement form they take. Contexts and speakers' presuppositions do change according to the situations. The contrast between the infinitive as referring to particular agents and situations and the gerund as referring to general situations seems to represent an additional function fulfilled alternatively by both forms.

Grammarians and linguists all agree on the distinction traditionally ascribed to the verbs of perception smell, see, observe, hear, etc.: the infinitive would indicate the entire action that is being referred to by the preceding verb and therefore is 'perfective'; whereas the gerund tends to refer to actions in progress and is 'imperfective'. The opposite is true with the verbs regret, remember, and forget, to which even the most traditional grammars attribute two senses, recognizing two distinct meanings: the future one entailed in the use of an infinitive (imperfective) and the past meaning implied in a gerund form (perfective). For this group of verbs, in particular, the opposition to : ing is also found to be historically meaningful, therefore supporting Bolinger's claim.

There exist few textbooks that present the topic on gerunds and infinitives explaining the semantics of the English verbs; the majority of these textbooks, instead, present the topic through lists and charts. Therefore, it seems desirable to adopt a different approach to the teaching of these two complements, in order to facilitate students' acquisition of the correct usage of both forms. 


\section{Chapter III}

\section{Research Methods}

This chapter outlines the methods and procedures used in this experiment to teach gerunds and infinitives using the Bolinger Principle. The subjects participating in this experiment were ENNL (English as a Non-Native Language) learners attending advanced and intermediate classes at college level. After being pre-tested for the experiment and assigned to the Control and Experimental Groups, the subjects were administered the same pre and posttests and the same contextualized materials with the exception of the lesson on gerunds and infinitives. The Experimental Group was taught gerunds and infinitives using the Bolinger principle, while the Control Group was taught the lesson according to the traditional method of list memorization. The following paragraphs will describe the experiment in a more detailed fashion.

\section{Subjects}

The ENNL student population was originally represented by a group of 93 students consisting of 17 different nationalities and language backgrounds. However, 
on the day of the posttests some students were absent or had to leave earlier, so the total number lessened to 78 students. These students attended grammar and writing classes at Mt. Hood Community College and Lewis \& Clark College in Portland. Seven classes were selected, four Advanced and three Intermediate classes. As Figure 1. shows, the student population consisted of four groups:

a) Southeast Asia with 47 students representing Laos, the People's Republic of China, the Philippines, Vietnam, Japan, Korea, Indonesia, and Thailand.

b) South America with 10 students representing Chile, Mexico, Colombia, and Honduras.

c) Eastern Europe with 11 students representing Romania, Siberia, and Ukraine.

d) Middle East with 6 students representing Saudi Arabia, Yemen, and Qatar. (See Table I for a profile of the Experimental and Control Groups).

Table I Profile of Experimental and Control Groups

\begin{tabular}{lllllllll}
$\begin{array}{l}\text { \# of } \\
\text { Subjects }\end{array}$ & Group & Level & $\begin{array}{c}\text { Average } \\
\text { Age }\end{array}$ & $\begin{array}{l}\text { Far } \\
\text { East\% }\end{array}$ & $\begin{array}{l}\text { Middle } \\
\text { East\% }\end{array}$ & $\begin{array}{l}\text { Eastern } \\
\text { Europe\% }\end{array}$ & $\begin{array}{l}\text { South } \\
\text { Amer.\% }\end{array}$ & $\begin{array}{l}\text { Text } \\
\text { Used* }\end{array}$ \\
\hline 19 & Exper. & Adv. & 23.4 & 73.7 & 0 & 21.1 & 5.2 & RCS \\
9 & Exper. & Adv. & 21.6 & 100 & 0 & 0 & 0 & FEG \\
8 & Exper. & Adv. & 20.4 & 87.5 & 12.5 & 0 & 0 & FEG \\
8 & Exper. & Inter. & 32.4 & 50 & 0 & 12.5 & 37.5 & GD3 \\
14 & Control & Inter. & 21.5 & 64.3 & 35.7 & 0 & 0 & UUEG \\
8 & Control & Adv. & 29.6 & 25 & 0 & 12.5 & 62.5 & RCS \\
12 & Control & Inter. & 26.3 & 50 & 0 & 41.7 & 8.3 & GD3
\end{tabular}

\section{Texts Used*:}

FEG $=$ Fundamentals of English Grammar, by B. Azar.

GD3 = Grammar Dimensions 3, by D. Larsen-Freeman \& S. Thewlis.

RCS $=$ Refining Composition Skills, by Smalley .

UUEG = Understanding and Using English Grammar, by B. Azar. 


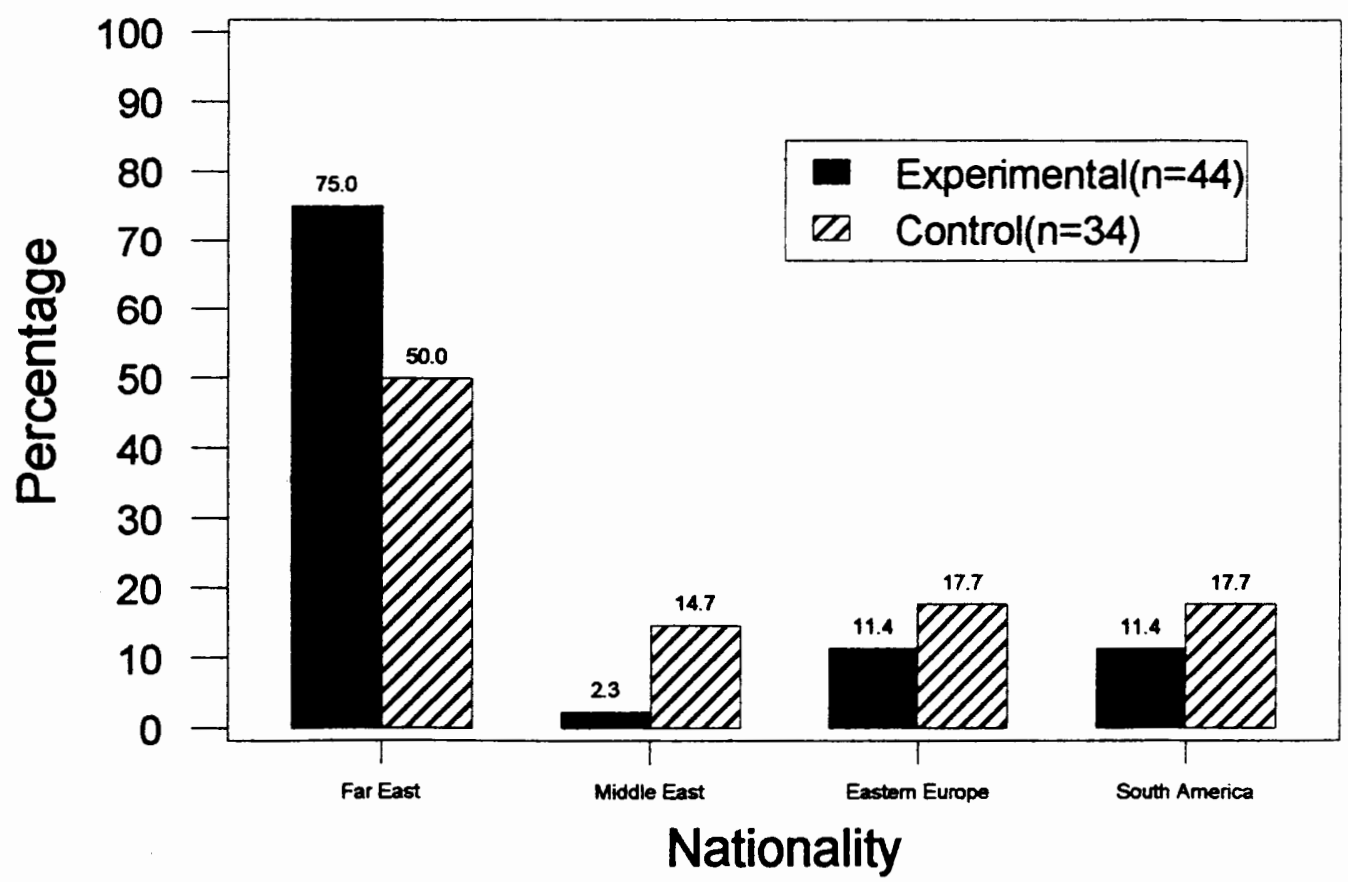

Figure 1. Nationality Spread of Experimental and Control Groups.

In order to participate in the experiment, the students were asked to read and sign a Consent Form (Appendix A). Then, to select the subjects for the experiment, the researcher examined their pretest scores - the Discrete Point and Sentence Combining pretests (Appendix B) - and the level of class they were enrolled in, and then she divided them into Experimental and Control Groups. As the main criterion for the selection of the subjects, the researcher had their pretest scores analyzed to see whether or not the seven classes were comparable, that is, whether or not the subjects chosen from the two colleges were on the same level of language proficiency. The results of the pretests showed that the classes were the same. As for the textbooks used by the students, the advanced level used Refining Composition Skills by Smalley (1995), while Grammar Dimensions 3 (1997) was used by the 
intermediate level at Mt. Hood Community College. At Lewis \& Clark College, the advanced classes used Fundamentals of English Grammar by Azar (1985), while the intermediate level used Understanding and Using English Grammar by Azar too (1989) (see Table II).

Table II Texts Used by MHCC* and L\&CC*' Subjects

\begin{tabular}{lcclcl} 
Level & Exp. Group & \multicolumn{2}{c}{ Text Used* Level } & Control group & Text Used* \\
\hline Intermediate & 8 & GD3 & Intermediate & 26 & GD3/UUEG \\
Advanced & 36 & RCS/FEG & Advanced & 8 & RCS
\end{tabular}

Texts Used*:

FEG $=$ Fundamentals of English Grammar, by B. Azar.

GD3 $=$ Grammar Dimensions 3, by D. Larsen-Freeman \& S. Thewlis.

RCS $=$ Refining Composition Skills, by Smalley.

UUEG $=$ Understanding and Using English Grammar, by B. Azar.

MHCC* $=$ Mt.Hood Community College; LCC $^{*}=$ Lewis \&Clark College

Since the lesson on gerunds and infinitives presented the topic with a semantic principle whose understanding requires a high-intermediate/advanced level of language proficiency, the researcher tried to combine an equal number of advanced and intermediate subjects in the Experimental and Control groups, but because of the limited number of students participating in the study the distribution was unequal. Therefore, the Experimental Group ended up with a higher number of advanced students than the Control Group did. However, as previously mentioned, the results of the pretests showed that the groups were comparable, leading to the assumption that the labels intermediate or advanced did not necessarily apply and that the students could be considered as one level of language proficiency. 
In order to assess whether Mt. Hood Community College students were comparable to Lewis \& Clark College students, the researcher ran their Discrete Point pre-test and Sentence Combining pre-test scores through a statistical analysis. The Two-Sample t-test on the Discrete Point Test scores for both groups showed that the distributions appeared the same (see Table III). The mean values obtained for MHCC and L\&CC were 1.46 and 1.35 respectively and showed no significant difference in means $(t=-0.07, p=0.95)$. On the other hand, the Two Sample $t$ test on the Sentence Combining pretest scores for both groups showed that the distribution of L\&CC ' scores appeared to be the distribution of MHCC ' scores translated 2.5 units, that is, there was a slight difference in means $(\mathrm{MHCC}$ mean $=$ 3. 93, $\mathrm{L} \& C C$ mean $=-1.06 ; \mathrm{t}=-3.46, p=0.0008$ ). The actual difference between the means of MHCC and L\&CC was between - 1.06 and 1. 35, with a $95 \%$ certainty (Confidence Interval) (see Table IV). However, the difference between the two groups was not a statistically significant one $(p=0.94, t=0.07)$, and it did not influence the results significantly. In fact, to minimize the difference in means, the Control and Experimental Groups were balanced between the subjects coming from MHCC population and the subjects coming from L\&CC population. After the pretests, the subjects were assigned to the Experimental and Control Groups by the researcher with the exception of one class, which was selected by its teacher. She asked the researcher that her class participate in the study as part of the Experimental Group. Before the treatment took place, the researcher discovered that the grammar textbook used in one Control class presented the topic on gerunds and 
Table III Two Sample T-Test for the Discrete Point Tests

\section{Two Sample t-test for MHCCD* vs LCCD*}

$\begin{array}{lcccc} & \text { N } & \text { Mean } & \text { StDev } & \text { SE Mean } \\ \text { MHCCD* } & 56 & 13.84 & 3.20 & 0.43 \\ \text { LCCD }^{*} & 37 & 13.89 & 3.41 & 0.56\end{array}$

95\% CI* for mu MHCCD* - mu LCCD*: ( $-1.46,1.35)$

T-Test mu MHCCD $=$ mu LCCD (vs not $=): T=-0.07 \quad \mathrm{P}=0.94 \quad \mathrm{DF}=73$

*MHCC $=$ Mt. Hood Community College

LCC $=$ Lewis \& Clark College

$\mathrm{D}=$ Discrete Point Test

$\mathrm{CI}=$ Confidence Interval

mu MHCC $=$ Mt. Hood Community College student population

mu LCC $=$ Lewis \& Clark College student population

\section{Table IV Two Sample T-Test for the Sentence Combining Tests}

Two Sample t-test for MHCCS vs LCCS

$\begin{array}{lrrrc} & \text { N } & \text { Mean } & \text { StDev } & \text { SE Mean } \\ \text { *MHCCS } & 56 & 12.07 & 4.34 & 0.58 \\ \text { LCCS } & 37 & 14.57 & 2.62 & 0.43\end{array}$

95\% CI for mu MHCCS - mu LCCS : $(-3.93,-1.06)$

T-Test mu MHCCS $=$ mu LCCS (vs not $=$ ) : $T=-3.46 \mathrm{P}=0.0008 \mathrm{DF}=90$

$* \mathrm{MHCC}=\mathrm{Mt}$. Hood Community College

LCC $=$ Lewis \& Clark College

$\mathrm{CI}=$ Confidence Interval

$S=$ Sentence Combining Test

$\mathrm{mu} \mathrm{MHCC}=\mathrm{Mt}$. Hood Community College student population

$\mathrm{mu}$ LCC $=$ Lewis \& Clark College student population

infinitives by using the semantic principle tested in this experiment. Consequently, the teacher of this class was instructed to ask her students to skip the Unit on Gerunds and Infinitives and to have them do three exercises, required for the Control Group, by using photocopies of the activities. Also, the researcher double 
checked with the students, and she was told that they had complied with their teacher's instructions and none had read the chapter.

Overall, 78 subjects were tested: 44 in the Experimental group, and 34 in the Control group. Figure 1 . shows the nationality distribution of both groups. The numbers regarding the nationality of the subjects show that $50 \%$ of the Control Group represented Southeast Asia, 14.7\% represented the Middle East, 17.7\% represented South America, and 17.7\% represented Eastern Europe. On the other hand, the numbers for the Experimental Group show that $75 \%$ represented Southeast Asia, 2.3\% represented the Middle East, 11.4\% represented Eastern Europe, and $11.4 \%$ represented South America (Figure1). The demographic distribution of the students according to age, residency in the country, and length of time studying English is shown in Appendix C (Figures 1a, 1b, and 1c).

\section{$\underline{\text { Materials and Procedures }}$}

The researcher administered the pre and posttests and taught the lesson on gerunds and infinitives to both the Experimental and Control groups in order to provide consistency to the treatment (Appendix D). Each lesson lasted 50 minutes, and the subjects received a short introduction ( 15 minutes) on gerunds and infinitives right after the pretests (Appendix B), and a short review right before the posttests (Appendix E). It would have been more helpful if the researcher had the time to explain the use of the Bolinger Principle in context. However, not every teacher was 
willing to give more hours because of their term schedule or because they needed extra hours to complete their curricula.

In order to activate the students' background knowledge on the topic, the researcher gave a short introduction and explained the morphology of gerunds and infinitives (for example, the verb ride: stem + ing $=$ riding, or to + stem $=$ to ride), and the difference between a gerund and a progressive form (I like reading poems - reading $=$ Gerund $=$ object of the main verb; I am going home tomorrow am going $=$ Progressive $=$ Main Verb). A further explanation was that gerunds and infinitives act like nouns, in that they occur as subjects or objects of a verb, and for this reason they were described as verbal nouns (For example: subject position: "Riding a bicycle is fun"; object position: "I like writing poems"). The researcher presented the topic by providing examples of the two forms in subject and object positions on the blackboard.

After two weeks, the researcher taught the lesson on gerunds and infinitives to each Control and Experimental group (Appendix D). Two weeks later, the subjects were given a 15 -minute review of the topic by using their homework (the Michael Jackson story) (Appendix D). Then, they were administered the posttests. The students were given 10/15 minutes for each test. The teachers of the Control Groups were told to avoid teaching gerunds and infinitives, with the exception of the three activities provided during the treatment, so as to not threaten the validity of the experiment. In order to check the students' memorization of the verb lists, the Control Group's teachers were asked to have them do three exercises: one requiring 
an infinitive, one requiring a gerund, and one requiring both (Appendix F). These exercises were taken from Grammar Dimensions 3, (1997) by S. Thewlis and Understanding and Using English Grammar, (1989) by B. S. Azar. Also, the researcher observed the Control and Experimental Groups' instructors in order to find out their teaching styles, and noticed that there were not substantial differences amongst them, their lessons being mostly teacher-centered. Each part of the experiment - the pretests and introduction; the lesson; and the review and posttests was audio taped for back up use, so that the researcher and the teachers could check the Experimental and Control lessons, if necessary. This experiment took place during a four-week period instead of a one-two week period, as did Vawser's study (1988), of which this particular study is a replication.

With the exception of the pre and posttests, the researcher slightly modified the lessons and the materials; in particular, she utilized the Elvis Presley life story (Appendix D) to present the lesson on gerunds and infinitives instead of the Bruce Springsteen life story considered outdated by the majority of ESL/ENNL teachers. The researcher supplemented Vawser's lesson with a new contextualized activity as a substitutive for the Elvis Presley's activity that was used, instead, for the presentation of gerunds and infinitives. However, the original design of the experiment was maintained identical except for the lesson materials. 


\section{Description of the Experimental Lesson}

Right after the pretests, the researcher introduced gerunds and infinitives.

First, she described how a gerund or an infinitive is formed, stem + ing or to-stem, providing examples of gerunds and infinitives in subject and object positions on the blackboard. For example, in subject position: "Riding the bicycle is fun"; "To ride the bicycle is fun"; and in object position: "I like riding the bicycle"; "I like to ride the bicycle". Second, she explained that gerunds and infinitives have a definite function in as much as they can be used as nouns in a sentence, that is as objects and subjects of a verb. The students were provided with the examples above. Then, she went about describing the differences between a gerund and a progressive form, emphasizing that a gerund can never function as the main verb of a sentence, while in a progressive form it does and is described as a Present Participle.

During the 50-minute lesson, the researcher first presented a picture of Elvis Presley and asked the students whether they could recognize the pop star singer. Nearly everyone did. A transparency of his life story was displayed on the overhead projector after the students were given copies of the two contextualized exercises (Appendix D). The researcher asked the students to help her fill in the correct forms of the verbs in parentheses, using a gerund or an infinitive. Once they accomplished this activity, the researcher displayed a second transparency with three columns: Gerunds, Infinitives, and Both. Again the researcher called on each student asking him/her to identify the preceding verb and to fill in the correct column. After completing this activity, the researcher asked the students whether they saw any 
difference in the verbs preceding the infinitives and in those preceding the gerunds. Not many were able to. Then, the researcher explained the Bolinger principle. This was scripted and consistent for each experimental class. She told them that the verbs preceding the infinitive implied a future meaning, an unrealized possibility, or an action not yet experienced. On the other hand, the verbs preceding the gerund implied an action that had already occurred, a past action or an action in progress, and that these verbs are often emotive, that is, they entail positive/negative feelings toward the event on which they operate. For instance, the verb plan (to-V) and the verb enjoy (V-ing). The verb "plan" indicates the accomplishment of a future action, while the verb "enjoy" implies the continuation, in a series, of a past action that has been experienced many times before. Some verbs do not fit the Bolinger principle, though, and for this reason, the researcher provided the students with lists of these verbs to be memorized (Appendix G). Since the researcher had only 50 minutes for the lesson, the use of the Bolinger Principle depending on context was hinted but not fully explained. However, in order to practice the principle, one of the three contextualized exercises was done in class (Appendix D). All three were taken from two texts: English Alive (1982) by Fingado \& Jerome, and The English Connection (1981) by Fingado \& Freeman. These exercises are highly contextualized and were chosen so as to apply the Bolinger Principle in context.

During the activity, the researcher elicited the correct forms from the students and they were told to refer to the principle so as to be able to produce the correct form. Finally, the students were given homework in the form of a fill-in-the 
blanks exercise describing the life story of Michael Jackson (Appendix D). This exercise, requiring the use of gerunds and infinitives too, was developed by Julie Vawser and followed the format of the Elvis Presley story.

Lastly, right before the posttests, 15 minutes were spent reviewing the Bolinger principle together with the class using the Michael Jackson homework.

\section{Description of the Control Lesson}

The Control Group's lesson lasted 50 minutes, and its subjects were taught gerunds and infinitives with the same contextualized activities (Appendix D). The same picture of Elvis Presley was shown to the students who were asked to recognize him. The students immediately recalled the pop-star singer. Then, the researcher presented a transparency representing his life story in the form of a fillin-the blanks exercise, and she elicited the correct forms from the students.

Afterwards, another transparency was displayed on the overhead projector with three columns titled Gerunds, Infinitives, and Both. The students helped the researcher to write the preceding verbs in each column and they did so by using their lists of verbs taken from their textbooks: Refining Composition Skills (1995) by Smalley \& Ruetten, Grammar Dimensions 3 (1997) by Thewlis, and Understanding and Using English Grammar (1989) by Azar. Then, they were asked to memorize these lists. Finally, one of the three contextualized activities was done in class, after being chosen with the help of their teachers (Appendix D). One of the contextualized activities was taken from Grammar Dimensions 3 (1997) by Thewlis. The Control 
Group teachers were instructed to have their students do an exercise requiring an infinitive, an exercise requiring a gerund, and an exercise requiring both, in order to review the memorization of the items with the subjects before the posttests as required by the original research design (Vawser, personal communication). These exercises were taken from the students'grammar book: Grammar Dimensions 3 by Thewlis (Appendix D). The Control Group was given the same Michael Jackson homework (Appendix D).

\section{Description of the Tests}

Each pretest and each posttest, consisting of the Discrete Point Test, Sentence Combining Test, and Writing Test, took 40 minutes. The pretests were followed by a 15 -minute introduction to Gerunds and Infinitives (Appendix B). The posttests were preceded by a 15-minute review of Gerunds and Infinitives (Appendix E). The pretests consisted of three parts: the Discrete Point Test, a 20 fill-in-the blank sentences; the Sentence Combining Test; and a free writing test. These tests were developed by Vawser and test-piloted with ESL students labeled intermediate in Portland schools. Before the tests, the researcher read the instructions to the students and wrote examples of the sentences on the blackboard, explaining the meaning of unknown or more difficult words: for example, the verbs dread, deny, look forward to, resent, and hubcaps. The subjects were told to use one form only, a gerund or an infinitive. 
The Discrete Point Test consisted of 20 sentences, of which 10 required a gerund and 10 required an infinitive (Appendix B). The preceding verbs all fitted the Bolinger Principle, and consequently, only one form was possible (Appendix $\mathrm{H}$ ). The subjects were given ten minutes to complete the Discrete Point Test.

For the second pretest, more difficult than the first one, the students were given 15 minutes. The Sentence Combining Test is an adaptation of the Davidson Ability to Subordinate text. Each sentence is the result of two shorter sentences combined with a gerund or an infinitive. The subjects were asked to combine the two sentences by using a gerund or an infinitive to obtain one sentence. In this case too, the verbs used were compatible with the Bolinger Principle: 10 sentences required a gerund and 10 required an infinitive, and both forms were not possible (Appendix I). This test appeared to be more difficult as it required the students to distinguish two types of sentences and then subordinate the secondary clause by using one correct form, a gerund or an infinitive.

The third pretest was a free writing test. The students were asked to write about hobbies or activities they liked doing for 15 minutes. They were told to use a minimum of 5-6 sentences. "Write about your hobbies. Think of several hobbies you enjoy. What do you do? Where? When? Why? Mention some interesting experiences". This topic, as Vawser's (1988) study concluded, showed to be effective in the elicitation of gerunds and infinitives (Appendix B).

The three posttests had the same format and similar context (Appendix E), but the preceding verbs used were different from those of the pretests (Appendix $\mathrm{H}$ 
and I). Since four weeks elapsed between pre and posttests, it was very unlikely that the students could remember the verbs or the sentences used in the pretest. However, that was not an issue because the researcher wanted to test the principle and not the verbs themselves. The Discrete Point Test was worded in a different way, though it tested the same structures. The researcher adopted Vawser's pre and posttests (1988) for her experiment.

The Sentence Combining posttest presented the same structures of the Sentence Combining pretest, but it had different wording. This test followed the lesson on gerunds and infinitives and was administered to both Experimental and Control Groups after two weeks. Before the posttests, students were given instructions and examples by the researcher orally.

The Writing Sample posttest was also a free writing test (Appendix E). The subjects were asked to write on the topic for 15 minutes or as much as they needed: "Write about your spare time activities. Think of several spare time activities that you enjoy. What do you do? When? Where? Why? Mention some interesting experiences." This topic appeared to be useful in the elicitation of gerunds and infinitives.

Each writing sample was analyzed by counting the words written per paper, and by noting only the number of correct and incorrect gerunds and infinitives in object position. Consequently, gerunds or infinitives in subject position were not included in the chart. Then, in order to find out any improvement in the groups between the pre and posttests, the researcher analyzed the difference in the use of 
gerunds and infinitives between the pre and posttests (selection and testing process are outlined in Figure 2.).

$$
\text { MHCC }
$$

\section{L\&CC}

Consent

Form

Pretests

Selection

Control Group

Control Lesson

List Memorization

Control Review of $\mathrm{G} \& \mathrm{I}$
Experimental Group

Experimental Lesson

Bolinger's Principle

Posttests

Figure 2. Diagram of Selection and Testing Process of Control and Experimental Groups. 
${ }^{*} \mathrm{MHCC}=\mathrm{Mt}$. Hood Community College, L\&CC $=$ Lewis and Clark College; G\&I = Gerunds and Infinitives.

\section{$\underline{\text { Instruments }}$}

Overall, the study presented two main threats to validity: first, four weeks elapsed between the pre and posttests; and two weeks elapsed between the lesson and the posttests. The second threat is represented by the students' history factor. Residency and Study of English appeared to be very close for both groups, but the various students' age could be considered an intervening factor affecting their learning, and eventually their scores. Nonetheless, the statistical analysis of the students' pretest scores showed their relative comparability.

Since the tests measured the subjects' knowledge of gerunds and infinitives, the content validity of the experiment is high. In fact, the experiment focused on a narrow topic such as gerunds and infinitives in object position. Likewise, the topic chosen was about a semantic/pragmatic principle, that, formulated in 1968 , has been embraced by contemporary linguists and textbook writers such as Diane LarsenFreeman, who is the director of the Grammar Dimensions Series.

\section{$\underline{\text { Summary }}$}

This chapter described the methods used to test and teach gerunds and infinitives to ENNL learners. The subjects participating in the study were advanced and intermediate ENNL students attending writing and grammar classes at Portland colleges. After being chosen, the subjects were assigned to the Control and 
Experimental Groups. Then, they were administered the pre- and posttests as they were described in the previous sections. The Experimental Group was taught gerunds and infinitives by using the Bolinger principle, in order to minimize list memorization and facilitate language learning. The Control Group was taught gerunds and infinitives by applying the traditional method of list memorization. The students had to memorize three lists of verbs: those requiring a gerund, those requiring an infinitive, and those requiring both. However, both groups used the same materials: the pre- and posttests (Appendix B and D), the contextualized exercises, and the homework (Appendix E).

Indeed, there are limitations to this study: first, the small number of subjects who participated in the experiment; the availability of the teachers allowing the researcher to teach their classes; and finally, the topic itself, since not every instructor planned to teach gerunds and infinitives during the same period. This experiment involved grammar and writing classes only because the Discrete Point Tests and the Writing Test are part of the Hypotheses.

This study has questionable external reliability, because of the different results one may obtain if the experiment were replicated again. For example, the subjects' language background, age, and study of English; the teaching style of the researcher; and the length of time within which the experiment would take place, would probably yield different results. However, this experiment presents high content and construct validity. The high content is represented by the narrow topic, gerunds and infinitives in object position, while the construct was based on the 
ability of the subjects to use gerunds and infinitives in object position according to the Bolinger principle. 


\section{Chapter IV}

\section{Results}

This chapter outlines the results of the experiment and the data analysis

utilized. In order to examine any differences between the Discrete Point Test and the Sentence Combining Test scores, the researcher used t-tests - a Two Sample t-test and a t-test of the mean differences- to compare the means of both groups. What follows is an analysis of the results of these statistical tests. The writing samples were not run through a statistical analysis, but they will be described in detail in the forthcoming sections as well.

\section{Results of the Discrete Point Tests}

The Discrete Point pre and posttests consisted of 20 sentences. Their format resembled that of a fill-in-the blank exercise. The subjects were asked to insert a gerund or an infinitive form using the verb given in parentheses (Appendices B and D).

In order to access the differences between the Experimental and Control Groups, a Two Sample t-test for Paired Data was used. This test was run on the 
scores of the Discrete Point and Sentence Combining pre and posttests (Appendix B and D). The values showed that there was no detectable difference between the improvement in the Experimental Group versus the Control Group $(p>.05$, $t=0.78, \mathrm{~F}=76$ ) (see Table $\mathrm{V}$ for the mean scores of these tests).

Table V Scores for the Discrete Point Tests

\begin{tabular}{|c|c|c|c|c|}
\hline & $\begin{array}{l}\text { Mean of } \\
\text { Pretest }\end{array}$ & $\begin{array}{l}\text { Mean of } \\
\text { Posttest }\end{array}$ & $\begin{array}{l}\text { Mean of } \\
\text { Difference }\end{array}$ & $\begin{array}{l}\text { SDEV of } \\
\text { Difference }\end{array}$ \\
\hline Experimental $(n=44)$ & 14.61 & 16. 16 & 1. 55 & 2. 65 \\
\hline Control $(n=34)$ & 13. 56 & 14. 56 & 1 & 3.52 \\
\hline Difference & 1.05 & 1.50 & 0.55 & \\
\hline \multicolumn{5}{|c|}{$\begin{array}{l}\text { Experimental Group: \% improvement }(\text { raw })=7.75 \\
\text { \%improvement (based on pretest })=10.61(1.55 / 14.61)\end{array}$} \\
\hline \multicolumn{5}{|c|}{$\begin{aligned} \text { Control Group: } & \text { \%improvement (raw) }=5 \\
& \% \text { improvement (based on pretest })=7.37(1 / 13.56)\end{aligned}$} \\
\hline
\end{tabular}

The t-test results showed that the mean score of the Discrete Point pretest for the Experimental Group was 14.61, and that of the posttest was 16.16. As for the Control Group the mean score of the Discrete Point pretest was 13. 56 and that of the posttest was 14.56 . The Experimental Group showed a $10.61 \%$ gain and the Control Group a $7.37 \%$ gain in the posttest. The improvement of the Experimental Group, based on raw scores, was 7. 75\%, while the improvement of the Control Group was $5 \%$. Consequently, the increase between pre and posttests was $7.8 \%$ for the Experimental Group, and $5.0 \%$ for the Control Group (see Figure 6.). However, the difference in improvement between the two groups was not statistically significant, and these results apparently did not support Vawser's study, 
in which the gain in improvement was $12 \%$ for the Experimental Group and 3\% for the Control Group. Consequently, a second t-test for the mean differences was performed (a t-test of the mean of the total pre and posttest scores of both groups combined) and the values obtained showed a statistically significant improvement for the Experimental Group in both Discrete Point and Sentence Combining pre versus posttests (see Table VII). According to these results, the Experimental Group appears to have improved significantly in their use of gerunds and infinitives in the Discrete Point posttest, while the Control Group did not.

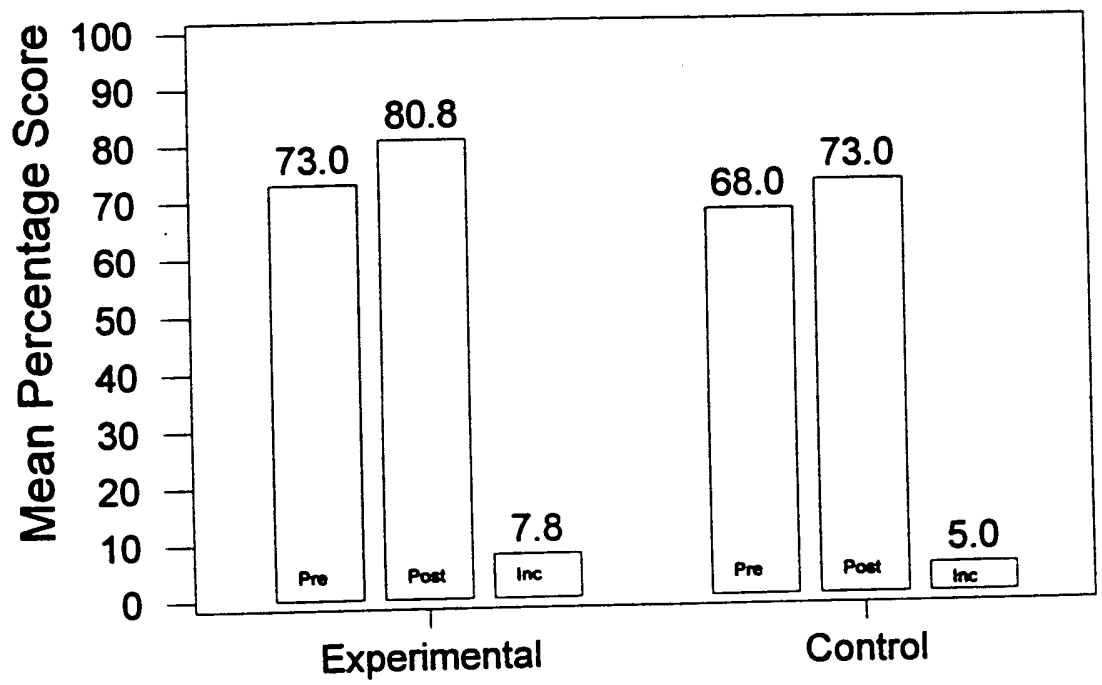

Figure 3. Mean Scores of Discrete Point Tests. 


\section{Results of the Sentence Combining Tests}

The Sentence Combining pre and posttests presented 20 questions, each one consisting of two sentences that the subjects were asked to combine by using a gerund or an infinitive form. A Two-Sample t-test was performed on the scores of the Sentence Combining Test $(\mathrm{t}=-0.52, p=0.60)$. According to the tests' results, the means for the Experimental and Control Groups were respectively

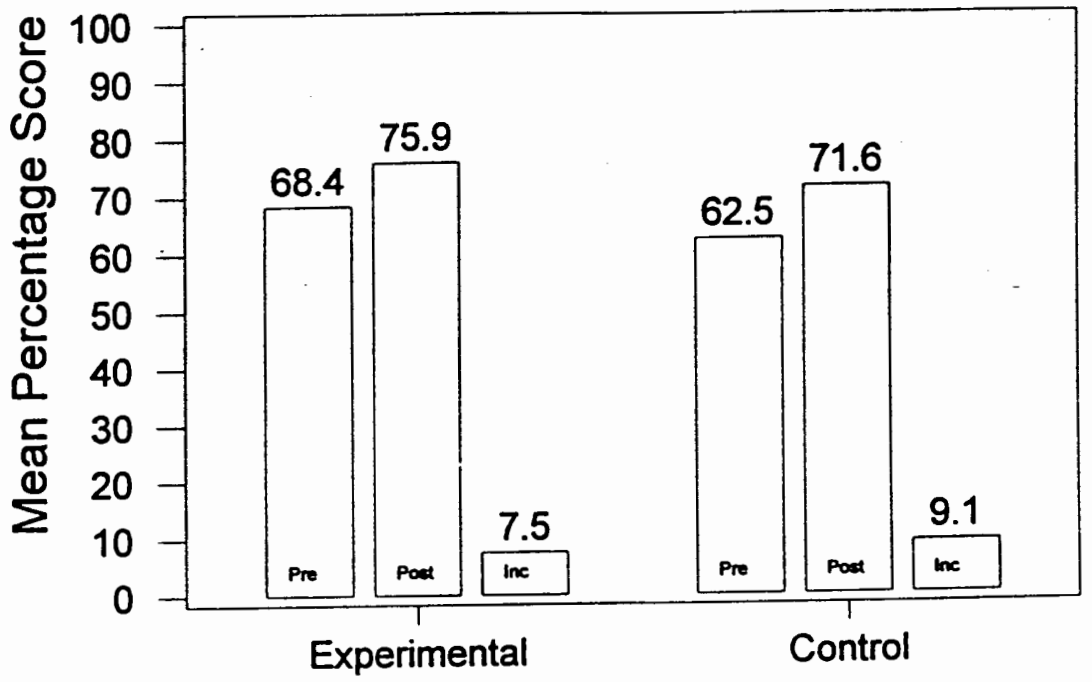

Figure 4. Mean Scores of Sentence Combining Tests.

1. 50 and 1. 82. The percentage improvement for the Experimental Group, based on the pretest, was $10.96 \%$ and for the Control Group it was $14.56 \%$. The improvement for the Experimental Group, based on raw scores, was 7. 50\% and for the Control Group it was $9.10 \%$ (see Table VI for the mean scores of the Sentence Combining Test, and Figure 4. for the Mean Percentage Score). 
Since the results of the Two-Sample t-tests seemed inconclusive, a t-test of the Mean for Paired Data (a t-test for the mean differences) was performed to determine whether there was any significant difference between the two groups in the total Discrete Point Test scores $(\mathrm{t}=3.79, p=0.0001)$. The values were statistically significant. As for the Sentence Combining Tests, the values for both groups were statistically significant too $(\mathrm{t}=5.38, p=0.0000)$. In the Discrete Point Test the Experimental Group showed a significant improvement $(\mathrm{t}=3.88$, $\mathrm{p}=0.0002$ ); in the Sentence Combining Test, instead, the Experimental Group did not improve as significantly as the Control Group did $(t=4.12, p=0.0001)$ (see Table VII). As for the Control Group, the Discrete Point test did not show statistically significant values $(\mathrm{t}=1.66, p=0.053)$; the Sentence Combining Test, instead, showed values that were statistically significant, more significant than the Experimental Group's tests scores $(t=3.50, p=0.0007)$ (see Table VII).

These values revealed first, a statistically significant improvement in the total Discrete Point tests and the total Sentence Combining tests for the total scores of both groups combined; second, a significant improvement in both the Discrete Point and Sentence Combining tests for the Experimental Group; and third, a significant improvement in the Sentence Combining Test only for the Control Group. As for the Experimental Group, the values of the t-test of the mean differences showed a significant improvement in both the Discrete Point Test and the Sentence Combining Test combined (see Table VII for the results of the t-test of the mean differences), partially validating the first hypothesis, that is, that teaching ENNL learners gerunds 
and infinitives with the Bolinger principle would result in a significant improvement in Discrete Point tests.

\section{Table VI Scores of the Sentence Combining Tests}

\begin{tabular}{lcccc} 
& $\begin{array}{c}\text { Mean of } \\
\text { Pretest }\end{array}$ & $\begin{array}{c}\text { Mean of } \\
\text { Posttest }\end{array}$ & $\begin{array}{c}\text { Mean of } \\
\text { Difference }\end{array}$ & $\begin{array}{c}\text { SDEV of } \\
\text { Difference }\end{array}$ \\
$\begin{array}{l}\text { Experimental } \\
(\mathrm{n}=44)\end{array}$ & 13.68 & 15.18 & 1.5 & 2.42 \\
$\begin{array}{l}\text { Control } \\
(\mathrm{n}=34)\end{array}$ & 12.50 & 14.32 & 1.82 & 3.04 \\
Difference & 1.18 & 0.86 & -0.32 & \\
\hline
\end{tabular}

Experimental Group: \% improvement (raw) $=7.50$

$\%$ improvement $($ based on pretest $)=10.96(1.5 / 13.68)$

Control Group: \% improvement (raw) $=9.10$

$\%$ improvement (based on pretest) $=14.56(1.82 / 12.5)$

Table VII $t$-test for the Mean Differences of the Total Scores Combined

$\begin{array}{lllllll}\text { Variable } & \text { N } & \text { Mean } & \text { StDev } & \text { SE Mean } & \text { T } & \text { P } \\ & & & & & & \\ \text { Total DPT* } & 78 & 1.308 & 3.046 & 0.345 & 3.79 & 0.0001 \\ \text { Total SCT } & 78 & 1.641 & 2.692 & 0.305 & 5.38 & 0.0000 \\ \text { Exp. DPT } & 44 & 1.545 & 2.645 & 0.399 & 3.88 & 0.0002 \\ \text { Exp. SCT } & 44 & 1.500 & 2.416 & 0.364 & 4.12 & 0.0001 \\ \text { Ctr. DPT } & 34 & 1.000 & 3.516 & 0.603 & 1.66 & 0.053 \\ \text { Ctr. SCT } & 34 & 1.824 & 3.040 & 0.521 & 3.50 & 0.0007\end{array}$

*DPT $=$ Discrete Point Test

SCT $=$ Sentence Combining Test

Exp. = Experimental Group

Ctr. = Control Group

\section{$\underline{\text { Results of the Writing Sample Tests }}$}

The two writing samples were previously piloted by Vawser in her study (1988) and they then were chosen by the researcher for her experiment. The researcher adopted Vawser's topics for the pre and post writing tests. The topic for 
the pretest was: "Write about your hobbies. Think of several hobbies that you enjoy. What do you do? Where? When? Why? Mention some interesting experiences." The subjects were given 15 minutes to write on the topic. The posttest writing sample had a similar topic with the word "hobby" replaced by "spare time activities": "Write about your spare time activities. Think of several spare time activities that you enjoy. What do you do? When? Where? Why? Mention some interesting experiences." For this test too, the subjects were given 15 minutes. These questions were designed to elicit gerunds and infinitives in the subjects' writing (Appendices B and D).

The number of words in each sample writing were counted, charting only gerunds and infinitives in object position. Correct and incorrect usage of these forms was included. The samples showed that the subjects in both groups wrote a similar number of words per paper, with the Experimental Group using more words per paper. The Experimental Group wrote an average of 110 words per paper in both the pre and postwriting tests and used more gerunds and fewer infinitives in the posttest; instead, the Control Group wrote an average of 86 words in both the pre and postwriting tests and used more gerunds and infinitives in total (see Figure 6.).

For the Experimental Group the difference in total ratio of correct and incorrect gerunds and infinitives between pre and posttest was $1.17: 100$, with an overall significant increase of $30.4 \%$. For the Control Group, the difference between the pre and posttest was 1.03: 100, with an overall increase of $19.6 \%$. The total ratio of correct and incorrect gerunds and infinitives in the posttest for both 
groups was $0.99: 100$, while the difference in total ratio between pre and posttests was 0.18:100 for the Experimental Group and 0. 05:100 for the Control Group (see Table VIII). These results appeared to be statistically significant for the Experimental Group, with a $30.4 \%$ increase in the total ratio of correct and incorrect gerunds and infinitives.

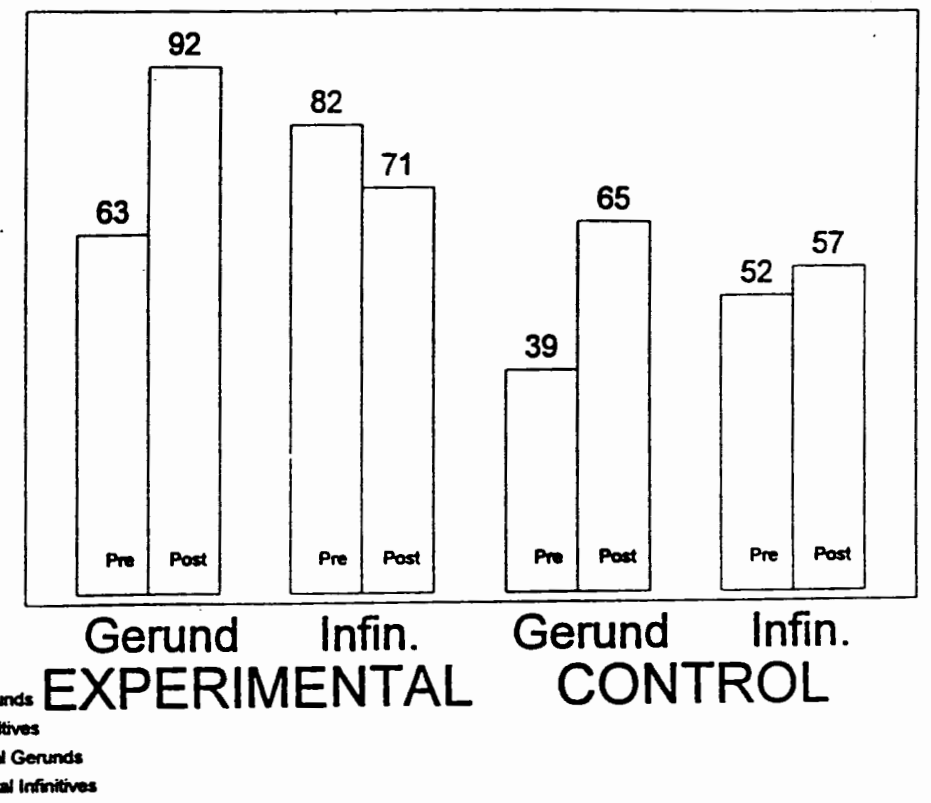

Figure 5. Number of Correctly Used Gerunds and Infinitives.

Table VIII Total Ratio of Correct and Incorrect Gerunds and Infinitives

Experimental Group
Total Correct Incorrect
Ratio

Pretest

Posttest

$$
3.85: 100
$$

$3.43: 100$

$0.42: 100$

5.02:100

$4.42: 100$

$0.60: 100$

0.99:100

Difference

$1.17: 100$

28.9
$0.18: 100$

43.1

\section{Control Group}

Total Correct Incorrect

Ratio

$\begin{array}{ccl}5.26: 100 & 4.29: 100 & 0.96: 100 \\ 6.29: 100 & 5.28: 100 & 1.01: 100 \\ 1.03: 100 & 0.99: 100 & 0.05: 100 \\ 19.6 & 23.1 & 5.19\end{array}$


The Experimental Group wrote an average of 110 words per paper in both the pre and postwriting tests. The subjects produced a minimum of 32 words and a maximum of 267 words per paper in the pretest. In the posttest, they produced between 37 and 289 words per paper. The Experimental Group's writing samples showed that the total ratio of correct and incorrect gerunds and infinitives in the pretest was 3.85:100. In the posttest writing sample, the Experimental Group showed an improvement of 1.17:100, that is, a $30.4 \%$ increase (see Table VIII).

In the Writing sample pretest, the Experimental Group showed a 3.43:100 ratio of correct usage of gerunds and infinitives. In the posttest, the ratio increased to $4.42: 100$, showing a $28.0 \%$ increase (see Table VIII). Interestingly, the Experimental Group produced a higher number of total usage of correct gerunds compared to the Control Group, but also a $13.4 \%$ decrease in correct infinitives (see Figure 8.). The difference in ratio of correct usage of gerunds and infinitives to the number of words produced in the posttest showed a $28.9 \%$ increase (see Figure 6). With respect to the ratio of incorrect to correct usage of gerunds and infinitives, the Experimental Group showed an increase of $11.4 \%$ (see Figure 7). The ratio of incorrect usage of gerunds and infinitives to the number of words produced in the posttest showed a $43.1 \%$ increase (see Figure 8 ). The Experimental Group seems to have produced more incorrect gerunds and infinitives in the posttest. However, they produced more words per paper and did not receive any review of gerunds and infinitives. Consequently, the subjects could not be expected to always produce gerunds and infinitives correctly. As for the total usage of gerunds and infinitives 
per 100 words, the Experimental Group showed a $30.4 \%$ increase (see Figure 9).

The Control Group wrote an average of 78 words in the pre writing test, and an average of 93 words in the post writing test. They produced a minimum of 28 and a maximum of 198 words per paper in the pretest. In the posttest, the subjects wrote a minimum of 33 and maximum of 146 words per paper.

In the writing sample pretest, the total ratio of correct and incorrect gerunds and infinitives was 5.26:100 words. In the posttest, it was 6.29:100, with a $19.6 \%$ increase between the two tests (see Table VII). The Control Group showed a $66.7 \%$

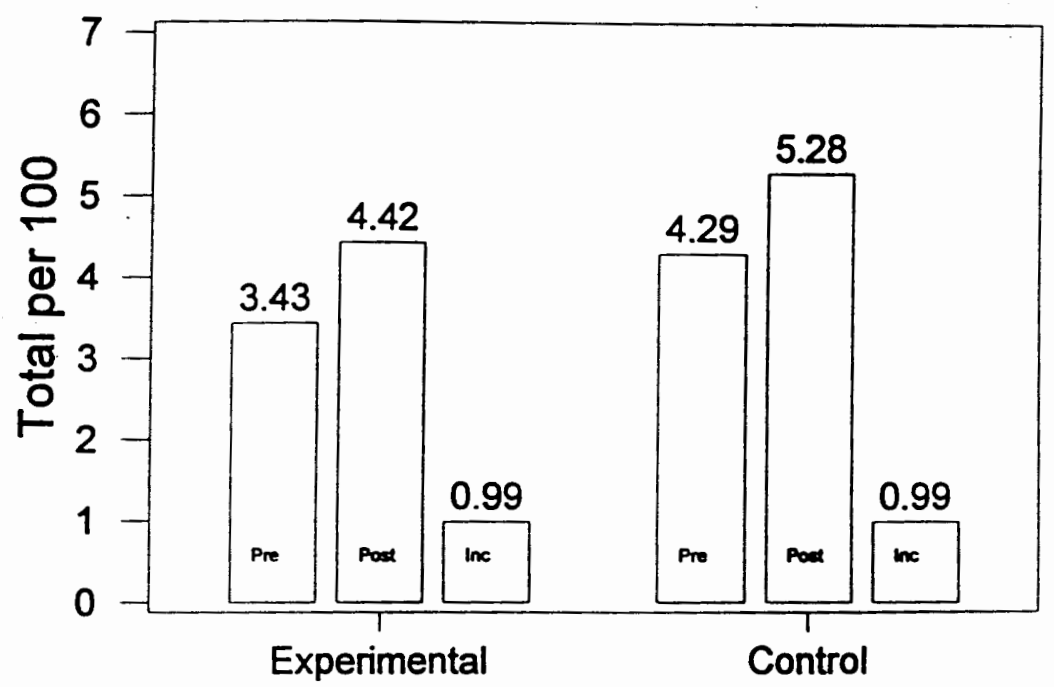

$28.9 \%$ Increase in Experimental Group

$23.1 \%$ Increase in Control Group

Figure 6. Correct Usage per 100 Words of Gerunds and Infinitives

increase in the number of correctly used gerunds and a $9.62 \%$ increase in the number of correctly used infinitives (Figure 5). As for the correct usage of gerunds and infinitives, the pretest showed a ratio of $4.29: 100$, while in the posttest the ratio 
was 5.28:100 with a $23.1 \%$ increase (Figure 6). The ratio of incorrect to correct usage of gerunds and infinitives to the number of words produced per paper showed a $14.7 \%$ decrease for the Control Group (Figure 7).

The incorrect usage of gerunds and infinitives per 100 words showed a $5.19 \%$ increase (see Figure 8). The total usage of gerunds and infinitives per 100 words showed a $19.6 \%$ increase (see Figure 9). Overall, the Experimental Group showed a $46.0 \%$ increase in the number of correctly used gerunds, and a $13.4 \%$ decrease in the number of correctly used infinitives (Figure 5). The Control Group, instead, showed a $66.7 \%$ increase in the number of correctly used gerunds and a 9.62\% increase in the number of correctly used infinitives (Figure 8). Overall, however, the Experimental Group showed a $28.9 \%$ increase in correct usage of gerunds and infinitives and the Control Group showed a $23.1 \%$ increase in correct usage of gerunds and infinitives (Table VIII).

Finally, the total usage of gerunds and infinitives per 100 words showed a $30.4 \%$ increase for the Experimental Group and a $19.6 \%$ increase for the Control Group. This increase in percentage for the Experimental Group seemed to indicate a significant improvement in the overall usage of gerunds and infinitives between the pre and posttests, though the Experimental Group produced more gerunds than infinitives (see Figure 9). These results seem to validate only partially the second hypothesis, according to which by learning the Bolinger principle learners would increase their overall correct use of gerunds and infinitives. The Experimental Group, however, produced more gerunds than infinitives, but not always correctly. 


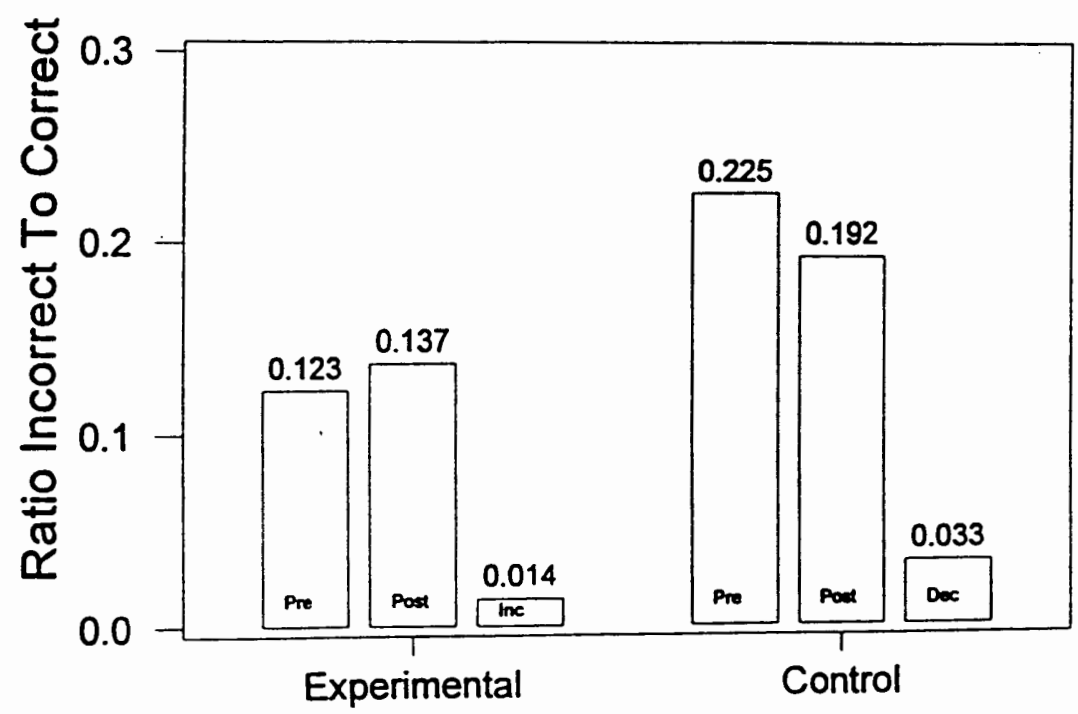

$11.4 \%$ INCREASE in Experimental Group

$14.7 \%$ DECREASE in Control Group

Figure 7. Ratio of incorrect to Correct Usage of Gerunds and Infinitives

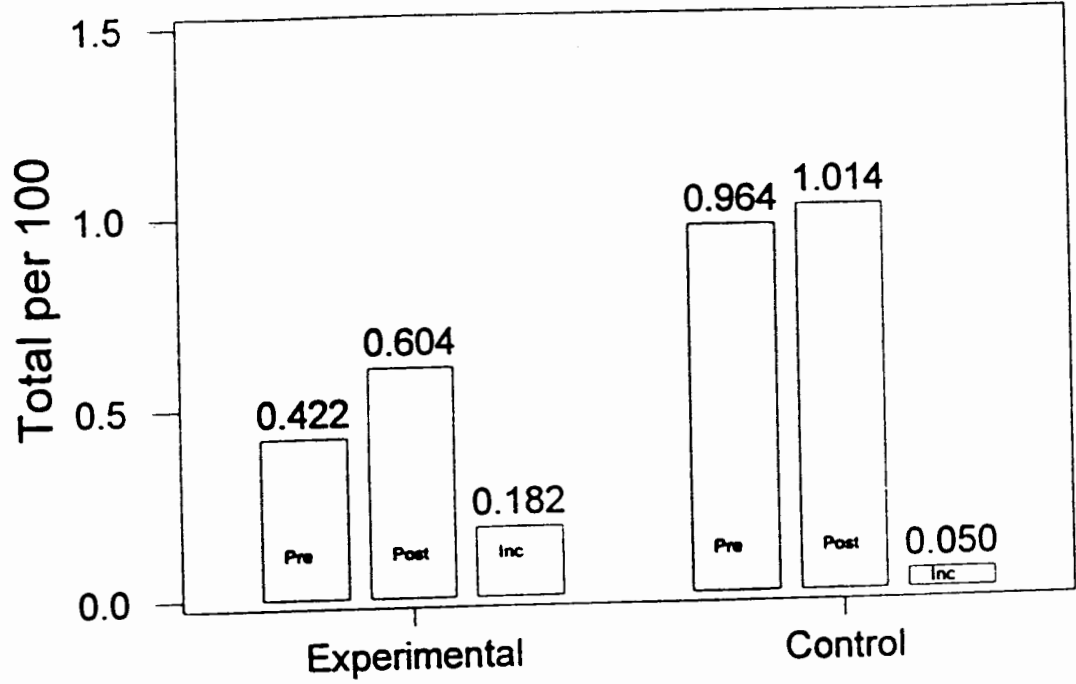

43.1\% Increase in Experimental Group

$5.19 \%$ Increase in Control Group

Figure 8. Incorrect Usage per 100 Words of gerunds and Infinitives. 


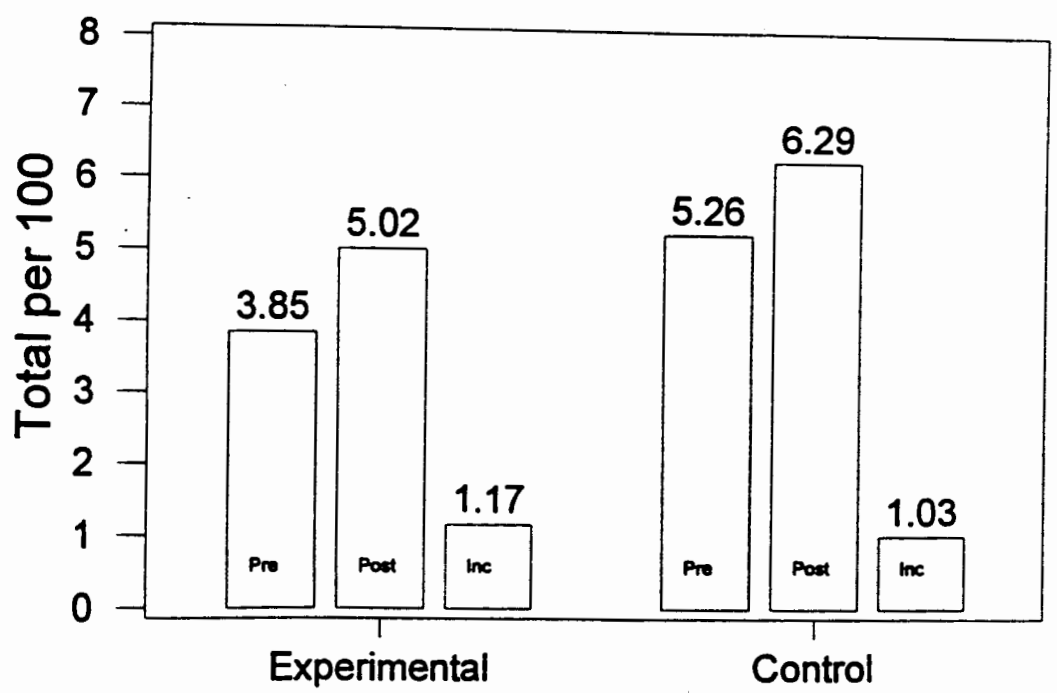

$30.4 \%$ Increase in Experimental Group $19.6 \%$ Increase in Control Group

Figure 9. Total Usage per 100 Words of Gerunds and Infinitives.

\section{Summary}

In this chapter were described the results of the Discrete Point Test, the Sentence Combining Test, and the Writing Sample Test for the Experimental and Control Groups. The improvement between the Discrete Point pre and posttest and between the Sentence Combining pre and posttest was not significant for either group. However, the results of the t-test for the Mean Differences of total scores combined for both groups showed a significant improvement for the Experimental Group, in particular between the Discrete Point and the Sentence Combining pre versus posttest scores. Equally significant was the improvement for the Control Group in the Sentence Combining pre versus posttest. As for the writing samples, 
the results showed an improvement in the total usage of gerunds and infinitives for the Experimental Group, and an improvement as well for the Control Group in the correct use of infinitives. Although the Control Group did better on the Sentence Combining Test only, overall the Experimental Group performed significantly better than the Control Group on both the Discrete Point and Sentence Combining pre versus posttests. In the writing sample posttests, the Experimental Group showed a $28.9 \%$ increase in the correct usage of the two complements, while the Control Group showed a $23.1 \%$ increase in the correct usage of gerunds and infinitives. 


\section{Chapter V}

\section{Conclusions and Recommendations}

In this chapter, the hypotheses and the test results obtained from the experiment will be restated and discussed. Hence, the researcher will be able to draw implications and provide further recommendations for this particular teaching methodology. Also, she will note and document limitations to this study and offer suggestions for future research.

\section{Discussion of Hypotheses}

The first hypothesis stated that teaching ENNL learners gerunds and infinitives using the Bolinger principle would result in a significant improvement in their ability to use gerunds and infinitives in Discrete Point and Sentence Combining Tests. The t-test for the Mean Differences of the pre and posttests'scores combined showed that both groups improved between the tests, in particular, the Experimental Group's mean score increase was 1.55 and 1.50 in both tests. There was also a significant improvement for the Control Group in the Sentence Combining posttest. Then, though the Control Group did better than the Experimental Group on the 
Sentence Combining Test, it seems apparent that the first hypothesis was partially validated, as the Experimental Group showed a significant improvement in the use of Gerunds and Infinitives on both the Discrete Point and Sentence Combining tests.

Of course, these results are not conclusive. The stretch of time between the tests, four weeks, certainly influenced the subjects' recall of the items, and if they were to be tested again, the results would most likely be different. The Experimental Group scored $2.75 \%$ higher than the Control Group on the Discrete Point posttest, while in the Sentence Combining posttest the Control Group scored $2.40 \%$ higher than the Experimental Group. The mean of the Discrete Point posttest for the Experimental Group was 1. 55, and the mean of the Sentence Combining for the Control Group was 1.82. However, in order to see whether these differences were significant, a t-test for the Mean Differences of the total scores combined for both groups was performed. It showed that the difference between the two tests was significant. Indeed, the Experimental Group showed a significant improvement between the pre and post Discrete Point and Sentence Combining tests versus the Control Group. It showed that there was a significant improvement between the Discrete Point pre and posttests for the total scores of both Groups combined. Second, it showed a significant improvement for the Experimental Group in both the Discrete Point Test and the Sentence Combining Tests, and also a significant improvement for the Control Group in the Sentence Combining Test only. The Experimental Group showed a $10.96 \%$ improvement between the pre and post Sentence Combining Test, while, surprisingly, the Control Group showed a $14.56 \%$ 
improvement on the same test. The fact that this test was cognitively a more difficult one did not seem to affect the subjects' scores, and it definitely confirms that their level of language proficiency was adequate for the study. A second, tentative explanation might be the fact that the Control Group reviewed the topic with three exercises in the week or days preceding the posttests. The Experimental Group did not get any review, because it was assumed that once they grasped the semantic principle, the subjects would not have to memorize any verbs or complementisers. A third explanation is the possibility that the subjects of the Control Group could have talked to those of the Experimental Group, and that they, eventually, found out about the Bolinger principle. However, these results cannot be considered representative of the Control Group population, since the study involved only 34 students. Nonetheless, the t-test for the Mean Differences of the total scores combined showed a significant improvement in the Experimental Group between the pre and posttests, in the Discrete Point Test with a mean improvement of 1.545 and in the Sentencè Combining Test with a mean improvement of 1.5.

The results of the Discrete Point pre versus posttests seem to support Vawser's study (1988) and the first hypothesis. However, the results of the Sentence Combining pretest versus posttest were nonetheless unexpected; the Control Group showed a significant improvement in this test with a mean of 1.82 . There exist alternative explanations for such an ambiguous outcome. The first one seems likely to involve the higher level of contextualization of its sentences as compared to the Discrete Point Test. The context in which the sentences were presented may have 
facilitated the subjects' correct use of the items. A second plausible explanation is related to one particular event: the textbook of one of the Control Group classes, consisting of 12 students, presented the topic on gerunds and infinitives according to the Bolinger principle. Though the teacher and the researcher asked the subjects to skip the chapter, it was still possible for some of them to read the unit on verbal nouns, therefore performing well on the posttests. This combined with the list memorization assigned to them and the review of gerunds and infinitives that they received could have influenced their scores significantly. Yet, the results from the discrete point tests showed a significant improvement for the Experimental Group, so as to suggest educators in ENNL/ESL classes teaching gerunds and infinitives by using the Bolinger principle and by combining this "rule of thumb" with the memorization of those verbs that do not fit the Bolinger principle. Also, preceding verbs should be presented according to their semantic classification together with this semantic principle.

The second hypothesis stated that teaching ENNL students gerunds and infinitives with the Bolinger principle would result in a significant improvement in the use of gerunds and infinitives in writing. In the writing sample posttests, the Experimental Group showed a $30.4 \%$ increase for the total ratio of correct and incorrect gerunds and infinitives. However, it also showed a $43.11 \%$ increase in their incorrect use of gerunds and infinitives. The subjects appeared to improve in their overall use of gerunds and infinitives. Although the Control Group improved in their total usage of gerunds and infinitives, the Experimental Group improved in 
their total correct usage of gerunds only. Indeed, there was a significant increase in their use of gerunds and a correspondent decrease in their use of infinitives. The Control Group instead showed an increase in their overall use of gerunds and infinitives (see Table VIII). Overall, although the Control Group produced more gerunds and infinitives altogether, the Experimental Group showed a higher increase in their correct usage of Gerunds and Infinitives per 100 words than the Control Group did.

Contrary to Vawser's conclusions (1988), the results of the Writing Tests seem to support the second hypothesis only in part, since the treatment elicited a greater number of gerunds and infinitives overall, though it did not elicit more infinitives than gerunds as assumed, and not always correctly. The results of the post Writing tests showed that the subjects in the Experimental Group used more gerunds than infinitives. This could be explained with the topic of the tests, in which the verbs used required gerunds. Hobbies and spare time activities are always expressed in English with verbal nouns. One goes hunting/ fishing/ dancing/ running and so forth or one likes cooking/painting/singing, etc. Enjoy and like do elicit more gerunds than infinitives. Furthermore, the type of writing test may have affected the results as it was a free writing test. The students were asked to write as much as they could or a minimum of six sentences. They ended up writing as much as 267 and as little as 28 words. Some students left their page blank. Those who wrote the most may have done so because of the nature of the test. They knew that these tests would 
not affect their scores at all; therefore, they expressed themselves without feeling intimidated by or concerned with their use of grammar.

An interesting outcome of the Writing Tests is the verbs that were listed according to their frequency of occurrence (see Table IX). A total of 29 verbs were charted: like was the most used $29.8 \%$ of the time. Enjoy was also used $17.5 \%$ of the time. A few of the papers were long enough, but most of the papers were quite short and the number of verbs was not particularly high since only gerunds and infinitives in object position were counted. The Experimental Group showed a $28.9 \%$ increase in correct usage of gerunds and infinitives, while the Control Group showed an almost equal improvement with a $23.1 \%$ increase (see Figure 8 ). The $5.8 \%$ difference in increase between the two groups may been accounted for by the treatment, the Bolinger principle, that the Experimental group received. Nonetheless, these conclusions should not be considered definitive since the small number of subjects in both groups does not allow one to make generalizations about the subjects' actual use of gerunds and infinitives.

\section{$\underline{\text { Limitations }}$}

Various problems were encountered by the researcher during the experiment. These problems were related to different factors, such as the number of subjects participating in the study and the time allotted to carry out the tests and the treatment. It is well known that in true experiments the higher the sample size the better the chances that the results can be generalized to the entire population. Indeed, 
from an original number of 93 students the researcher could actually test only 78 subjects. Some were eliminated for a few reasons: those who were present during the pretests did not show up for the lesson or during the posttests. At least 6 students missed the lesson on gerunds and infinitives. Indeed, because of the small number of students available, the subjects could not be randomly assigned to the Experimental and Control Groups. This is the main reason why the researcher cannot generalize these results to the ENNL student population.

A further limitation was given by the fact that the textbook of one Control Group class, consisting of 12 students, presented the topic according to the Bolinger principle, and explained the use of gerunds and infinitives with pragmatic/semantic principles. The teacher and the researcher attempted to make sure that the students would not read the unit in question and the researcher herself double checked with the students before the posttests. However, there still was a chance that some students might have read the chapter, thus invalidating the results of this study. The researcher considered the possibility of eliminating this class from the experiment, but this would have decreased the number of Control subjects to 20. It seems evident that some choices were necessarily biased.

Another limitation was presented by the tests themselves. These tests were piloted by Vawser in her previous study (1988), and were chosen by the researcher, who attempted to avoid problems with some difficult words by explaining them right before the tests. The subjects were able to perform relatively well on these tests. 
However, some sentences were more difficult than others either for their vocabulary or for their syntax.

Table IX Frequency of Preceding Verbs in the Writing Sample Tests.

\begin{tabular}{|c|c|c|c|c|c|c|}
\hline Verb & $\begin{array}{l}\text { Pretest } \\
\text { Exp. }\end{array}$ & $\begin{array}{l}\text { Posttest } \\
\text { Exp. }\end{array}$ & $\begin{array}{l}\text { Pretest } \\
\text { Control }\end{array}$ & $\begin{array}{l}\text { Posttest } \\
\text { Control }\end{array}$ & Total & Percen \\
\hline like & 32 & 28 & 20 & 19 & 99 & 29.8 \\
\hline enjoy & 10 & 24 & 9 & 15 & 58 & 17.5 \\
\hline want & 11 & 6 & 6 & 3 & 6 & 7.8 \\
\hline go & 6 & 6 & 2 & 5 & 9 & 5.7 \\
\hline start & 4 & 1 & 3 & 2 & 0 & 3.0 \\
\hline try & 5 & 5 & 1 & 3 & 14 & 4.2 \\
\hline decide & 1 & 0 & 3 & 3 & 7 & 2.1 \\
\hline begin & 2 & 1 & 1 & 0 & 4 & 1.2 \\
\hline keep & 1 & 0 & 0 & 0 & 1 & .3 \\
\hline hope & 1 & 1 & 0 & 0 & 2 & .6 \\
\hline know & 1 & 0 & 0 & 0 & 1 & .3 \\
\hline stop & 0 & 1 & 0 & 2 & 3 & .9 \\
\hline help & 2 & 3 & 3 & 1 & 9 & 2.7 \\
\hline need & 2 & 2 & 0 & 2 & 6 & 1.8 \\
\hline would like & 2 & 4 & 5 & 3 & 14 & 4.2 \\
\hline spend & 1 & 3 & 3 & 0 & 7 & 2.1 \\
\hline used to & 4 & 4 & 3 & 2 & 13 & 3.9 \\
\hline learn & 4 & 1 & 1 & 1 & 7 & 2.1 \\
\hline love & 6 & 4 & 2 & 3 & 15 & 4.5 \\
\hline give up & 1 & 0 & 0 & 0 & 1 & .3 \\
\hline ask & 1 & 0 & 0 & 0 & 1 & .3 \\
\hline choose & 1 & 0 & 0 & 0 & 1 & .3 \\
\hline encourage & 1 & 0 & 0 & 0 & 1 & .3 \\
\hline interested in & n 0 & 0 & 3 & 0 & 3 & .9 \\
\hline continue & 0 & 2 & 0 & 0 & 2 & .6 \\
\hline offer & 0 & 0 & 0 & 1 & 1 & .3 \\
\hline finish & 0 & 0 & 0 & 3 & 3 & .9 \\
\hline expect & 0 & 0 & 0 & 2 & 2 & .6 \\
\hline practice & $\underline{0}$ & $\underline{0}$ & $\underline{0}$ & $\underline{2}$ & $\underline{2}$ & .6 \\
\hline Total & 99 & 96 & $\overline{65}$ & 72 & 332 & \\
\hline
\end{tabular}


For example, sentence \# 18 in the Discrete Point pretest was missed by $72 \%$ of the subjects. In Vawser's study (1988), it was missed by $96 \%$ of the subjects:

18. Many Portland residents resent paying (pay) high property taxes.

The next most difficult sentence was \#1, which $50 \%$ of the subjects missed. In Vawser's study, it was missed by approximately $70 \%$ of the subjects:

1. The defendant admitted stealing (steal) the car.

The difference between the two sentences was $29 \%$ lower than sentence \#18. As previously mentioned, the students received clear instructions regarding those words that were unknown. Indeed, during the test some students did ask the researcher for the meaning of the words resent, admit, and looking forward to. The rest of the questions missed were between the $3 \%$ and $72 \%$ range.

As for the Discrete Point post-test, the most difficult sentence resulted to be \# 5 which $56 \%$ of the students missed:

5. The boys admitted starting (start) the fire which burned down some houses.

The rest of the questions missed ranged from $50 \%$ to $1 \%$. However, the most difficult test was Sentence Combining, which required the students to combine two sentences with a gerund or an infinitive in order to obtain one sentence. The subjects in both Groups did well on the Sentence Combining posttest, with the Control Group performing better than the Experimental Group. Amongst the possible causes, the fact that this type of test was more contextualized, played a major role. The subjects 
had more difficulty with sentence $\# 1, \# 8$ and $\# 2$. As for sentence $\# 1,69 \%$ of the subjects missed it:

1. a. Portland residents pay high property taxes.

b. They resent it.

Portland residents resent paying (pay) high property taxes.

Sentence \#8 was as difficult as \#1. In fact, $62 \%$ of the subjects missed this sentence:

8. a I must work every other weekend.

b I can't get used to that.

I can't get used to working every other weekend.

Sentence \#8 was misleading because of the particle to, which seems to require an infinitive rather than a gerund, and also because it was a phrasal verb, a very difficult grammar subject for non-native speakers. The next most difficult sentence was $\# 2$, which $62 \%$ of the subjects missed.

As for the Sentence Combining posttest, the most difficult sentence was \#1 which $59 \%$ of the subjects missed:

11. a The boys stole the neighbor's hubcaps.

b They admitted it.

The boys admitted stealing the neighbor's hubcaps.

The meaning of the verb admit appeared problematic for the majority of the students as they missed the same verb in sentence \#5 of the Discrete Point posttest as well. The rest of questions missed ranged from $.04 \%$ to $49 \%$. Question $\# 3$ presented the same problems as question \#6 in the Sentence Combining Pretest. Most of the 
students had problems identifying which verb to use, and it was missed by more than $46 \%$ of them.

3. a Bob was accused of cheating on his test.

b He denied it.

Bob denied cheating on his test.

A few students used the verb accuse instead of deny:

3. *Bob denied accusing of cheating on his test.

However, despite some more difficult sentences in the tests, they were not so significant as to distort the results. In general, they seemed to be compatible with the language level of the subjects by being not particularly difficult or easy.

The last limitation in our study concerns the time elapsed between the pretests, the lesson, and the posttests. Four weeks seem sufficient to learn a new subject, but the passing of time could influence the recall of the items, particularly if the subjects had only to grasp a semantic principle. List memorization may have been affected by the passing of time as well. The teachers of the Control Group classes were instructed to have their students do three exercises to check the memorization of the items, while the Experimental Group could only rely on their understanding of a semantic principle. The researcher wanted to see whether a longer stretch of time between the pre and posttests would affect the subjects's ability to recall the items. Since Vawser's study took place within less than two weeks, the results of this experiment, taking place in four weeks, may have been affected by the students' retention of the items. In other words, the Experimental and 
Control groups' scores might vary because of the longer stretch of time and because of a less efficient recall of the grammatical items. Consequently, the replication of this study may yield different results.

Vawser (personal communication, 1998) taught gerunds and infinitives to a class of high-intermediate ESL students enrolled in Warner Pacific College, in an academic program. The students were in the third and fourth level, and their textbook was Azar's Understanding and Using English Grammar (1989). After having taught the students the Bolinger principle for an entire week, Vawser observed that her students seemed more confused than if she had had them just memorize the lists of verbs. Her conclusions seem to suggest teaching gerunds and infinitives with the Bolinger principle to students who are not at a too advanced level. She claims that at that stage of language acquisition, students are too knowledgeable and, therefore, they get more confused by the different shades of meaning associated with the use of these two complements. Finally, Vawser claims that the Bolinger principle may not be as effective as she had assumed. However, based on the overall improvement of the Experimental Group on both tests, it seems that students at an intermediate or high intermediate level could benefit from this semantic approach.

Limitations were identified and discussed, and recommendations were given in this section. Indeed, the conclusions cannot be considered definitive, although they indicate that teachers might apply the Bolinger principle to teach 
intermediate/high-intermediate ENNL learners gerunds and infinitives, in order to facilitate their learning precess and correct usage of these items.

\section{Further Research}

A possible area of research for teaching gerunds and infinitives would be the use of the Bolinger principle in context. Although context was an important feature of the study, the Discrete Point and Sentence Combining pre and posttests were not contextualized, with the exception of the lesson activities. The 20 sentences in the Discrete Point test present the grammatical structures void of any context; only the Sentence Combining test provides a small amount of context, though this cannot be considered a contextualized test. It would be particularly helpful, for instance, to rewrite the tests by using whole paragraphs taken from literature texts. They should be appropriate to the level of language proficiency of the students and can be prepared by omitting all of the gerunds and infinitives in object position, that the subjects would fill in. This could be an important improvement in the research design of the experiment.

This study involved students in the intermediate to advanced level range. However, it seems advisable to carry out this research with intermediate or high intermediate students only. Lower-intermediate level students do not seem to be able to grasp the principle without lengthy explanations. An advanced level might have seemed more appropriate, but most students who are already proficient in the language should not need this principle to learn the use of gerunds and infinitives. 
Summary

The investigator carried out this experiment to see whether the use of the Bolinger principle to teach gerunds and infinitives could facilitate students' learning of the items. This semantic principle can be used as a "rule of thumb" to learn the complex topic of verbal nouns. Such a method is contrasted with list memorization in which the students have to memorize the items. A statistical analysis was performed on the results of the pre and posttests, showing that overall the Experimental Group did somewhat better than the Control Group in the Discrete Point and Sentence Combining pre versus posttests. Although the Control Group improved significantly on the Sentence Combining pre versus posttest and produced more gerunds and infinitives in the writing sample pre versus posttest, yet the Experimental Group improved significantly on both the Discrete Point and Sentence Combining pre versus posttests and showed a higher increase in their total correct usage of gerunds and infinitives. However, these results cannot be easily generalized since the sample size for both groups was not large enough. Nonetheless, the results of the tests seem to suggest that gerunds and infinitives should be taught by using this principle, necessarily combined with the memorization of those verbs that do not fit the Bolinger principle and with the semantic classification of the preceding verbs themselves. Teachers and learners in ESL/ENNL programs could benefit from this combined approach.

The test results partially supported the first hypothesis, according to which teaching ENNL learners the use of gerunds and infinitives with the Bolinger 
principle would result in a significant improvement in Discrete Point tests. Likewise, the results of the writing tests partially supported the second hypothesis, according to which teaching ENNL learners gerunds and infinitives with the Bolinger principle would result in a significant improvement in the use of gerunds and infinitives in writing. However, the Experimental Group produced more gerunds than infinitives, and there was a decrease in the usage of infinitives. As for the first hypothesis, the Experimental Group did better on the Discrete Point test, but it did not perform as well on the Sentence Combining Test. However, they showed a significant improvement between pre and posttests, partially validating the first hypothesis. Finally, the students' writing tests were not statistically analyzed, but they were described and discussed in this chapter. 


\section{References}

Aarts, J. \& F. Aarts (1995). Find and want. A corpus-based case study in verb complementation. Bas Aarts, and Charles, F. Meyer (Ed..), The Verb in Contemporary English. Theory and Description, Cambridge (UK): CUP, 159-182.

Andersson, E. (1985). On Verb Complementation in Written English. Lund: Gleerup.

Azar, B. S. (1985). Fundamentals of English Language. Englewood Cliffs, New Jersey: Prentice-Hall Regents.

Azar, B. S. (1989). Understanding and Using English Grammar. Englewood Cliffs (N. J.): Prentice Hall Regents.

Bladon, R. A. W. (1968). "Selecting the to- or -ing Nominal after like, love, hate, dislike and prefer." English Studies, 44, 203-214.

Bolinger, D. (1968a). "Entailment and the Meaning of Structures." Glossa 2, 2, 119-127.

Bolinger, D. (1968b). " The theorist and the language teacher". Foreign Language Annals, 2, 30-41.

Butoyi, C. A. (1978). "The Accuracy Order of Sentential Complements by ESL learners." Unpublished MA Thesis in TESL, UCLA.

Celce-Murcia, M. and L. McIntosh (1979). Teaching English as a Second or Foreign Language. Rowley, Mass.: Newbury House Publishers Inc.

Celce-Murcia, M., and Larsen-Freeman, D. (1983). The Grammar Book: An ESL/EFL Teacher's Course. Rowley, MA: Newbury House. 
Comrie, B. (1976). Aspect. Cambridge: Cambridge University Press.

Dixon, R. M. W. (1991). A New Approach to English Grammar, on Semantic Principles. Oxford: Clarendon Press.

Dixon, R. M. W. (1995). "Complement clauses and complementation strategies." In R. F. Palmer (Ed.), Grammar and Meaning, Cambridge: University of Cambridge, 175-220.

Duffley, P. J. \& Tremblay, R. (1994). The infinitive and the -ing as complements of verbs of effort. English Studies, 6, Vol. 75, 567-575.

Eagleson, E. (1972). Selecting the to- and -ing Nominal after Prefer. English Studies, 53, 141-144.

Ek, van, Jan. A. \& Robat, N. J. (1984). The Student's Grammar of English. Glasgow, (G.B.): Bell and Bain Ltd., 297-332.

Fanego, T. (1997). On patterns of complementation with verbs of effort. English Studies. 1, Vol. 78, 60-67.

Fingado, G. \& Jerome, M. (1982). English Alive. Boston: Little, Brown \& Co.

Fingado, G. \& Freeman, L. (1981). The English Connection. Boston: Little, Brown, \& Co.

Freed, A. F. (1979). The Semantics of English Aspectual Complementation. Dordrecht: Reidel.

Jackson, H. (1990). Grammar and Meaning. A Semantic Approach to English Grammar. New York: Longman Inc. 
Jespersen, O. (1933). Essentials of English Grammar. University, Alabama: University of Alabama Press.

Jespersen, O. (1954). A Modern English Grammar On Historical Principles. Part V, Syntax. London: George Allen \& Unwin LTD.

Huddleston, R. (1971). The Sentence in Written English. A Syntactic Study Based on an Analysis of Scientific Texts. Cambridge: Cambridge University Press.

Huddleston, R. (1988). English Grammar: an Outline. Cambridge: Cambridge University Press.

Jorgensen, E. (1982). To think of + gerund - To think + to-infinitive. English Studies, 63, 55-62.

Karttunen, L. (1970). On the semantics of complement sentences. Papers from the Sixth Regional Meeting of the Chicago Linguistic Society, Chicago, III. p. 328-339.

Karttunen, L. (1971). "Implicative Verbs." Language, 47, 3, 340-358.

Kempson, R. M. \& Quirk, R. (1971). "Controlled Activation of Latent Contrast." Language 47, 3, 548-572.

Kiparsky, P. \& Kiparsky, C. (1970). "Fact." M. Bierwisch and K. Heidolph (Ed..), Progress in Linguistics. The Hague: Mouton, 143-173.

Leech, G., N. (1987). Meaning and the English Verb. New York: Longman Inc. Mair, C. (1990). Infinitival Complement Clauses in English. A study of Syntax in Discourse. Cambridge: Cambridge University Press. 
Menzel, P. F. (1971). Semantics and Syntax in Verb Complementation. The Hague: Mouton.

Mills, D. G. (1987). Infinitival verb complementation: theory and usage as basis for pedagogy. World Englishes, Vol. 6, No. 3, 227-239.

Newmeyer, F. J. (1975). English Aspectual Verbs. The Hague: Mouton.

Nguyen, Van So (1973). "The Semantic Interpretation of Infinitives and Gerunds as Sentential Complements." Unpublished M.A. Thesis in TESL, Los Angeles, CA: University of California.

Palmer, F., R. (1974). The English Verb. London: Longman Group Limited.

Quirk, R., S. Greenbaum, G. Leech., J. Svartvik (1972). A Grammar of Contemporary English. London: Longman Group Limited.

Quirk, R., \& Greenbaum S. (1974, 1985). A University Grammar of English. London: Longman Group Limited.

Rudanko, J. (1993). Reducing someone to groveling: aspects of an object- control pattern in present-day English. English Studies, 5, 485-495.

Smalley, R. L., M. Ruetten (1995). Refining Composition Skills. Rethoric and Grammar. University of New Orleans: Heinle and Heinle.

Stockwell, R. P., Schachter P., Partee, B. (1973). The Major Syntactic Structures of English. New York: Holt, Rinehart, and Winston.

Teschner, R. V., E. Eston (1993). Analyzing the Grammar of English. A Brief Undergraduate Textbook. Washington, D.C.: Georgetown University Press. 
Thewlis, S. (1997). Grammar Dimensions 3. Form, Meaning, and Use (2nd ed.). D. Larsen-Freeman (Series Ed.) Boston, Mass.: Heinle \& Heinle Publishers.

Tregidgo, P. S. (1980). Some observations on verb + ing and verb + infinitive. English Language Teaching, 35, 1 Oct., 45-48.

Young, D. J. (1980). The structure of English Clauses. New York: St. Martin Press.

Van der Meer, G. (1994). Verbs of perception and their complementation. English Studies, 5, Vol. 75, 468-480.

Wood. F. T. (1956). Gerund versus infinitive. English Language Teaching, 11, $11-16$. 
SGDIવNGddV 


\section{APPENDIX A: CONSENT FORM}

I, . . . . . . . . . . . . . agree to participate in the research project on teaching gerunds and infinitives to ENNL students supervised by Anna Maria Baratta-Zborowski.

I understand that I will be required to answer questions and allow the researcher to test my writing ability during the experiment, and that I will have to follow the instructions in order to ensure a correct realization of the project.

I understand that this study may take up some of my own time in class (circa three hours).

Anna Maria Baratta-Zborowski or my ENNL instructor, . . . . . . . . . . . . . . . . . has told me that the purpose of this study is to learn more about the process of language acquisition and the methodologies that can improve language acquisition in ESL/ ENNL students. I may not receive any direct benefit from taking part in this study, but my participation in the study may contribute to a better understanding of the process involved in acquiring a second language by learning the Bolinger principle.

Anna Maria Baratta-Zborowski will answer any questions I have and about what I am expected to do. She has promised that all the information that I provide will be kept confidential and that the students' names will remain anonymous and confidential. I understand that I do not have to participate in this study and that my refusal will not affect my further participation or grade in my ENNL classes.

I have read and understood the above information and agree to participate in this study.

Date: . . . . . . . . .

Signature: . . . . . . . . . . .

If you have any questions, please contact Anna Maria Baratta-Zborowski at 503203 8531 or the Chair of the Human Subject Review Committee, Research and Sponsored Projects, 105 Neuberger Hall, Portland State University, 725 - 3417 
Name:

Date:

Age: _ Nationality:

How many months or years have you been in the United States?

How many years have you studied English?

Directions: Fill in the blanks using either the infinitive or gerund of the verbs in parentheses.

Examples: He was invited to lecture ( lecture) at Portland State. She hated riding (ride) the bus to work every day.

1. The defendant admitted (steal) the car.

2. They are preparing (go) to Africa next year.

3. I heard my neighbors (have) an argument last night.

4. Joan expects (enter) university next term.

5. Tom hopes (learn) Russian, but he hasn't started yet.

6. My father stopped (smoke) because it was bad for his health.

7. Please remind me (take) this letter to the Post Office.

8. Finally she completed (write) her report.

9. Tammy dislikes (ride) the buses in China.

10. I can't afford (buy) a new car.

11. He forgot (lock) the door. 
12 I smell something good (cook) in the oven.

13. She begged her husband not (leave) her but he ignored her plea.

14. She offered (lend) me her umbrella.

15. The doctor is trying to persuade the patient (remain) in the hospital a little longer.

16. They finished (paint) the house yesterday.

17. You should practice (speak) English every chance you get.

18. Many Portland residents resent (pay) high property taxes.

19. The man is pretending (be) a millionaire.

20. Tom denied (steal) the neighbor's dog. 


\section{II) SENTENCE COMBINING PRETEST}

Name:

Date:

Directions: In each question you will be given two sentences and asked to combine them into one sentence by filling in the missing words in a sentence frame. Use the infinitive or gerund form of the verb.

EXAMPLES: $\quad$ a. We will visit Italy this summer.

b. We look forward to that.

We look forward to visiting Italy this summer.

a. Janet exercises every day.

b. It is necessary for her.

It is necessary for Janet to exercise every day.

1. a. Portland residents pay high property taxes.

b. They resent it.

Portland residents resent

2. a. The boys threw stones at some parked cars.

b. They admitted their crime.

The boys admitted

3. a. Ann dislikes school.

b. Her mother makes her go anyway.

Even though Ann dislikes to school, her mother makes her anyway.

4. a. The school imposed stricter discipline on the students.

b. The teachers agreed to it.

The teachers agreed

5. a. The carpenters built the house.

b. They finished it last week.

The carpenters finished

6. a. John was accused of drunk driving.

b. He denied it.

John denied under the influence of alcohol.

7. a. The police caught the thief in the act of stealing the car and yelled at him.

b. The thief ran.

The thief kept on even though the police yelled at him.

8. a. I must work every other weekend.

b. I can't get used to that.

I can't get used to 
9. a. The student didn't mail the letter.

b. He forgot.

The student forgot

10. a. The couple next door quarrel continuously.

b. People complain about this.

People complain about the couple's

11. a. We ski every winter in Colorado.

b. We enjoy it.

We enjoy

12. a. Tim hopes to go to graduate school.

b. His parents will pay for it.

Tim's parents plan

13. a. We will spend Thanksgiving with my grandparents.

b. We are excited.

We are excited about

14. a. I must go to the doctor for a physical.

b. I don't like it.

I don't want

15. a. Have lunch with me.

b. I would like this.

I would like you

16. a. The Simpsons are going to the South Seas this winter.

b. They are preparing for their trip.

The Simpsons are preparing

17. a. My mom lost a lot of weight this summer.

b. Her doctor warned her about it.

My mom's doctor warned her not

18. a. Mary swept the floor.

b. Then she dusted the furniture.

After sweeping the floor, Mary decided

19. a. I am going to a staff meeting at $2: 00 \mathrm{pm}$ tomorrow.

b. Please remind me about it.

Please remind me

20 a. I will go to Europe next year.

b. I hope it will work out.

I hope to Europe next year. 
III) WRITING SAMPLE PRE-TEST

Pretest: Writing activity (15 minutes)

Name:

Date:

Write about your hobbies. Think of several hobbies that you enjoy:

What do you do? Where? When? Why?

Mention some interesting experiences. 
APPENDIX C: DEMOGRAPHIC DISTRIBUTION OF THE STUDENTS ACCORDING TO AGE (FIGURE 1a), RESIDENCY (FIGURE 1b), AND LENGTH OF TIME STUDYING ENGLISH (FIGURE 1c)

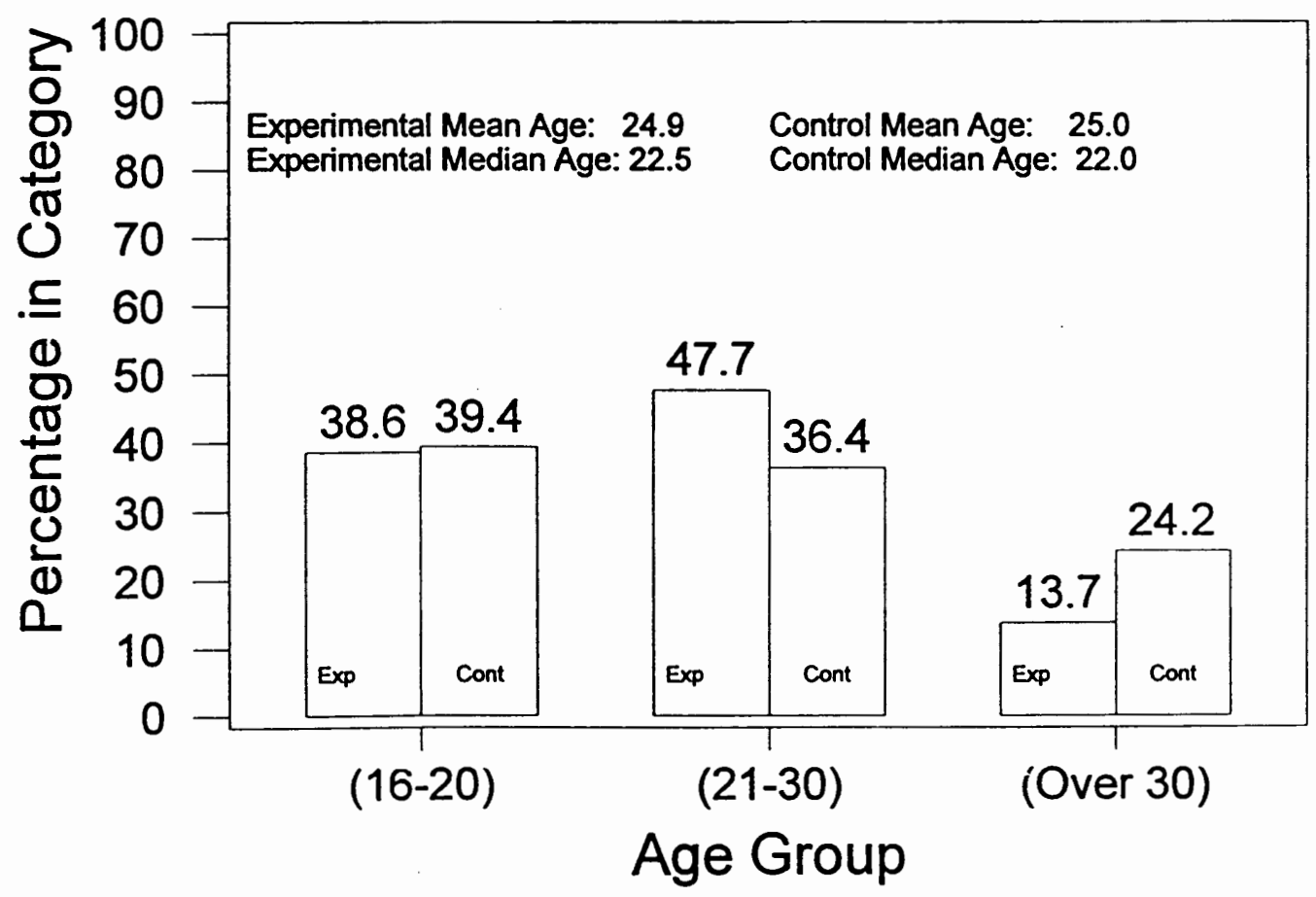

Figure 1a. Age Spread of Experimental and Control Groups. 


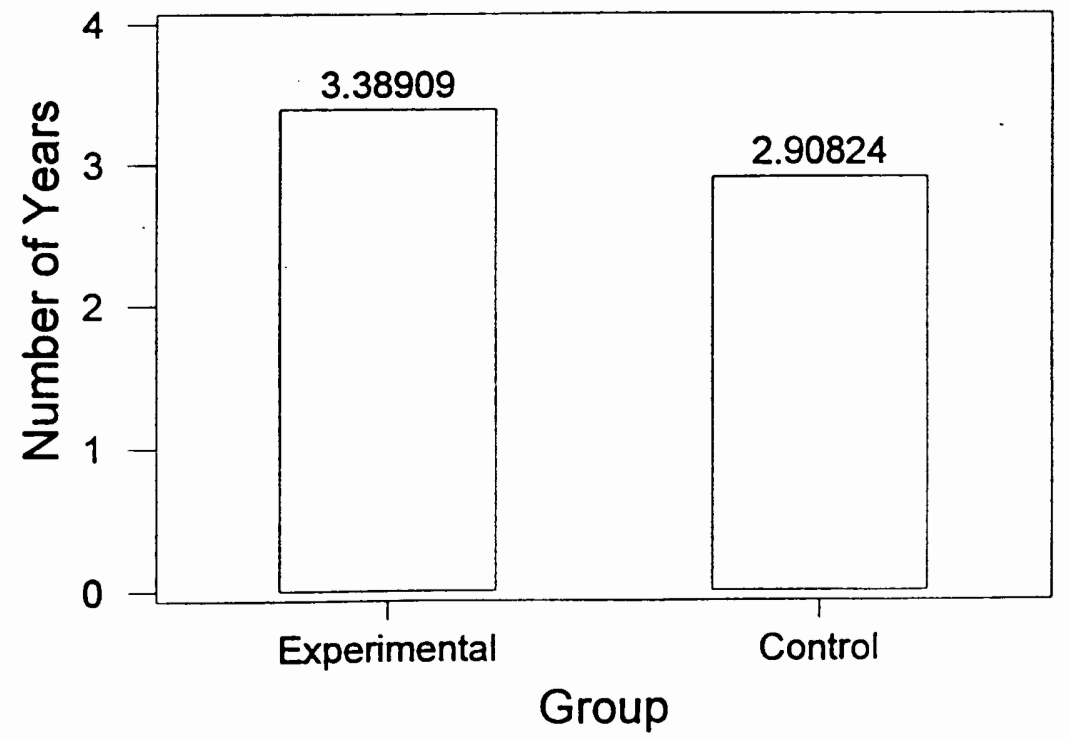

Figure 1b. Average Length of Residency.

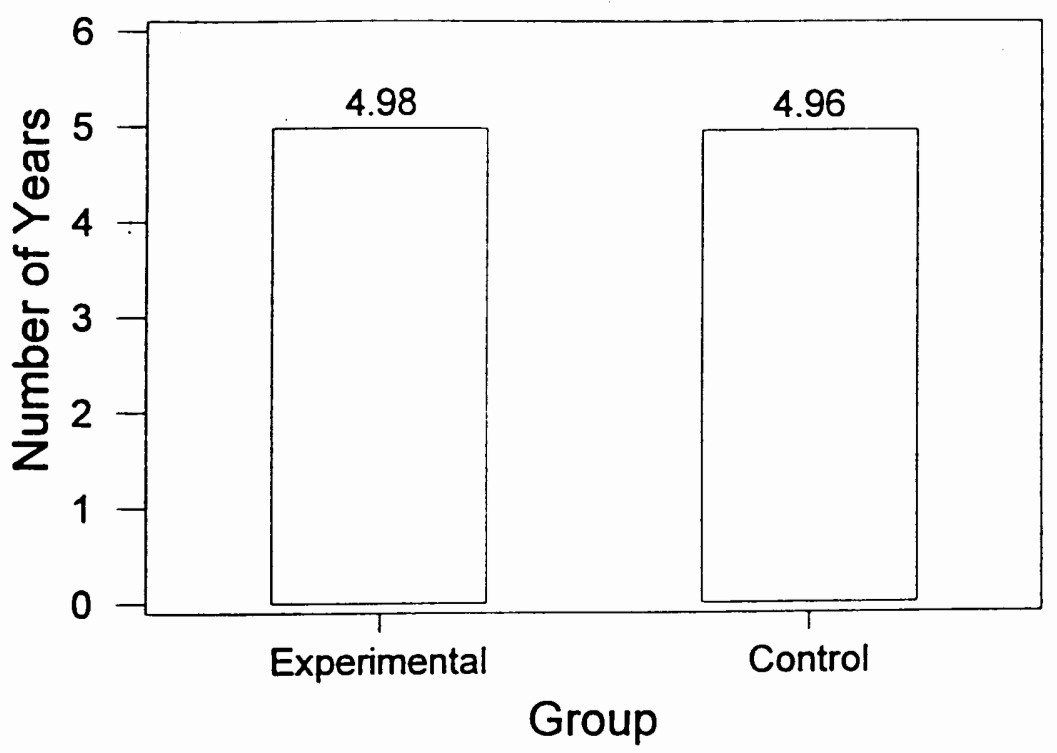

Figure 1c. Average Length of Time Studying English. 


\section{APPENDIX D: CONTEXTUALIZED ACTIVITIES}

\section{Activity 1}

Elvis Presley, the great rock guitarist and singer, was born on January 8, 1935, in Tupelo, Mississippi. His parents (like/take) him to church. He

(enjoy/listen) to the church music and (sing).

Elvis was very close to his mother, Gladys. She (negative, want/be) out of her sight, so she walked him to school every day until he was senior in High school.

Elvis (want /have) a bicycle, but his parents (refuse/give) him one. Instead, they bought him a guitar. Elvis ((practice/play) the guitar every free moment that he had. He (try/imitate) music from the radio.

Elvis' mother (encourage/play) the guitar and sing. Elvis also (like/play) football, but she (urge, negative/play) football because she was afraid he would get hurt. She (ask/give up) the game. Elvis (negative, want/ worry) his mother, so he quit (play) football. She also (force/quit) a job because she thought it would interfere with his school work.

In 1953 Elvis (decide/record) his first album. Soon after, disc jockeys (start/play) Elvis's records on their radio stations. Elvis also sang on television on the Ed Sullivan Show, but the TV network (refuse/show) Elvis from the waist down because he wiggled his hips so erotically.

Elvis earned millions of dollars from his records and movies and (like/hear) people call him the "King" of rock'n roll.

In 1976 Elvis's doctors ordered him to stop (perform) because he was quite sick. In 1977 Elvis died of heart attack at the age of forty two. His mother had died at the same age. 
Activity 2

Fill in the blanks with the correct form of the verbs given in parentheses. There may be more than one correct answer!

Before the invention of the radio and television, people spent much of their leisure time (1) (pursue) activities that involved (2) or (3) ( make) something. They practiced (4) (play) a musical instrument or studied (5) (sing). Most people learned (6) (keep busy) by (7) (try) (8)

(improve) their abilities in some way or by (9) (practice) a skill. Many women were extremely clever at (10) (make) and (11) (decorate) articles of clothing. Men often kept busy by (12) (make) toys for children, or (13) (carve) small sculptures out of wood.

Nowadays, television has encouraged many people (14) (stop) (work on) their hobbies or pastime accomplishments. Children are spending more and more time (16) (watch) TV or (17) (play) video games. Traditional skills such as embroidery, crocheting, and wood carving are failing (18) (be) passed from parent to child. People seem (19) (prefer) activities that allow them (20) (be) passive observers rather than active participants. 
Activity 3

Choose the correct tense for the first verb and put the second verb in the infinitive or gerund form.

Joe's and Diane's personalities are different in other ways too. Diane is a very quiet person, but Joe is very talkative. He (like/talk) all the time. He especially (enjoy/discuss) politics. Diane (hate/discuss) politics. Also, when she is tired, she doesn't (want/talk) about anything: She (need/have) peace and quiet. Joe does not understand. When Diane is quiet, he thinks she's unhappy. Sometimes when Joe talks a lot, it drives Diane crazy. Then she jokes and says, "Joe, you never (stop/talk)."

However, Joe and Diane are not completely different. They share some interests, and they (enjoy/do) many things together. For example, both Joe and Diane are interested (of, in, about) (cook). On

Saturdays they (like/spend) all day (cook), but they both (hate/wash) dishes. They also (like/go) to old movies from the 1930s and 1940s together, and they (like/go) to the theater. They have some problems in their relationship, but in general they (enjoy/be) together. 


\section{Activity 4}

Directions: Choose the correct tense of the first verb. Choose the infinitive or the gerund form for the second verb. There are some verbs in this exercise for which both the infinitive and the gerund are correct.

During the summer of 1969 one of the most important events in the history of rock music took place in Woodstock, New York. Around half a million people traveled to this small town for a weekend rock music festival. Many more people (want/come) but couldn't get near the area because of all the traffic. People (report/see) traffic backed up for ten miles.

The weather was bad on the weekend. It rained everyday except for the last one. When promoters of the concert heard the weather forecast, they (consider/negative/ have) the festival, but finally they (decide/go) ahead with their plans. Some people (choose/leave) but most (prefer/stay) and (refuse/allow) the rain to spoil their weekend. They (enjoy/listen) to the music even in the rain.

Many of the young people who came to Woodstock believed in a world of music, drugs and free love. They (hope/set) an example for a new world, and they

(expect/change) society. They called themselves the Woodstock Nation.

Many of the local townspeople (negative, appreciate/have) so many hippies in their town and (resent/see) nudity and drugs so near their homes. Some people (expect/see) a lot of trouble with so many people living together in a small area for three days, but the visitors (enjoy/share)everything with each other and (avoid/argue) or (fight) with each other or the residents of Woodstock. The local townspeople (appreciate/have) the extra business but (negative, look forward to/clean)up after the weekend. 
In the years after Woodstock, many rock promoters (attempt/copy) this rock festival, but they all (fail/achieve) the same spirit of happiness, peace, and good music that the Woodstock festival symbolized.

\section{Exercise 5}

\section{Michael Jackson \& His Brothers}

He was born in Gary, Indiana in 1958.

His parents intended him (be) a musician.

He started (play) the guitar at a young age.

He got his love for the guitar from his father who encouraged him (play) the guitar.

He practiced (play) every free minute.

He formed The Jackson Five in 1970.

Michael kept on (play).

The group enjoyed (perform) at local talent shows.

They began (practice) regularly.

In 1972 they decided (cut) "I'm a Big Boy Now".

They began (work) for Motown Records.

Eventually Michael gave up (do) records with his brothers.

They wanted him (remain) with them.

He decided (stay) solo.

He made it big with hits like "Thriller" and "Billie Jean".

He hopes (perform) at all the hot spots.

But he avoids (talk) to reporters if possible.

He resents (have) nosey people around all the time.

He would like (get married) someday but the right girl hasn't come along yet. 


\section{APPENDIX E: I) DISCRETE POINT POSTTEST}

Name:

Date:

Directions: Fill in the blanks using either the infinitive or gerund form of the verbs in parentheses.

Examples: She enjoys watching (watch) television.

She hopes to go (go) to Spain one day.

1. She completed (write) her term paper one hour before class.

2. We hope (see) you graduate next year.

3. I heard my mother (tell) my father about my fight with my brother.

4. Rick plans (ask) his parents for a computer for Christmas.

5. The boys admitted (start) the fire which burned down some homes.

6. When will you finish (read) that book?

7. Gary denied believe him. (take) the last piece of pie but his mother didn't

8. Marsha chose (stay) home instead of going to the movie.

9. Glenn agreed (help) his son start up a lawn service but it never materialized.

10. Michael Jackson practiced (play) the guitar every day.

11. The teacher encouraged me (be) more careful when I write.

12. John dislikes (read) literature.

13. Anna detests (clean) up her room but her mother makes her do it anyway.

14. Please remind me (stop) for a loaf of bread on the way home.

15. Mike dreads (wake) up so early every morning.

16. My friend offered (lend) me her notes for the class I'd missed. 
17. Mrs. Smith persuaded Jane not (drop out) of school but Jane's mind was already made up.

18. Tom's father warned him (be) careful with the car.

19. My neighbor promises (keep) her dog in her yard, but sometimes she isn't always successful.

20. After their quarrel they stopped (talk) to each other. 
II) SENTENCE COMBINING POSTTEST

Name:

Date:

Directions: In each question you will be given two sentences and asked to combine them into one sentence by filling in missing words in a sentence frame. Use the infinitive or gerund form of the verb.

EXAMPLES: a. We will visit Italy this summer.

b. We look forward to that.

We look forward to visiting Italy this summer.

a. Janet exercise every day.

b. It is necessary for her.

It is necessary for Janet to exercise every day.

1. a. The boys stole the neighbor's hubcaps.

b. They admitted it.

The boys admitted

2. a. Marsha dislikes preschool.

b. Her mother makes her go anyway.

Even though Marsha dislikes her anyway. to preschool, her mother makes

3. a. Bob was accused of cheating on his test.

b. He denied it.

Bob denied

4. a. Ian caught his cat in the act of stealing the fish and yelled at him.

b. The cat ate the fish.

The cat kept on even though he yelled at him.

5. a. Some of my students didn't do their homework.

b. They forgot.

Some of my students forgot

6. a. Kim's parents imposed restrictions on watching T.V..

b. They agreed to it.

Kim's parents agreed

7. a. We sail every summer on lake Dillion.

b. We enjoy it.

We enjoy

8. a. Jenny hopes to go to India.

b. Her parents will pay for it.

Jenny's parents plan 
9. a. We will spend Christmas with my family.

b. We are excited.

We are excited about

10. a. I must go to the dentist.

b. I don't like it.

I don't like

11. a. Have dinner with me.

b. I would like this.

I would like you

12. a. The Johnsons are sailing around the world next spring.

b. They are preparing for their trip.

The Johnsons are preparing

13. a. Pat answered the correspondence.

b. Then she typed the letters.

After answering the correspondence, Pat decided

14. a. Our neighbors argue a lot.

b. People complain about it.

People complain about

15. a. Denver residents pay a high sales tax.

b. They resent it.

Denver residents resent

16. a. My dad smokes too much.

b. The doctor warned him about it.

The doctor warned my dad not

17. a. The painters painted our classroom.

b. They finished yesterday.

The painters finished

18. a. I am going to a football game at 7:00 pm tomorrow night.

b. Please remind me about it.

Please remind me

19. a. My dad doesn't drink anymore.

b. He stopped last year.

My dad stopped

20. a. Timmy must work nights.

b. He can't get used to that.

Timmy can't get used to 
III) WRITING SAMPLE POSTTEST

Posttest: Writing Activity (15 minutes)

Name:

Date:

Write about your spare time activities. Think of several spare time (free time) activities that you enjoy. What do you do? When? Where? Why?

Mention some interesting experiences. 


\section{APPENDIX F: ACTIVITIES FOR THE CONTROL GROUPS' REVIEW}

\section{1) ACTIVITIES FOR THE CONTROL GROUP'S REVIEW AT MT. HOOD COMMUNITY COLLEGE}

\section{Exercise 11}

Combine these sentences pairs. Replace the underlined word with an infinitive phrase made from the information in the first sentence.

Example: John will spend a year in France. Mary doesn't want this. Mary doesn't want John to spend a year in France.

1. John will write a long letter once a week. Mary has requested this.

2. John might postpone his trip until next year. Mary would prefer this.

3. She will try to visit him while he's there. She has decided this.

4. She was upset by the news of his plans. He didn't expect this.

5. John got a very cheap ticket. Mary's father arranged this.

6. John didn't apply for a passport. He neglected this.

7. John will report to police when he arrives. French law requires this.

8. Mary will begin to study French herself. John has encouraged this.

9. Mary feels hurt that John is leaving. John never intended this.

\section{Exercise 9}

Combine these sentence pairs. Replace the indicated word with a gerund phrase made from the first sentence.

EXAMPLE: John will spend a year in France. Mary resents this.

Mary resents John's spending a year in France.

1. John sings a funny song whenever he sees her. Mary will miss this great deal. 
2. He wants to become really fluent in French. Mary doesn't really understand this.

3. He applied to the program without consulting Mary. She resents this.

4. She will not have a chance to talk with him every day. She's not looking forward to this.

5. John is leaving in two weeks. He is quite excited about this.

6. John needs at least three weeks to get a passport. He didn't anticipate this.

7. This will make his departure even later than expected. John wanted to avoid this.

\section{Exercise 12}

Fill in the blank with the gerund or infinitive form of the word in parentheses. There may be more than one correct answer.

1. If you want to lose weight you should try sweets. That might be better than going on a diet. (avoid) all

2. I know Dimitri was at the party, but I don't remember (talk) to him.

3. On her way home my mother stopped (pick up) a few things at the store.

4. Suddenly all the dogs in the neighborhood began (bark) at the same time. 
5. My sister has never been able to quit (smoke).

6. Ruth couldn't watch TV because she forgot (bring) her glasses with her.

7. Nowadays, children have stopped (a) children's games and seem (b) (play) traditional (play) video games instead. (prefer) (c)

8. I'll try (eat) any kind of food once. 
II) ACTIVITIES FOR THE CONTROL GROUP'S REVIEW AT LEWIS AND CLARK COLLEGE

Exercise 9

Using the given ideas and the verb in parentheses, make sentences by using an infinitive phrase.

1. The teacher said to me, "You may leave early"

2. The secretary said to me, "Please give this note to Sue"

3. My advisor said to me, "You should take Biology 109"

4. When I went to traffic court, the judge said to me, "You must pay a thirtydollar fine"

5. During the test, the teacher said to Greg, "Keep your eyes on your own paper"

6. During the test, the teacher said to Greg, "Don't look at your neighbor's paper"

7. At the meeting, the head of the department said to the faculty," Don't forget to turn your grade reports by the 15 th"

8. Mr. Lee said to the children, "Be quiet"

9. The hijacker said to the pilot, "You must land the plane"

10. When I was growing up, my parents said to me, "You may stay up late on Saturday night" 
11. The teacher said to the students, "Speak slowly and clearly"

12. The teacher always says to the students, "You are supposed to come to class on time"

Exercise 6

By using a gerund, supply any appropriate completion for each of the following.

1. When Beth got tired, she stopped working / studying .

2. Would you mind ___ the door? Thanks.

3. The weather will get better soon. We can leave as soon as it quits

4. The police officer told him to stop, but the thief kept

5. I enjoy a long walk every morning.

6. I have a lot of homework tonight, but I'd still like to go with you later on.

I'll call you when I get through

7. I would like to have some friends over. I'm thinking about

8. He told a really funny joke. We couldn't stop

9. Jack almost had an automobile accident. He barely avoided Elm. another car at the intersection of 4th and

10. Where are you considering for vacation?

11. Sometimes I put off my homework. 
12. You have to decide where you want to go to school next year. You can't postpone that decision much longer.

13. I wanted to go to Mexico. Sally suggested to Hawaii.

14. Tony mentioned the bus to school instead of walking.

15. I appreciate able to study in peace and quiet.

\section{Exercise 12}

Complete the sentences with the correct form(s) of the verbs in parentheses.

1. I like (go) to go / going to the zoo.

2. The play wasn't very good. The audience started (leave)

3. After a brief interruption, the professor continued (lecture)

4. The children love (swim) in the ocean.

5. I hate (see) any living being suffer. I can't bear it.

6. I'm afraid of flying. When a plane begins (move) runaway, my heart starts (race) The plane is beginning (move) (race) ) Oh-oh! down the and my heart is starting

7. When I travel, I prefer (drive) plane. to (take) a

8. I prefer (drive) rather than (take) a plane.

9. I always remember (turn) leave my house. off all the lights before I 10. I can remember (be) graduated. very proud and happy when I

11. Did you remember (give) Jake my message?

12. I remember (play) with dolls when I was a child. 
13. What do you remember (do) when you were a child?

14. What do you remember (do) before you leave class every day?

15. What did you forget (do) morning? before you left for class this

16. I'll never forget (carry) my wife over the threshold when we moved into our first home.

17. I can't ever forget (watch) goal in the last seconds of the game to capture the national championship.

18. Don't forget (do) your homework tonight!

19. I regret (inform) you that your loan application has not been approved.

20. I regret (listen, not) to my father's advice. He was right.

21. When a student asks a question, the teacher always tries (explain) the problem as clearly as possible.

22. I tried everything, but the baby still wouldn't stop crying. I tried (hold) him. I tried (feed) him. I tried (burp) him. I tried (change) his diapers. Nothing worked. 
APPENDIX G : VERBS WHICH DO NOT FIT THE BOLINGER

PRINCIPLE

Gerunds

imagine

anticipate

consider

keep

mind

postpone

suggest

understand

delay

envision

recommend

risk

\section{Infinitives}

manage

continue

fail

get

have

claim

teach

hire

tell 
APPENDIX H: I) CHART OF PRECEDING VERBS IN DISCRETE POINT PRETEST

1. admit - G

2. prepare - I

3. hear $-\mathrm{G}$

4. expect - I

5. hope - I

6. stop $-\mathrm{G}$

7. remind - I

8. complete - G

9. dislike $-\mathrm{G}$

10. afford - I

11. forget - I

12. smell $-\mathrm{G}$

13. beg $-I$

14. offer - I

15. persuade - I

16. finish $-G$

17. practice - G

18. resent - G

19. pretend - I

20. deny - G

\section{II) CHART OF PRECEDING VERBS IN DISCRETE POINT POSTTEST}

\begin{tabular}{|c|c|c|c|}
\hline 1. complete & $-G$ & 11. encourage & $-I$ \\
\hline 2. hope & $-G$ & 12. dislike & $-G$ \\
\hline 3. hear & $-G$ & 13. detest & $-G$ \\
\hline 4. plan & $-I$ & 14 , remind & $-I$ \\
\hline 5. admit & $-G$ & 15. dread & $-G$ \\
\hline 6. deny & $-G$ & 16. offer & $-I$ \\
\hline 7. finish & $-G$ & 17. persuade & $-I$ \\
\hline 8. choose & $-I$ & 18. warn & $-I$ \\
\hline 9. agree & $-I$ & 19. promise & $-I$ \\
\hline 10. practice & $-G$ & 20. stop & $-G$ \\
\hline
\end{tabular}




\section{APPENDIX I : I) CHART OF PRECEDING VERBS IN SENTENCE COMBINING PRETEST}

1. resent - G

11. enjoy $-\mathrm{G}$

2. admit - G

3. dislike - G

12. plan $-I$

4. agree - I

13. excite $-\mathrm{G}$

5. finish $-\mathrm{G}$

14. want - I

6. deny - G

7. keep on - G

15. would like - I

16. prepare - I

17. warn - I

8. get used to - G

18. decide - I

9. forget - I

10. complain - G

19. remind

20. hope

$-\mathrm{I}$

- I

$$
\begin{aligned}
* I & =\text { Infinitive } \\
\mathrm{G} & =\text { Gerund }
\end{aligned}
$$

\section{II) CHART OF PRECEDING VERBS IN SENTENCE COMBINING POSTTEST}
1. admit - G
2. dislike $-\mathrm{G}$
3. deny - G
4. keep on - G
5. forget - I
6. agree - I
7. enjoy $-\mathrm{G}$
8. plan -I
9. excite - G
10. want - I

11. would like

- I

12. prepare

- I

13. decide

- I

14. complain

$-\mathrm{G}$

15. resent

$-\mathrm{G}$

16. warn

- I

17. finish

$-\mathrm{G}$

18. remind

- I

19. stop

$-\mathrm{G}$

20. get used to

$-G$

$$
\begin{aligned}
*^{*} \mathrm{G} & =\text { Gerund } \\
\mathrm{I} & =\text { Infinitive }
\end{aligned}
$$


APPENDIX J: LIST OF VERBS TAKING THE INFINITIVE, THE GERUND, OR BOTH*

\section{Verbs taking the Infinitive}

1. $\mathrm{V}+$ to $\mathrm{V}$

$\begin{array}{llll}\text { (can't) afford } & \text { demand } & \text { manage } & \text { seek } \\ \text { agree } & \text { determine } & \text { offer } & \text { serve } \\ \text { care } & \text { disdain } & \text { pretend } & \text { strive } \\ \text { claim } & \text { endeavor } & \text { proceed } & \text { swear } \\ \text { condescend } & \text { fail } & \text { profess } & \text { tend } \\ \text { consent } & \text { hasten } & \text { refuse } & \text { think (expect) } \\ \text { decide } & \text { hope } & \text { resolve } & \text { threaten } \\ \text { deign } & \text { long } & \text { say } & \text { undertake }\end{array}$

2. $\mathrm{V}+\mathrm{NP}+$ to $\mathrm{V}$

$\begin{array}{llll}\text { admonish } & \text { defy } & \text { incite } & \text { provoke } \\ \text { advise } & \text { detail } & \text { induce } & \text { rate } \\ \text { allow } & \text { direct } & \text { instigate } & \text { remind } \\ \text { appoint } & \text { empower } & \text { instruct } & \text { schedule } \\ \text { assist } & \text { enable } & \text { invite } & \text { sentence } \\ \text { believe } & \text { enjoy } & \text { lead } & \text { set } \\ \text { beseech } & \text { entice } & \text { motion } & \text { solicit } \\ \text { bid } & \text { entitle } & \text { motivate } & \text { stimulate } \\ \text { bring oneself } & \text { entreat } & \text { name } & \text { stir } \\ \text { bring up } & \text { exhort } & \text { nominate } & \text { subpoena } \\ \text { call } & \text { force } & \text { oblige } & \text { summon } \\ \text { cause } & \text { goad } & \text { order } & \text { teach } \\ \text { challenge } & \text { (it) grieve } & \text { permit } & \text { tell } \\ \text { charge } & \text { hire } & \text { persuade } & \text { tempt } \\ \text { command } & \text { (it) hurt } & \text { pray } & \text { train } \\ \text { commission } & \text { impel } & \text { predispose } & \text { trouble } \\ \text { compel } & \text { implore } & \text { press } & \text { trust } \\ \text { consider } & \text { importune } & \text { prompt } & \text { urge } \\ & & & \text { warn }\end{array}$


3. $\quad \mathrm{V}+(\mathrm{NP})+\mathrm{V}$

$\begin{array}{llll}\text { ask } & \text { dare } & \text { help } & \text { promise } \\ \text { arrange } & \text { desire } & \text { move } & \text { request } \\ \text { beg } & \text { expect } & \text { plan } & \text { want } \\ \text { choose } & \text { get } & \text { prepare } & \text { wish }\end{array}$

Verbs taking the Gerund

1. $\quad V+V$-ing

$\begin{array}{lcll}\text { admit } & \text { confess } & \text { (can't) help } & \text { repeat } \\ \text { advise } & \text { (can't) endure } & \text { omit } & \text { resume } \\ \text { advocate } & \text { escape } & \text { permit } & \text { risk } \\ \text { allow } & \text { eschew } & \text { postpone } & \text { shirk } \\ \text { avoid } & \text { evade } & \text { practice } & \text { shun } \\ \text { boast } & \text { feign } & \text { preach } & \text { stop } \\ \text { cherish } & \text { finish } & \text { quit } & \text { teach } \\ \text { complete } & \text { give up } & \text { relish } & \end{array}$

2. $\quad \mathrm{V}+(\mathrm{NP})+\mathrm{V}$-ing

$\begin{array}{llll}\text { abhor } & \text { despise } & \text { include } & \text { reject } \\ \text { acknowledge } & \text { detest } & \text { involve } & \text { renounce } \\ \text { adore } & \text { discredit } & \text { justify } & \text { report } \\ \text { anticipate } & \text { disclaim } & \text { mention } & \text { repudiate } \\ \text { appreciate } & \text { discuss } & \text { mind } & \text { resent } \\ \text { await } & \text { endorse } & \text { miss } & \text { resist } \\ \text { consider } & \text { endure } & \text { necessitate } & \text { ridicule } \\ \text { contemplate } & \text { enjoy } & \text { object to } & \text { savor } \\ \text { criticize } & \text { entail } & \text { overlook } & \text { study } \\ \text { curse } & \text { examine } & \text { preclude } & \text { suggest } \\ \text { defend } & \text { excuse } & \text { protest } & \text { survive } \\ \text { defer } & \text { facilitate } & \text { publicize } & \text { tolerate } \\ \text { denounce } & \text { fancy } & \text { question } & \text { urge } \\ \text { deny } & \text { favor } & \text { recall } & \text { value } \\ \text { deplore } & \text { glorify } & \text { recollect } & \text { veto } \\ \text { deride } & \text { imply } & \text { reconsider } & \text { vindicate } \\ & & & \text { welcome }\end{array}$


Verbs taking both the Infinitive and the Gerund

1. $\mathrm{V}+$ to- $\mathrm{V} / \mathrm{V}$-ing

$\begin{array}{llll}\text { attempt } & \text { continue } & \text { fear } & \text { propose } \\ \text { begin } & \text { decline } & \text { forget } & \text { regret } \\ \text { cease } & \text { delay } & \text { intend } & \text { (can't) stand } \\ \text { chance } & \text { deserve } & \text { learn } & \text { start } \\ \text { choose } & \text { dislike } & \text { loathe } & \text { try } \\ \text { commence } & \text { dread } & \text { mean } & \text { venture } \\ & & \text { neglect } & \text { want }\end{array}$

2. $\quad \mathrm{V}+(\mathrm{NP})+$ to- $\mathrm{V} / \mathrm{V}$-ing

$\begin{array}{lll}\text { (can't) bear } & \text { hate } & \text { need } \\ \text { imagine } & \text { like } & \text { prefer } \\ \text { guarantee } & \text { love } & \text { remember }\end{array}$

3. $\quad \mathrm{V}+\mathrm{NP}+$ to- $\mathrm{V} / \mathrm{NP}+\mathrm{V}$-ing

$\begin{array}{lll}\text { approve of } & \text { find } & \text { recommend } \\ \text { authorize } & \text { forbid } & \text { understand } \\ \text { encourage } & \text { inspire } & \end{array}$

*It is obligatory that the NP before the gerund after "find" be only in the objective case: "I found the cat sleeping on the couch".

\section{Verbs taking either the bare Infinitive or the Gerund}

1. $\quad \mathrm{V}+\mathrm{NP}+\mathrm{V} / \mathrm{V}$-ing

$\begin{array}{lll}\text { feel } & \text { observe } & \text { see } \\ \text { hear } & \text { overhear } & \text { smell } \\ \text { notice } & \text { perceive } & \text { watch }\end{array}$

* The optional NP before the gerund after the above verbs can be in the possessive case or objective case, depending on the speaker's dialect. After a few verbs such as "admire, doubt, evaluate" the NP before the gerund is obligatory (Vawser, 1988). 